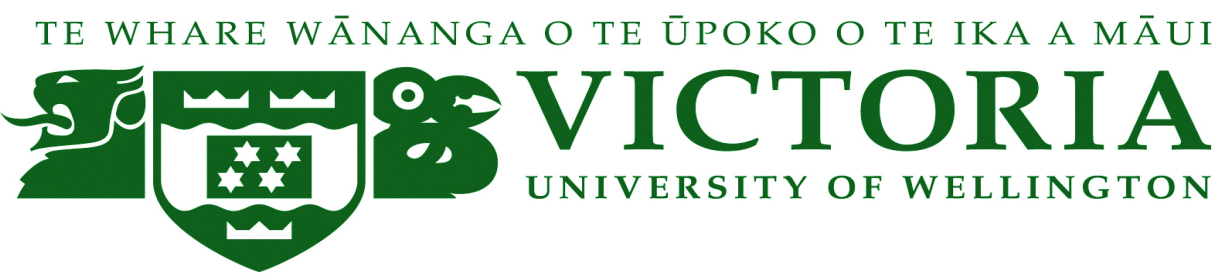

\title{
How Do Business People Rank Requirements Representations For Information Systems?
}

\author{
A paper presented to the \\ School of Information Management \\ Victoria University of Wellington
}

In partial fulfillment of the requirements for the Masters of Information Management Research Paper MMIM 592

by

Des Kenny

12 February 2013 


\section{Table of Contents}

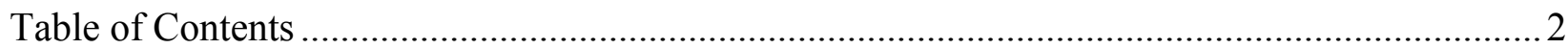

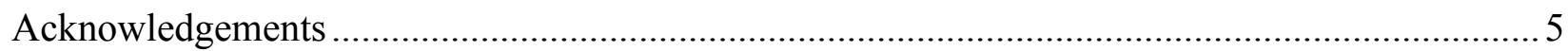

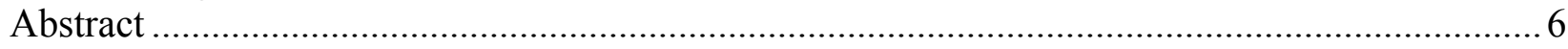

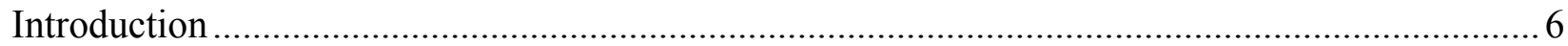

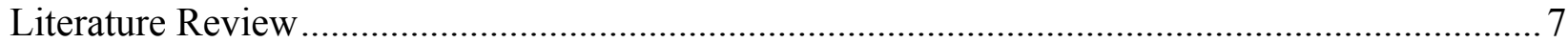

Requirements Elicitation Quality Issues ............................................................................

Requirements Representation During Requirements Elicitation .............................................. 9

Prose, Text and Hypertext in Requirements Representation .................................................... 10

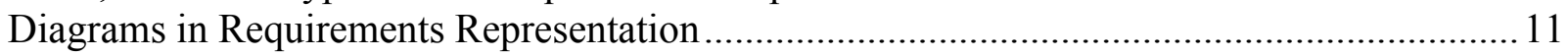

Images in Requirements Representation ............................................................................... 11

Video and Multimedia in Requirements Representation ............................................................. 11

Narratives and Storytelling Using Various Requirements Representations ...............................13

Conceptual Models and Tools for Requirements Representation Today....................................13

Intention To Use Requirements Representations................................................................. 14

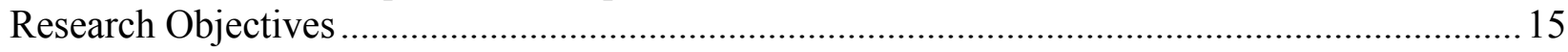

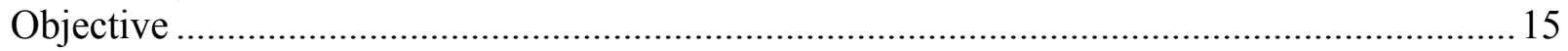

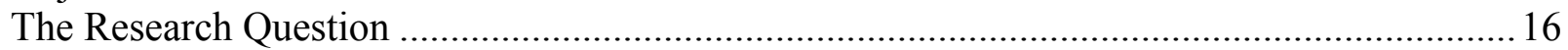

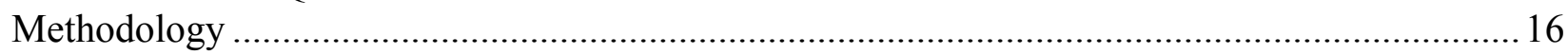

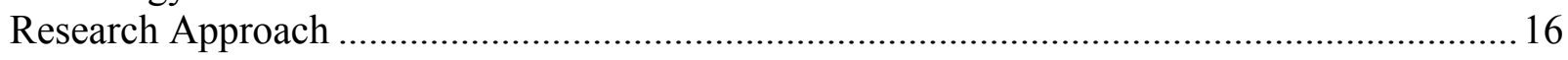

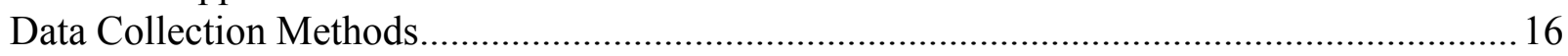

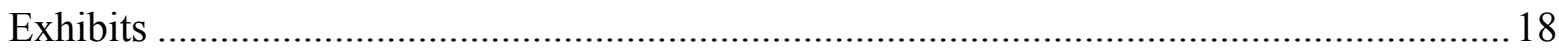

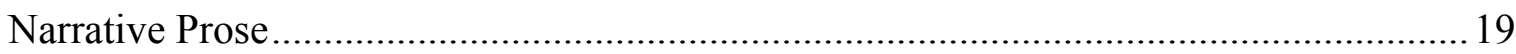

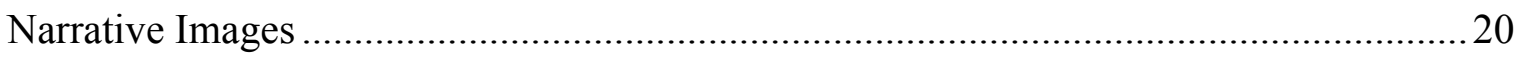

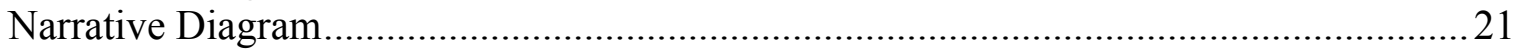

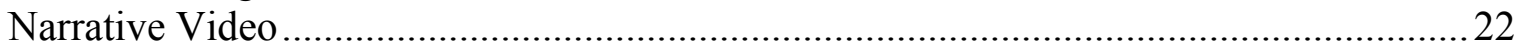

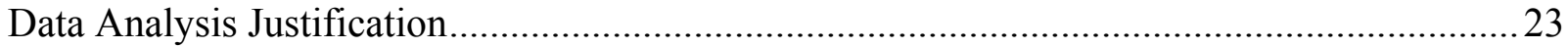

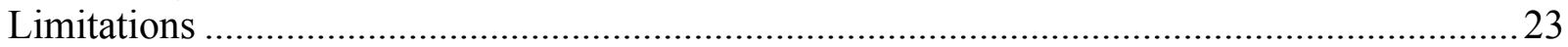

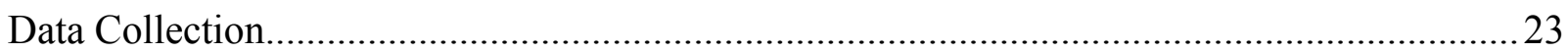

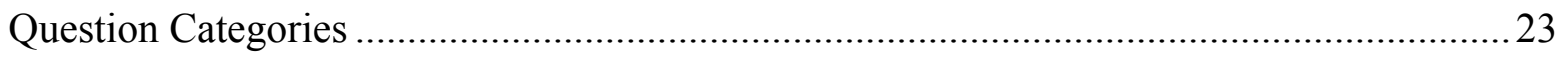

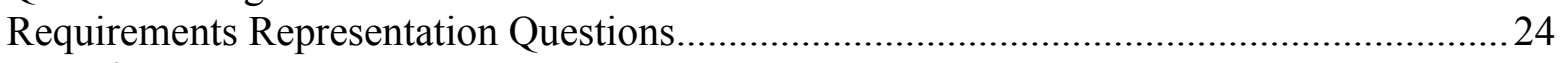

Performance Expectancy........................................................................................ 24

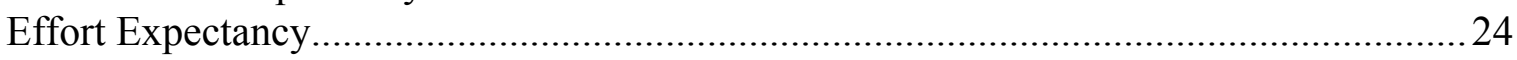

Attitude Toward Using The Type Of Representation ...................................................2

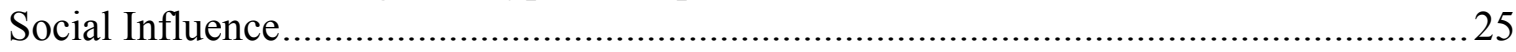

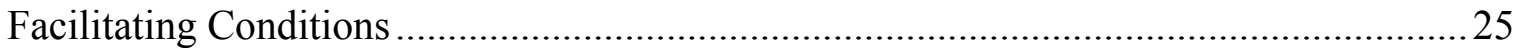

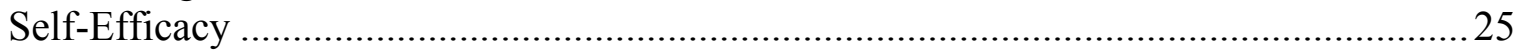

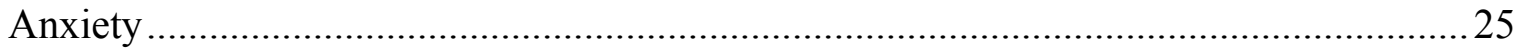

Intention To Use The Requirements Representation ……………………………….....2

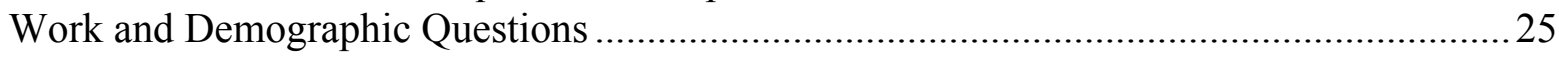

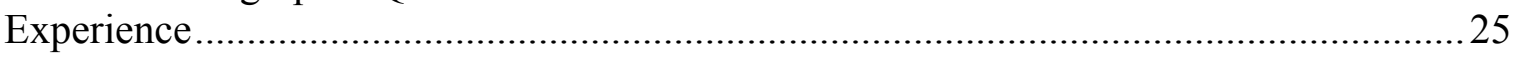

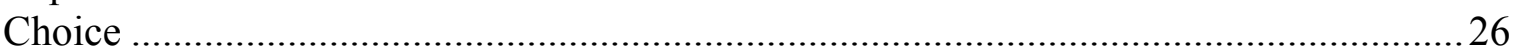

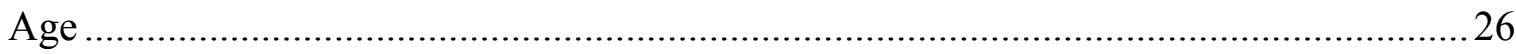

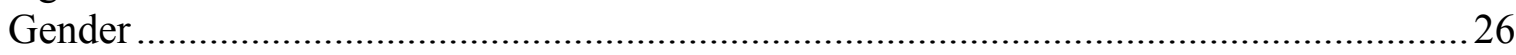

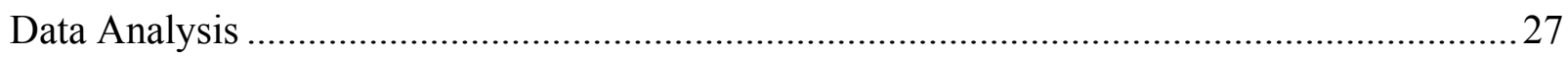

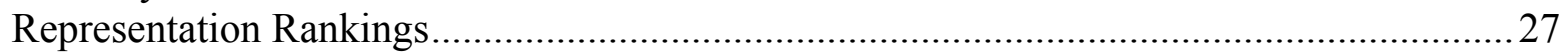

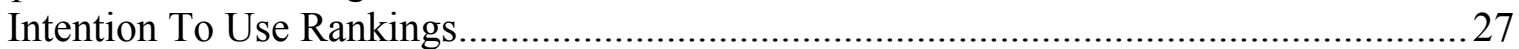

Multiple Linear Regression Model ...............................................................................22

Determinant Rankings Comparison For All Four Representations ……………………....22

Prose

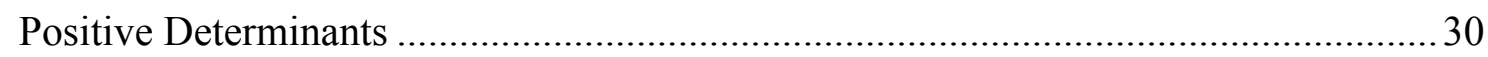

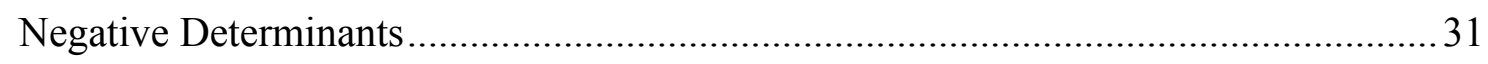

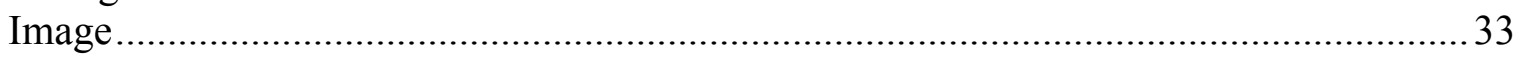




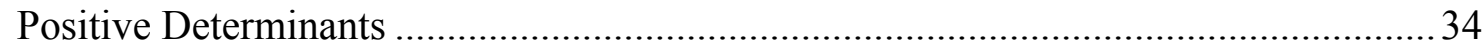

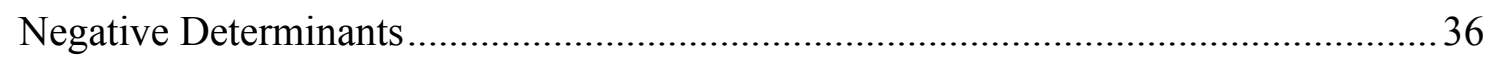

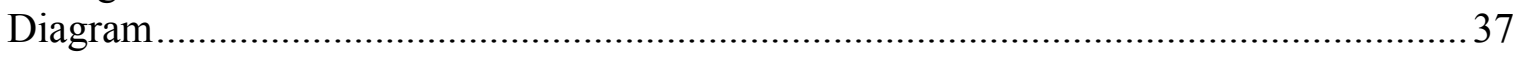

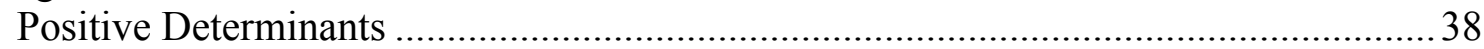

Negative Determinants.........................................................................................

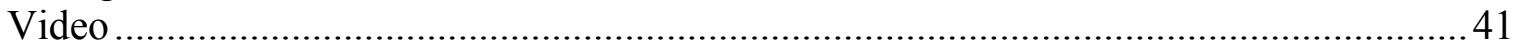

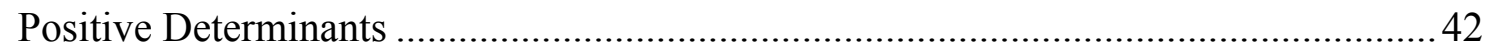

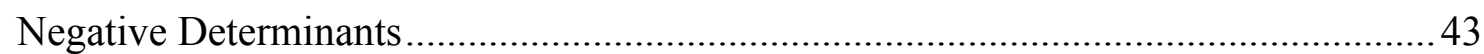

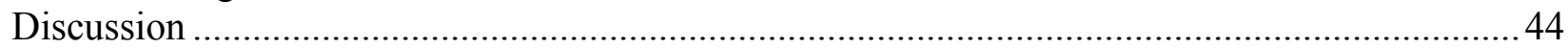

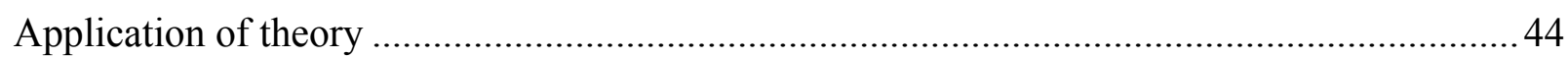

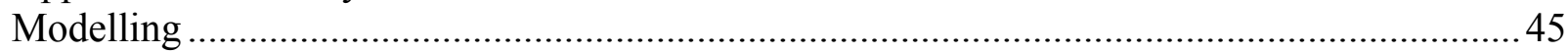

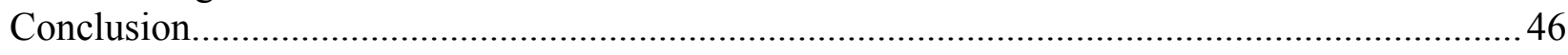

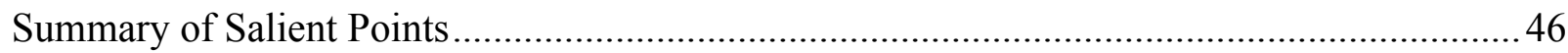

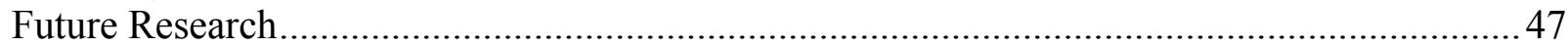

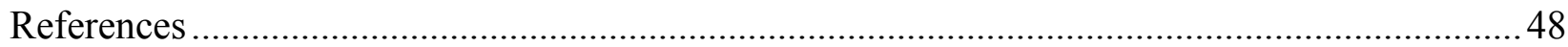

Appendix 1: Descriptive Statistics and Normality …………............................................52

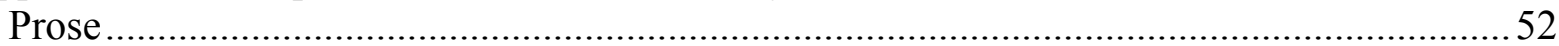

Prose Performance Expectancy …………………………………………………..... 52

Prose Effort Expectancy ……………………………………………………………....53

Prose Attitude Toward Using The Type Of Representation ...............................................54

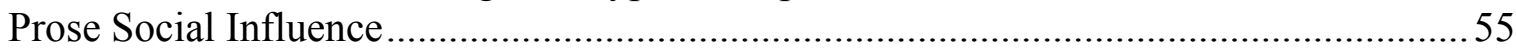

Prose Facilitating Conditions ……………………………………………………….....5 56

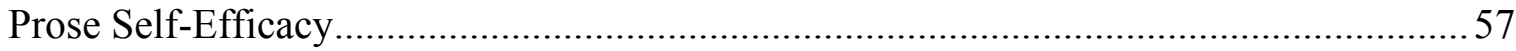

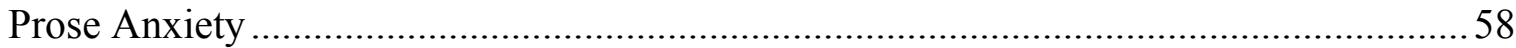

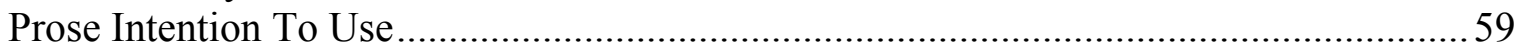

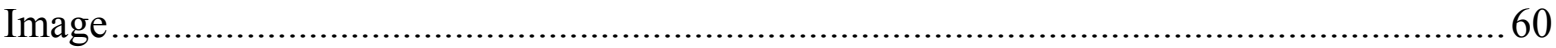

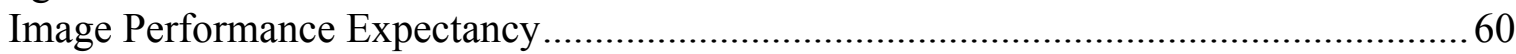

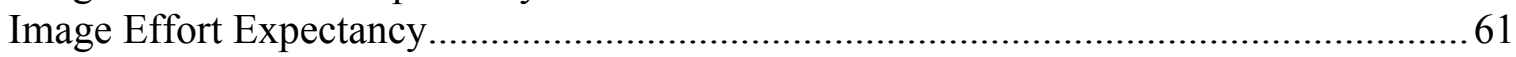

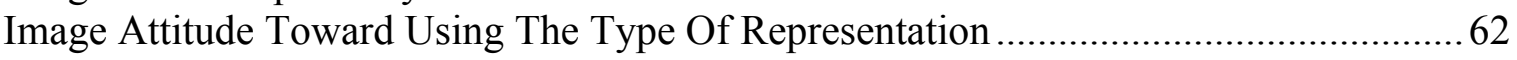

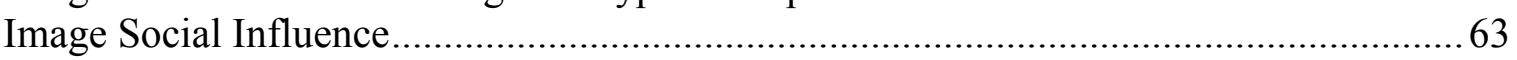

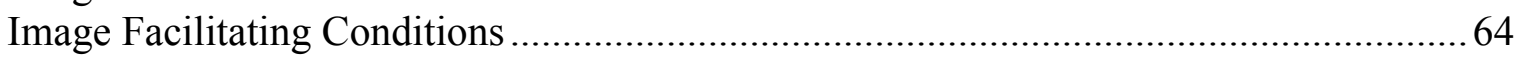

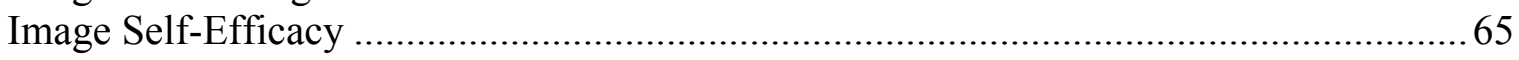

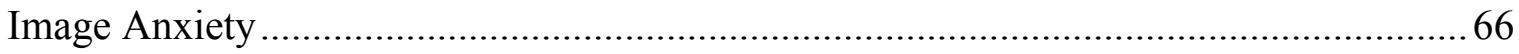

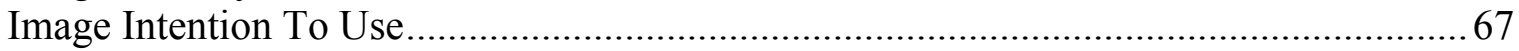

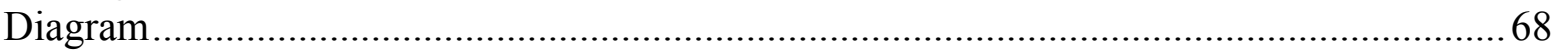

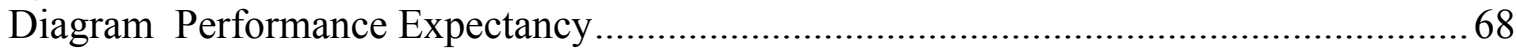

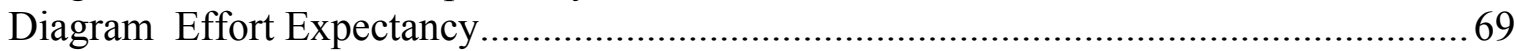

Diagram Attitude Toward Using The Type Of Representation ......................................... 70

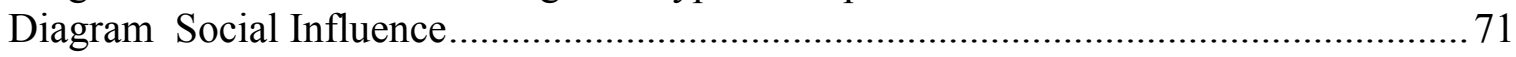

Diagram Facilitating Conditions ..................................................................................

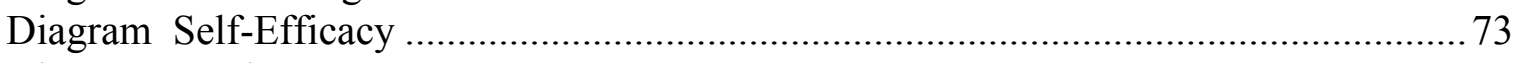

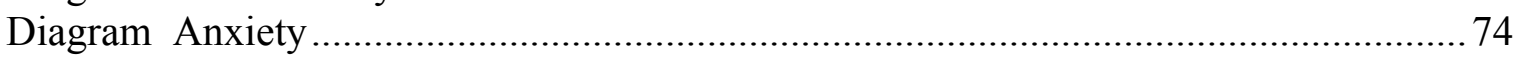

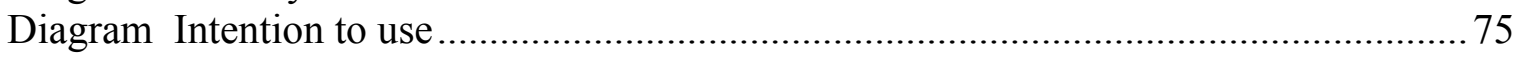

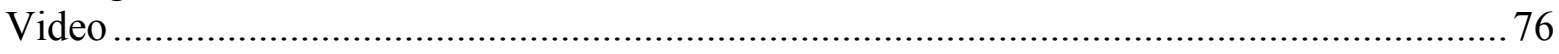

Video Performance Expectancy ................................................................................... 76

Video Effort Expectancy ……………………………………………………………77

Video Attitude Toward Using The Type Of Representation ................................................78

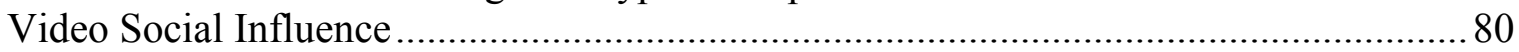

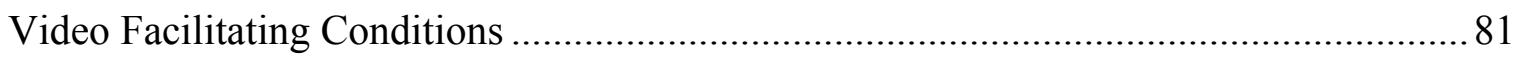

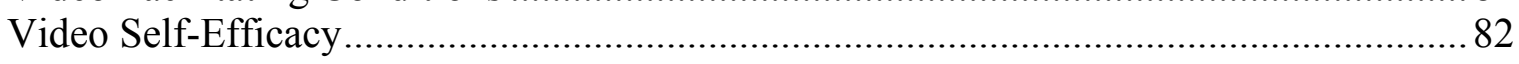

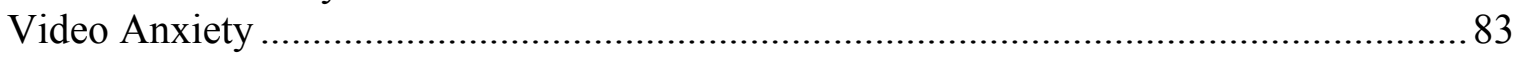

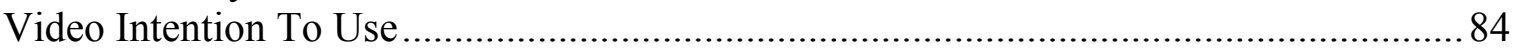

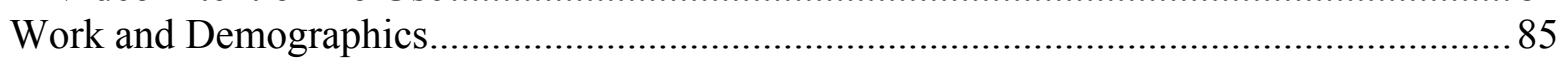


Page 4

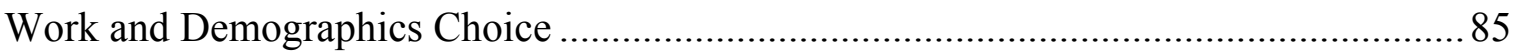

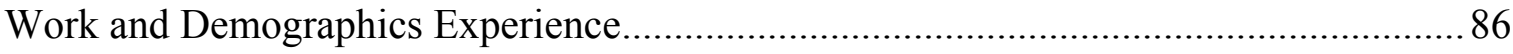

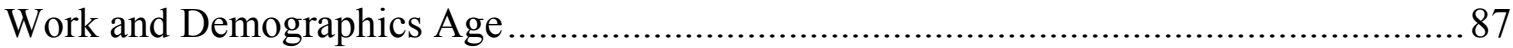

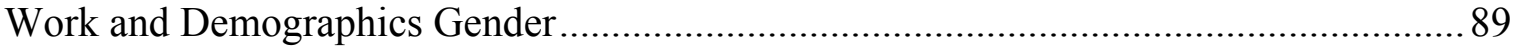




\section{Acknowledgements}

First I would like to thanks Professor Pedro Antunes for all his guidance, advice and encouragement. He helped me to focus on a manageable scope for the research project and kept me on the track when I started to wander into the forest. When I started to stray into personal observations he would bring my focus back to the evidence of the research, even if it was not what was expected. He also provided many insightful ideas about the representation of concepts from his experience in the worlds of design and engineering.

I would also like to thank my wife, Myrto, for her love, patience, help, guidance, advice and support during a long six months of research. She was with me all the way during this journey.

Also I would like to thank my son, Chris, for all his love, encouragement and advice on many topics related to his own research experiences.

Des Kenny

February 12, 2013 


\begin{abstract}
The research question that summarises the primary research goals is: How do business people rank their intentions to use different requirements representations for information systems? An additional goal of the research is to understand the determinants that contribute to these intentions. Business people in this research are defined as working people who are not in an information systems role. The requirements representations evaluated were Prose Narrative, Image Narrative, Diagram Narrative and Video Narrative. The results of this research show that business people rank their intention to use the requirements representations in the following order: Prose Narrative, Image Narrative, Diagram Narrative and Video Narrative. The determinants that influence the intention to use a representation are: Job Performance, Effort, Attitude to a Representation, Social Influence, Facilitating Conditions, Self-Efficacy, Anxiety, Freedom of Choice, Experience, Age and Gender. This research shows that the influence of each of these determinants on the intention to use a representation is significantly different for each requirements representation.
\end{abstract}

\title{
Introduction
}

Business people in the context of this research are defined as people who work in organisations, public or private, and who are not employed in an information systems role.

The objectives of the research are to determine the ranking by business people of their intention to use the different requirements representations, Prose, Images, Diagrams and Video and to understand the weighting of the determinants that contribute to their decisions. These determinants are Job Performance, Effort, Attitude to a Representation, Social Influence, Facilitating Conditions, SelfEfficacy, Anxiety, Freedom of Choice, Experience, Age and Gender. The determinants are derived from the UTAUT model (Venkatesh et al, 2003), which examined peoples' intentions to use a particular computer technology.

Information systems research literature states that insufficiency in requirements engineering still remains one of the root causes of poor quality in the information systems product lifecycle (Solms et al, 2011). Requirements errors and volatility increase project risks and may also result in failed or over schedule projects. (Woolridge et al, 2011). Requirements errors also have a higher impact on the cost of information systems than any other type of error (Jensen et al, 2011).

Requirements elicitation contributes a significant proportion of the errors in requirements engineering (Appan et al, 2012), (Kamalrudin et al. 2011). So reducing errors in requirements elicitation should yield a higher return than any other type of error reduction.

A significant contribution to requirements elicitation error may come from the way that people in the business domain and people in the information systems domain 
communicate about requirements (Maass et al, 2011) (Abdullah et al, 2011). A major aspect of this communication consists of the way requirements are represented by people in different roles (Choe et al, 2011), (Snyder, 2012).

The results of this research may help information systems people in understanding how business people prefer to communicate with the information systems community about their information systems requirements.

\section{Literature Review}

The research literature most relevant to the goal of this research is found in the disciplines of Requirements Engineering and Business Analysis.

\section{Requirements Elicitation Quality Issues}

The problem of low quality in information systems requirements elicitation has been elaborated very recently by (Solms et al, 2011), (Woolridge et al, 2011), (Appan et al, 2012) and (Kamalrudin et al. 2011). This literature describes the problem that is the context of this research: requirements elicitation product quality still remains a major issue in the information systems industry.

When information systems people in business analysis roles elicit information system requirements from business people there may be errors in these communications. There may also be errors in communicating requirements between business analysts and people in other information systems roles. Any type of communication always involves some type of representation of the information that is communicated. The choice of information representation may influence the quality of communication. Errors in requirements communication are described by (Maass et al, 2011) and (Abdullah et al, 2011). The relevance of requirements representations is described in (Choe et al, 2011) and (Snyder, 2012). Different requirements representations may help, hinder or have minimal influence on requirements communication (Huang et al. 2011) and (Mahmud et al, 2011). (Cui et al, 2012) discuss the importance of business motivations and goals on requirements representation.

Turning the clock back, over thirty years ago researchers (Kaiser and Bostrom, 1982) investigated the hypothesis that personality differences between business people and more technically capable systems staff are one of the primary reasons for a communication gap between these different roles. The results surprisingly showed that the personalities of the two groups were very similar. The conclusion was that the user representatives involved in systems development are different personalities to the business people that will use the developed systems on a daily basis. 
Lyytinen (1985) analysed the implications of theories of language for information systems representation. The author described five language representations: denotational, generative, cognitive, behavioristic and interactionist. The conclusion was that different representations suit different contexts and should be chosen contingently depending on the information systems context. The author also concluded that the history of information systems is a history of growing awareness of linguistic essence. In 2013 information systems practice is still struggling with a language communication gap between business people and information systems people even though theoretical linguistic models may have advanced with further research since 1985 .

Orman (1987) presents a view that requirements for information systems are influenced by an organisation's existing information systems in a circular feedback loop and that this undermines the "success of requirements analysis". The author considers solutions to this situation such as normative design, equilibrium analysis and evolutionary systems.

Orman (1987) suggests that normative design implies there are standard business processes that organisations should follow and that information systems should use representations of such processes as templates during requirements elicitation rather than start from a blank page in the requirements elicitation activity. This is a view promoted and adopted in some industries and professions today. For example, there are industrial standards bodies for the telecommunications industry such as the TM Forum Business Process Framework (TM Forum, eTOM, 2013) a process model for the global telecommunications industry, which may possibly be extended to other service industries. Such a template approach may not be suitable for all projects however it may also be unwise to ignore such prepackaged knowledge in other projects. All requirements representations whether elicited directly from business people in a more participatory fashion or adopted from a template industry model or a combination of both need to be validated with business people anyway to ensure that the communication of requirements is as complete and consistent as practical (IIBA, 2012).

Equilibrium analysis involves a detailed study of the effects of a future information system on the future of an organisation. This has been partially adopted in the enterprise analysis (IIBA, 2012) activities of business analysts most specifically in business case studies for projects. A business case study primarily asks the questions how do the benefits relate to the costs and risks of the project and what are the economic, technical and operational feasibilities of the project.

Evolutionary systems that are constantly evolving through feedback response and self-adapting learning behaviour have not become the dominant system design in information systems today. Business peoples' feedback does not dynamically change the internal system architecture of most systems today. Although business 
people have more flexibility today in the choice of system features that they may choose to activate than in 1987.

Green (1989) found that systems analysts recognized the importance of their own behavioral skills for effective development more than users of information systems. Users were more focused on the technical skills that they expected systems analysts to have and were less interest in the behavioral skills of systems analysts even when the analysts believed that the behavioral skills were more important. There was also additional variation between private and public sector organisations. Such different expectations of each other's roles may lead to conflict in what are the most suitable requirements representations in the context of a project. If the systems analysts is attempting to represent requirements in a way that they believe models the users behavior and the user is expecting a more technically focused requirements representation there will be a conflict of perceptions between the two roles.

Byrd (et al, 1992) did some research to compare requirements analysis as performed by systems analysts for information systems and knowledge acquisition as performed by knowledge engineers for expert systems. He found that the two types of activities were very similar and that they could learn much from each other rather than behave as though they were completely distinct roles. In fact this is what has happened today. The separate role of "knowledge engineer" has disappeared from the information systems industry and has become an aspect of the role of business analysis. If there is a need in a project to acquire large numbers of complex business rules for an information system, this declarative knowledge is typically elicited by business analysts for inclusion in a rules engine that the final system will use as a service to perform complex decisions in a deductive manner.

Anderson (1994) investigated the application of observational approaches to system design, in particular ethnography. Ethnography is the study of human cultures mainly by observation and participation in a social group. An ethnographer is supposed to minimize the influence of the social biases from their own culture. A business analyst also needs to help business people to communicate their requirements using their preferred requirements representation during the requirements elicitation process without excessive influence during this communication from the information systems culture. A business analyst may use observation of business people's behavior as a requirements elicitation technique in a similar way to an ethnographic study. However, a business analyst will most likely also use other requirements elicitation techniques that have a higher degree of interactive communication than observation, such as interviewing, requirements workshops, focus groups, brainstorming and prototyping. (IIBA, 2012)

\section{Requirements Representation During Requirements Elicitation}

The focus in this research is on the requirements representations of typical business people that often do not have specialized information systems knowledge about requirements engineering methodologies. If they are given a choice which 
representations do they intend to use to describe their requirements? Do they prefer to describe their requirements with prose, images, sketches, diagrams, audio, video, or some other representation, or combinations of many representations in a multimedia style? So the research is investigating how they prefer to represent the narrative of their information system requirements. The underlying assumption is that discovering their preferred requirements representations will lead to better communication with business people when eliciting requirements than imposing specialized approaches developed by the information systems community.

\section{Prose, Text and Hypertext in Requirements Representation}

(Nanduri et al, 1995) investigated using a natural language parser to analyse text based requirements documents to extract candidate objects, methods and associations to compose them into an object model diagram using the concepts of Object Oriented Analysis. They claimed that such a tool would provide valuable feedback to an analyst. If we assume that their tools worked adequately there is still another barrier to communication with business people and even business analysts. Most business people and many business analysts do not view their world or systems as represented by objects or classes. They are more inclined to view the behavioral, dynamic aspects of the business using some representation they understand. They view their business more as a narrative, as stories of behavior, than a static class or object type model. Class models may indeed be valid representations of a business as a system but many people, including many business analysts, do not yet have such a mental model of business. Class models, if they are ever developed, have been pushed into the information technology background for software people to develop and maintain and are now rarely seen by business people or even business analysts. It would be an interesting research project to discover why business people do not want to view class models as part of their mental models of a business and prefer to focus on process and behavior.

Fiorini (1996) described a project to integrate "business engineering" with "requirements engineering". The idea was to build a conceptual business model using principles of Total Quality Management to model information on the business processes of an organisation. The conceptual model was then implemented in "hypertext". The process models were then used to elicit requirements. In todays terminology a "business engineer" would be a business architect, enterprise architect or business analyst, a "requirements engineer" would be a business analyst or an architect/designer in some contexts. A similar process oriented approach is quite common today in some organisations today. In general, business people seem to prefer the process model as a high level model of an organisation rather than the Information Engineering (Martin, 1989) viewpoint, which considered data models as the high level models of organisations. Business people seem to prefer to view an organisation at a high level as a narrative, a story, rather than a collection of data types, however abstract they may be.

This research investigates the use of narratives in requirements representation by business people and shows that prose narratives, represented as natural language 
text, are the most preferred of the requirements representation types: prose, images, diagrams and video.

\section{Diagrams in Requirements Representation}

(Mahmud et al, 2011) used quantitative methods to test the hypothesis that mindmapping techniques could lead to a significant improvement of the quality of the "product backlog" within an agile methods project. In this agile methods project a "product backlog" played the role of an initial requirements specification document. The data showed that the overall quality of the product backlog is significantly higher using mind maps with general public users. Also the product backlog quality was no worse with business domain experts than with informal requirements engineering approaches. This research influenced the decision to use the diagram concept as one of the research exhibits of requirements representations. Mind maps show relations between concepts but these relations need not be ordered as a narrative sequence. This research does not use mind map diagrams because the exhibits are different representations of a narrative sequence concept. So the choice of diagram was the multi-functional process diagram to represent requirements.

\section{Images in Requirements Representation}

On the other hand, (Snyder, 2012) used qualitative methods. The research had findings related to representation of images and the development of visually enabled information and communication technologies. A discourse-oriented methodology is described for the direct observation and analysis of drawing during face-to-face conversations. Analysis used an iterative, grounded theory (Lehmann, 2010), (Urquhart et al, 2010) approach to multimodal social interactional analysis. In the grounded theory approach no assumptions are made about an existing theory. The theory is induced from the research data. These concepts influenced the decision to include images as one of the requirements representation types. However, the analysis of these image representations was based on the survey method and the UTAUT model (Venkatesh et al, 2003), which are quantitative.

\section{Video and Multimedia in Requirements Representation}

In 1993 the Software Engineering Institute described a project to develop a tool AMORE (The Advanced Multimedia Organize for Requirements Elicitation), (Christel, 1993) which was intended to support the development of information models in projects. The tools was intended to support information modeling projects that needed a wider range of information types including images, audio and video in addition to text and structured graphics. In other words the tool was intended to manage "large multimedia, object bases". The tool was intended to provide support for requirements elicitation by providing an "Elicitor's Assistant". AMORE was designed around the requirement as a basic organizational unit. Requirements would have attributes with a wide range of representations such as natural language text descriptions and possibly graphics, audio and video attribute representations, examples from other systems, interviews that may include business rationales, constraints and other concepts. Requirements would be organized into a 
modifiable hierarchical structure. The tool was intended to be a "Knowledge Assistant" to a requirements engineer by recording and managing requirements and teach skills to users.

(Haumer et al, 1998) described a project to include the use of rich media (video, speech, pictures and other representations) to support the elicitation and validation of high levels requirements as scenarios with "real world scenes" using rich media. They planned to derive the high level requirements by observing, documenting and analyzing scenarios, and illustrating problems, of the existing system using rich media. They intended to use rich media representations of scenarios to make the abstraction process to create conceptual models more transparent and traceable for a wider audience of stakeholders.

(Zachos et al, 2005) described a tool for investigating the right form of scenarios for different requirements tasks. They used an internet-based environment, ARTSCENE, which supports rich media scenarios in requirements discovery. They believed that using rich media scenarios would help stakeholders to recognize events that systems will need to manage.

(Gall et al, 2006) proposed a framework for using video to record requirements elicitation meetings and automatically extract important stakeholder statements. The stakeholder statements are represented as video clips by using a requirements engineering database to access the statements. Their intention was to improve completeness of requirements recording and to more effectively record the rationale for those requirements.

(Pitula et al, 2011), investigated using storytelling as a requirements elicitation technique in rural India. They described how they developed a system so that people could tell their information requirements as stories represented as audio records. The interface to the system used video tuition, graphical icons and audio prompts. Information systems people retrieved the stories later for review and analysis. Videos were also used as ways to elicit some high-level system features. The researchers wanted to use a variety of requirements representations to assist in more effective communication with the people providing the requirements. This is a good example of requirements elicitation using rich media representations of requirements.

Rich information models are now commonly available on public social media communication systems such as (Facebook, 2013), (YouTube, 2013), Wikipedia (2013). On such system people share multimedia representations such as text, general documents, photographs, audio and video. This may be closer to the concepts described in the AMORE project. Although the multi media base technology may be technically and economically feasible there may be other constraints in a business culture that limit the use of such multi media bases as described in the AMORE project. Investigation of possible business culture 
constraints on wider use of images and video in requirements elicitation activities in industry practice may be a useful research project.

The literature on multimedia influenced the research project to include video as a requirements representation.

\section{Narratives and Storytelling Using Various Requirements Representations}

(Alvarez and Urla, 2002) have described the importance of client narratives during requirements analysis since they provide pragmatic views of how systems are actually used and their embedded nature in the social context of organisations. The narratives were recorded during open ended or unstructured interviews. The concept is that the client should be able to narrate their story in a way that they choose rather than be constrained by a framework of information system models that the information systems people are attempting to complete at the same time as the interview. They say that other research has shown that such interview styles are useful for collecting global information specifications but not detailed information requirements. They also point out that other research has shown that ignoring nontechnical issues, social and political context that may emerge in such openended narratives has contributed to the failure of some system implementations.

(Boulila et al, 2011) investigated the effectiveness of storytelling techniques compared to brainstorming techniques. This case study involved twenty-five domain experts from different organisations to collect requirements using storytelling techniques. They did not focus on the representations used in the storytelling and how these might have influenced the effectiveness of the elicitation technique.

\section{Conceptual Models and Tools for Requirements Representation Today}

Information system requirements elicitation today is assisted by some conceptual models (IIBA, 2012), (OMG, 2013) and some requirements management tools such as (Coulin et al, 2010), Microsoft Office (Microsoft, 2013), (Sparx Systems, 2013), (Borland, 2013), IBM Rational RequisitePro (IBM, 2013) and many others. Some requirements quality management tools (Knauss et al, 2009), (Schneider et al, 2011) have been developed to provide feedback to requirements analysts based on heuristic rules and automatically derived models. New requirements are compared to existing ones and the analyst is provided with information on consistency. (Hendrik et al, 2011) described a tool to semi-automatically identify user tasks from unrestricted natural language and organize them into task models.

Requirements elicitation tools today may not be providing strong enough support for a major issue of requirements elicitation: the conceptual gap between requirements representation in business peoples' minds and information systems peoples' minds. A "picture" may tell a thousand words but semi-formal schematic model diagrams, like Universal Modeling Language (UML) diagram models 
(OMG, 2013), are not the types of representation being described by such a "picture". Such "pictures" are facsimiles of real world experience and include photographic images, videos and some paintings. That is not to say that business people cannot be taught UML and to even think in such abstract models. However, assuming that it is financially feasible to teach all business people UML, this will still not substitute for the richer information model proposed in AMORE (Christel, 1993), which would be more easily accessible to a wider span of organizational roles. The use of video, audio and storytelling recorded by business people (Pitula et al, 2011) might be a useful approach to improve communication. UML diagram requirements representations may be necessary but they may not be sufficient.

\section{Intention To Use Requirements Representations}

This research paper does not test the assumption that some representations types will produce higher quality systems. The research is only intended to discover which types of representations business people prefer. So a general model that describes the intentions of people to use various technologies can be used to discover the preferred requirements representations of business people.

Such a model in general information systems key theories and research findings are discussed in (Venkatesh et al, 2003). The goal of their research was to define and test a unified model, called the Unified Theory of Acceptance and Use of Technology (UTAUT). The research involved evaluating a number of previous models in experiments to discover determinants that could be used in the UTAUT model. The resulting UTAUT model was then evaluated in experiments to validate its theory. The experiments used quantitative methods to test the hypotheses of the original models, select components for the new model and test the new model. Aspects of the theory are relevant to this research because it evaluates users' intentions to use various technologies. Various forms of requirements representations are techniques and so constitute a technology in intentional form that models what is required of a solution. The solution may be information technology in the operational form.

(Appan et al, 2012) used quantitative methods to investigate a hypothesis that requirements analysts may introduce misinformation in the requirements elicitation process. They performed an experiment to test the hypothesis. Their results indicated that (1) introduction of misinformation reduces the accuracy of requirements provided by users, and (2) social techniques (interviews) are more vulnerable to the misinformation effect than nonsocial techniques (surveys). They concluded that the misinformation effect is a significant threat to the accuracy of requirements gathered for organizational systems. This research was a factor that influenced the decision to gather data using a survey method rather than interviews. However, the decision to use a survey method was also influenced by the UTAUT model (Venkatesh et al, 2003), which had already reliably tested the survey method to analyse the intentions of participants to use various computer technologies. So this research could use this same approach for researching the intentions of participants to use various requirements representations. 
Another qualitative approach in the literature is the case study method used in (Woolridge et al, 2011). This case study approach takes an existing theory, possibly from another research domain, and tests its validity in the context of the case study. The project sought evidence that Complex Adaptive Systems (CAS) theory explains the emergence and evolution of application domain specifications. Propositions were developed through analysis of the theory definitions and then tested in the case study. The case analysis confirmed the propositions with limitations. There are four problems to overcome when using a case study research methodology: controlling observations, controlling deductions, allowing for replication, and allowing for generalization (Lee, 1989). The control of observations and control of deductions was believed to be sufficient. One researcher on one case performed the research, which limits replication and generalization. The model suggests that stakeholders change their specifications in response to another stakeholder's specifications. This is called co-adaptation. The implications of the research are that the outcomes of multi-stakeholder coadaptations are not predictable with any accuracy. The lack of reliable prediction in this case study example partly influenced the research decision not to use a case study method to determine the intentions of business people to use various requirements representations.

The primary objective of this research is not to test the validity of the UTAUT model (Venkatesh et al, 2003). However, a secondary goal of the research is to confirm that the UTAUT model is consistent with the research data in the context of requirements representations. Also the data gathering approach is quantitative not qualitative so this is quite a different research process to the typical case study.

Some articles discovered are qualitative descriptions of research activities that do not attempt to validate the research by either quantitative or qualitative methods. For example, (Cui et al, 2012) describe a framework that integrates the development of motivation and requirements models at the organization, business, product, and system/software levels.

\section{Research Objectives}

\section{Objective}

The primary objective of this research is to discover the ranking that people in business roles have for their intentions to use various requirements representations for information systems. This ranking may assist people in the information systems role to understand which requirements representations more closely match the expectations of business people. In addition to the ranking of requirements representations information systems people will be able to see how the various determinants of the UTAUT model influence this ranking. These determinants are: job performance expectancy, effort expectancy, attitude toward using the representation, social influence, facilitating conditions, self-efficacy, anxiety, choice, experience, age and gender. 
Consequently the requirements elicitation process may be more effective in communicating business people's needs to people in the information systems domain (Mahmud et al, 2011). This in turn may contribute to higher quality solutions to business needs.

\section{The Research Question}

The research question is: How do business people rank their intentions to use different requirements representations for information systems?

\section{Methodology}

\section{Research Approach}

The research approach is based on the assumption that collecting information from business people directly about their preferred requirements representations may be more reliable than attempting to collect the same information indirectly from information systems people such as business analysts or requirements engineers. This assumption is partly supported by (Appan et al, 2012) who used quantitative methods to investigate a hypothesis that requirements analysts may introduce misinformation in the requirements elicitation process. They concluded that the misinformation effect is a significant threat to the accuracy of requirements gathered for organizational systems. The implication is that eliciting the survey data directly from business people may introduce fewer errors than eliciting it indirectly from the information systems community. More people in the communication chain may introduce more noise into the communication signal.

There is a potential counter argument to the assumption that the most direct communication with business people is the most reliable. Since some business analysts may have elicited similar requirements from many other people they may have acquired sufficient knowledge to anticipate what the business people may be expected to describe in their requirements. The risk is that the knowledge acquired by the business analyst may not be sufficiently complete or consistent in a new context with new ideas unexpected by the business analyst. It may be useful to compare the survey data from both business people and business analysts to see how the responses from the two populations vary. This research project will not make this comparison for practical reasons of the time limitation of the project.

\section{Data Collection Methods}

Quantitative methods, based on surveys, were used for ranking the intentions to use different requirements representations for information systems, and to analyse determinants that may contribute to their responses.

The research used the determinants discovered in the UTAUT model (Venkatesh et al, 2003) as possible factors influencing the intentions to use different requirements representations. The dependent variable "behavioral intention" had the independent variables "performance expectancy", "effort expectancy", "social influence", 
"facilitating conditions", "computer self-efficacy", "computer anxiety" and "attitude towards using computer technology". They also considered experience, age, gender and voluntariness as moderators of results. This research project will also use these 11 determinants and one dependent variable, "intention to use", paraphrased to make them more relevant to requirements representations rather than computer technology.

In the UTAUT model each category of question such as "performance expectancy", "effort expectancy", "attitude", "social influence", "facilitating conditions", "self efficacy" and "anxiety" was asked 4 times, paraphrased differently. The psychological intention of repeating questions in a different form is to attempt to detect inconsistencies within the answers of respondents.

The research project has 12 survey question type variables and 4 representation types. If the project followed the precise approach of the UTAUT questionnaire of 4 variants for each question category the result would be 192 questions. While this may have resulted in more consistent answers it would also have resulted in largescale survey fatigue and is very likely to have scared away potential participants. The research will describe later some evidence to support this conjecture by showing how difficult it was to get any willing participants for the survey at all, even with fewer questions.

So the research started with the UTAUT model questions and partitioned them across all the 4 representation types. For example instead of having 4 questions for "Performance Expectancy" such as:

\section{Performance expectancy}

1. I would find this computer technology useful in my job.

2. Using this computer technology enables me to accomplish my tasks more quickly.

3. Using this computer technology increases my productivity.

4. If I use this computer technology I will increase my chances of getting a salary increase.

The research project changed this set of questions to include each of the 4 representation types, one per question:

\section{Performance expectancy}

1. I would find Narrative Prose useful in my job.

2. Using Narrative Images enables me to accomplish my tasks more quickly.

3. Using Narrative Diagrams increases my productivity.

4. If I use Narrative Video I will increase my chances of getting a salary increase.

Once this substitution was done for all the UTAUT model questions the result was that each representation type was included once in each of the 8 categories of representation questions ( 7 determinants and 1 intention question). The research 
project then added the four work context and demographic type questions, "experience" and "freedom of choice", "age" and "gender". The research did not repeat these work context and demographic questions with paraphrased duplicates. The work/ demographic questions were very simple factual questions and so very unlikely to require much interpretation and inconsistencies. The result was 28 representation type questions, 4 intention questions and 4 work/demographic questions, making a total of 36 questions. This was a trade off between the risk of inconsistency and survey fatigue and even no responses at all.

The research project shuffled all the questions so that questions about the same representation type were not consecutive. So respondents had to read the questions more carefully than if all the questions about a representation type were consecutive. The hope was that this would elicit more focused and honest answers, although such rapid context switching would also be more mentally tiring for participants.

Fortunately their mental efforts would be over after only 36, easy to understand questions, based on 4 easy to understand exhibits. The research ran a test of the survey with work colleagues before making it public. The research project specifically asked was the survey too long and no participant said it was.

The research project originally planned to include a sample of more than $300 \mathrm{New}$ Zealand large businesses in the survey by contacting their senior management. However, after no valid responses from the senior management of such organisations, the project changed the sample to include 66 contacts in New Zealand and international businesses in different industries. These contacts were selected by the criteria that they were business people working in business organisations and the sampling technique used was convenience sampling. Since the questions of the questionnaire are directed at a general population of business people and does not expect any specialist knowledge, the research assumes that the sample is as representative as any other sample on requirements representation intentions by business people. However the research does not claim random sampling and convenience sampling may have introduced bias into the data. For example, the data has a significantly higher number of females and more respondents are in the older range of possible ages.

\section{Exhibits}

For each question that involves scoring a representation respondents were provided with an exhibit that demonstrated that type of representation. The exhibits were all based on a common theme: a narrative of doing the weekly shopping. The research project selected this theme because it is almost certain that all survey participants have had this weekly shopping experience numerous times. So it is unlikely that the survey questions required any specialist knowledge from participants. Each of the exhibits presented the weekly shopping narrative with a different representation. The survey asked questions about four requirements representations of the weekly shopping narrative: prose narrative, images narrative, diagram narrative and video narrative. Some samples from the exhibits are shown below. 


\section{Introduction}

This is a business requirements definition represented as narrative prose to describe the process of doing the typical weekly shopping.

\section{The Shopping Process}

\section{Decide What Items To Buy}

This will depend on the items required by the household. Some items may be used during the following week others may take longer to use. The buyer should check what items are already in stock.

\section{Record A Shopping List}

The buyer may record a shopping list of items in their head, on paper or on a mobile electronic device. Buying locations usually have most of their goods on display. This may help with recalling items to buy. Item displays at the buying location may also prompt the buyer to buy additional items.

\section{Decide Where To Buy Items}

Choose one or more buying locations such as supermarkets, open-air markets, specialty shops or online. The choice of buying location may depend on the buyer's perception of item availability, price and quality of the items at a buying location. Specialty shops may have more unique groceries, higher quality and may be more expensive. Open-air markets may have fresher farm produce. Open-air markets may be cheaper. Open-air markets do not generally operate on more than one day per week. Open-air markets are more affected by the weather than supermarkets.

Figure 1: Narrative Prose

The complete exhibit is located here:

https://docs.google.com/file/d/0BzNuON2za4F9LXZfQmppRno1Tnc/edit?usp=sharing

Note: to view the complete exhibit this PDF document must be opened with Adobe Reader to active the web link above. Other PDF readers may not activate the web link. 
Narrative Images

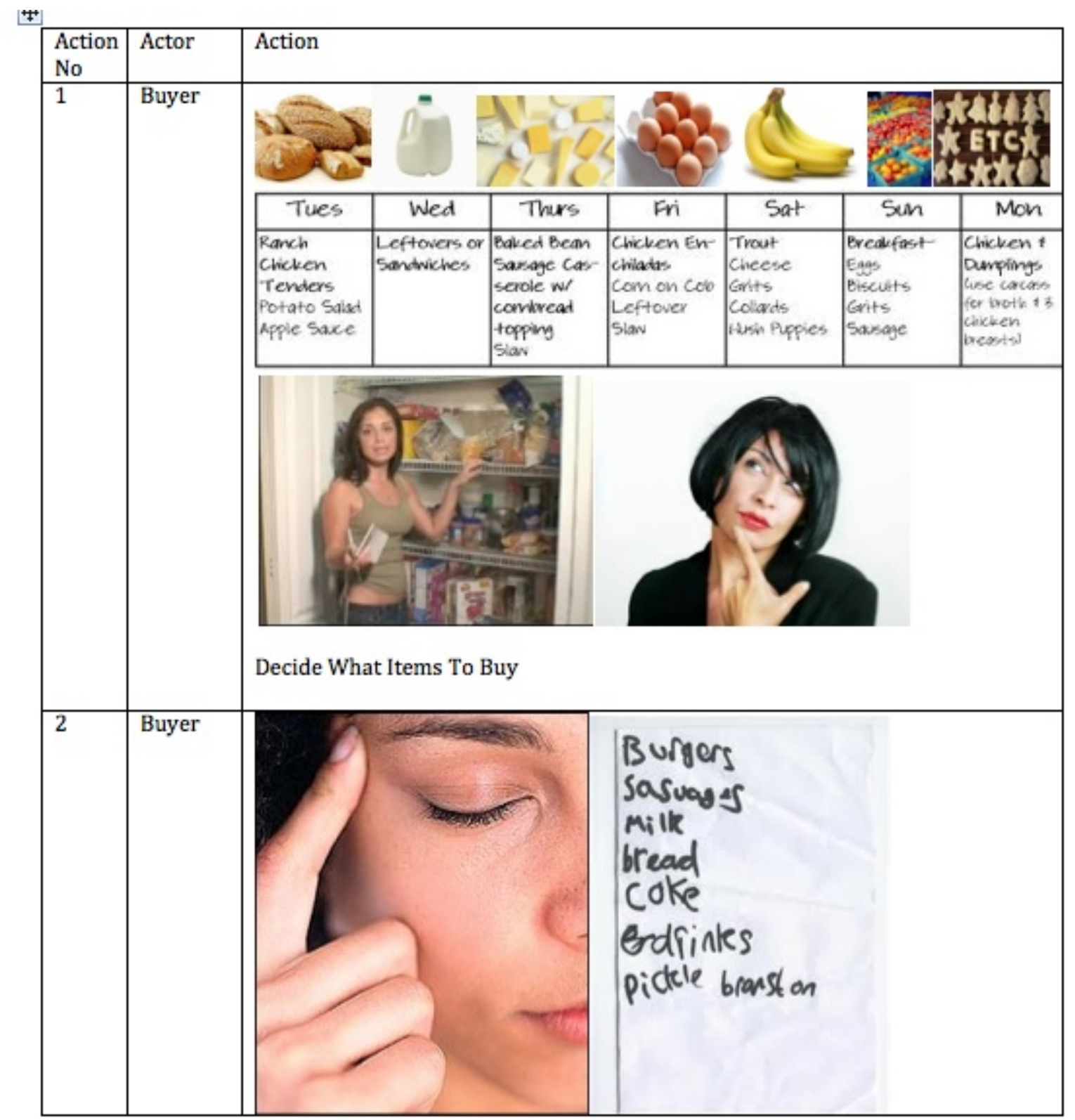

Figure 2: Narrative Images

The complete exhibit is located here:

https://docs.google.com/file/d/0BzNuON2za4F9VW5vaW5IOGFRcWM/edit?usp=sharing

Note: to view the complete exhibit this PDF document must be opened with Adobe Reader to active the web link above. Other PDF readers may not activate the web link. 


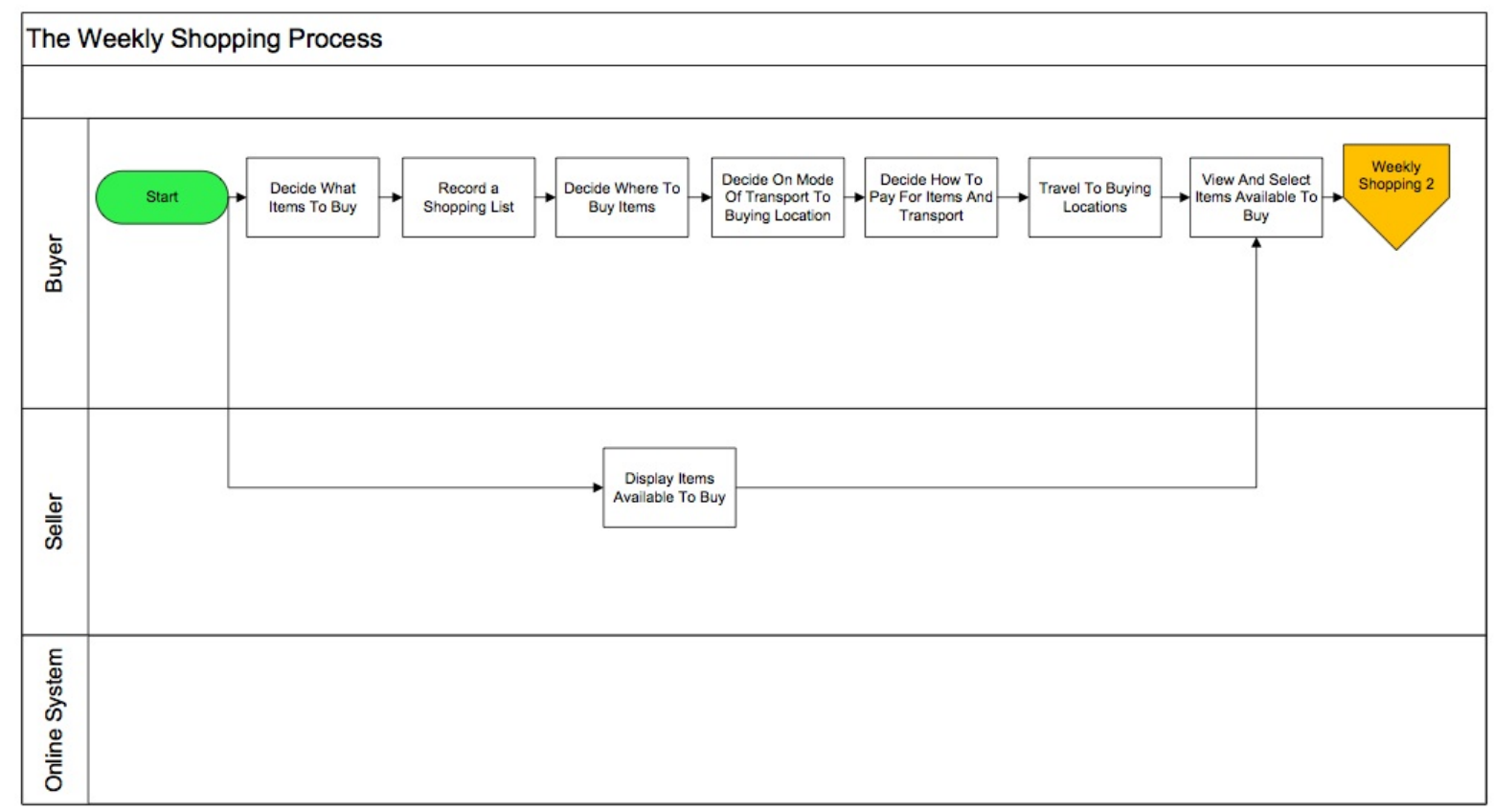

Figure 3: Narrative Diagram

The complete exhibit is located here:

https://docs.google.com/file/d/0BzNuON2za4F9aFhkWDdjaVBoUTQ/edit?usp=sharing

Note: to view the complete exhibit this PDF document must be opened with Adobe Reader to active the web link above. Other PDF readers may not activate the web link. 
Narrative Video

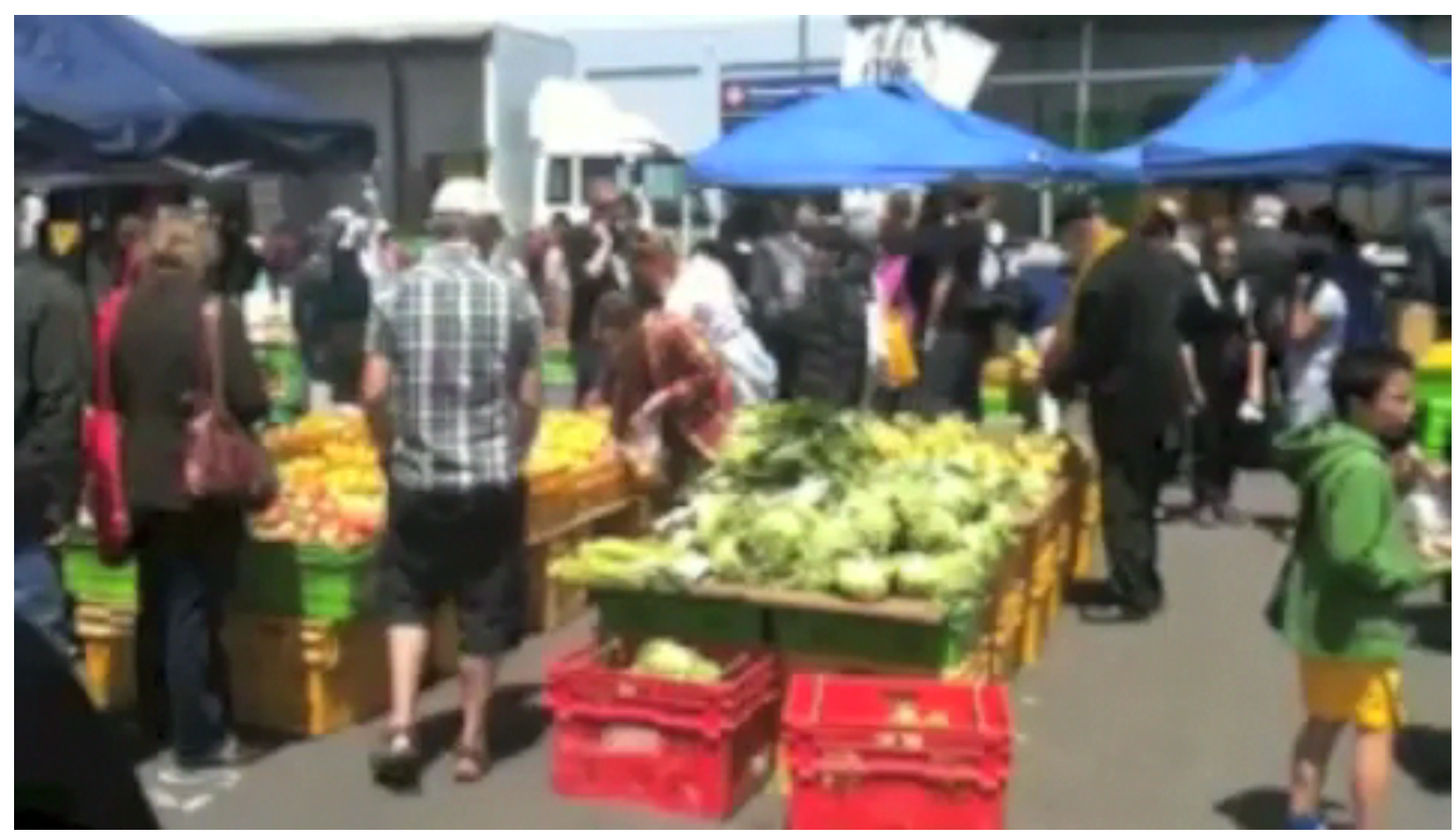

Figure 4: Narrative Video

The complete exhibit is located here:

https://docs.google.com/file/d/0BzNuON2za4F9RmpRN3lILUNfV1U/edit?usp=sharing

For devices without Adobe Flash, such as an iPad, use this link:

http://www.youtube.com/watch?v=myi5d0iLI4w

Note: to view the complete exhibit this PDF document must be opened with Adobe Reader to active the web link above. Other PDF readers may not activate the web link. 


\title{
Data Analysis Justification
}

The data analysis was based on a sample size of 34 . Using a sample size calculator (Raosoft, 2013), this allows a 10\% margin of error at 90\% confidence on a population of 66 and a $50 \%$ response distribution. The population of contacts, sampled by convenience, was 67 . The response rate was $52 \%$. So the sample of 34 was close to the value required for a $10 \%$ margin of error at $90 \%$ confidence. The use of the UTAUT model helps to add a little justification to the data analysis because that model was tested with a large sample size of 133.

The population of large New Zealand business organisations that the research project contacted was 323 . Unfortunately, none of these organisations agreed to participate in the survey. Further research could be done to understand why these organisations declined to participate in this type of survey.

\section{Limitations}

The margin of error at $10 \%$ is quite large and the confidence at $90 \%$ is quite small. Also the fact that the sample is by convenience means there is a risk of bias in the sample. This may related to the fact that the number of female respondents was over twice as many as male respondents. Also the age of the respondents was at the higher end of the age scale.

\section{Data Collection}

Data was collected online using the Qualtrics survey system (Qualtrics, 2013) from mid December 2012 to mid January 2013. For each of the 4 representations data was collected for these data variables, adapted from (Venkatesh et al, 2003):

\author{
Question Categories \\ 1. Performance expectancy \\ 2. Effort expectancy \\ 3. Attitude toward using the representation \\ 4. Social Influence \\ 5. Facilitating Conditions \\ 6. Self-efficacy \\ 7. Anxiety \\ 8. Choice \\ 9. Experience \\ 10.Age \\ 11.Gender \\ 12.Intention to Use
}

Performance expectancy means how would using the requirements representation help a person in their job role. Effort expectancy means how much effort is involved in using a requirements representation. Attitude toward using the requirements representation means would the person enjoy using the requirements 
representation or not. Social influence means what influence would other people in the person's work organisation have on their choice of requirements representation. Facilitating conditions means what facilities would be available at a person's work organisation to use a requirements representation. Self-efficacy refers to how easy it would be for a person to use a requirements representation without any additional instruction from other people. Anxiety refers to whether a person would have any anxiety, or discomfort, in using a requirements representation. Choice means whether a person would be free to choose a requirements representation that they might prefer. Experience refers to how many years a person has had describing their requirements to other people. Age and gender are the usual meanings. Intention to use means does the person intend to use the requirements representation in the next 12 months.

Apart from gender, the text category scale was a 7-point Likert scale and for data analysis this was converted to an equivalent numerical scale:

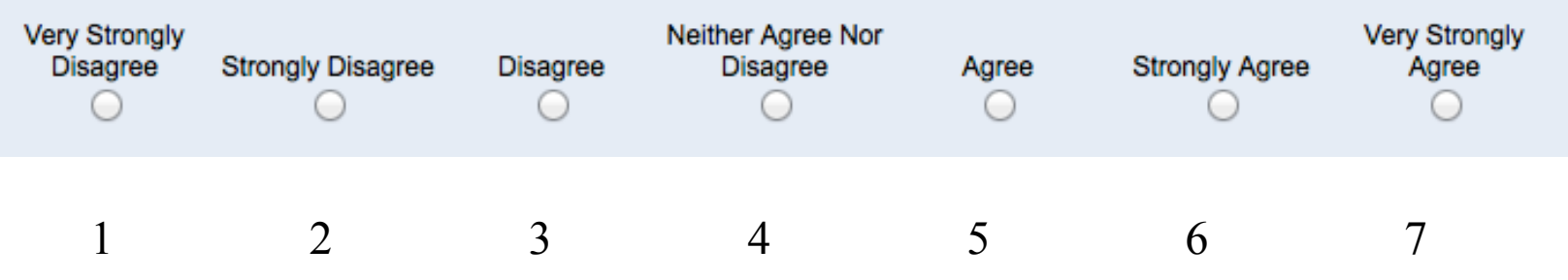

Figure 5: Question Scale

The survey questions, adapted from the UTAUT model (Venkatesh et al, 2003), are grouped into their determinant categories below. However in the actual survey distribution the questions were shuffled so that questions on the same representation were not consecutive.

\section{Requirements Representation Questions}

\section{Performance Expectancy}

1. I would find Narrative Prose useful in my job.

2. Using Narrative Images enables me to accomplish my tasks more quickly.

3. Using Narrative Diagrams increases my productivity.

4. If I use Narrative Video I will increase my chances of getting a salary increase.

\section{Effort Expectancy}

1. My use of Narrative Prose would be clear and understandable.

2. It would be easy for me to become skilful at using Narrative Images.

3. I would find Narrative Diagrams easy to use.

4. Learning to use Narrative Video is easy for me.

\section{Attitude Toward Using The Type Of Representation}

1. Using Narrative Prose is a good idea.

2. Narrative Images make my work more interesting.

3. Working with Narrative Diagrams is fun. 
4. I like working with Narrative Video.

\section{Social Influence}

1. People who influence my behaviour think I should use Narrative Prose.

2. People who are important to me think that I should use Narrative Images.

3. The senior management of this business has been helpful in the use of Narrative Diagrams.

4. In general, the organisation has supported the use of Narrative Video.

\section{Facilitating Conditions}

1. I have the resources necessary to use Narrative Prose.

2. I have the knowledge necessary to use Narrative Images.

3. Narrative Diagrams are compatible with systems that I use.

4. A specific person (or group) is available for assistance with difficulties related to Narrative Video.

\section{Self-Efficacy}

1. I need someone to instruct me during a requirements task using Narrative Prose.

2. I could complete a requirements task using Narrative Images if I could call someone for help when I got stuck.

3. If I had a lot of time I could complete a requirements task using Narrative Diagrams.

4. I could complete a requirements task using Narrative Video if I had only a built-in help facility for assistance.

\section{Anxiety}

1. I feel apprehensive about using Narrative Prose.

2. It scares me to think that I could lose a lot of information using Narrative Images.

3. I hesitate to use Narrative Diagrams for fear of making mistakes I cannot correct.

4. Using Narrative Videos is somewhat intimidating to me.

\section{Intention To Use The Requirements Representation}

1. I intend to use Narrative Prose in the next 12 months.

2. I predict I would use Narrative Images in the next 12 months.

3. I plan to use Narrative Diagrams in the next 12 months.

4. I expect to use Narrative Video in the next 12 months.

\section{Work and Demographic Questions}

\section{Experience}

1. How many years experience have you had describing your information systems requirements to other people? This question had a 7 point scale as follows:

1. Less than 5 years

2. $5-10$ years

3. 10-15 years 
4. 15-20 years

5. $20-30$ years

6. 30-40 years

7. More than 40 years

\section{Choice}

2. How much freedom do you have in choosing requirements representations? This question had a 7 point scale as follows:

1. No Freedom

2. Extremely Limited Freedom

3. Limited Freedom

4. Average Freedom

5. A High Degree of Freedom

6. An Extremely High Degree of Freedom

7. Unlimited Freedom

Age

3. What is your age?

This question had a 7-point scale as follows:

1. Less than 20

2. $20-30$

3. $30-40$

4. $40-50$

5. $50-60$

6. $60-70$

7. More than 70

Gender

4. What is your gender?

This question had a 2-point scale as follows

1. Male

2. Female 


\section{Data Analysis}

The primary objective of this research was to discover the preferred ranking of the four requirements representations: prose, images, diagrams and video.

\section{Representation Rankings}

\section{Intention To Use Rankings}

The Intention To Use Ranking results are as follows:

\begin{tabular}{|l|l|r|}
\hline \multicolumn{3}{|l|}{ Intention To Use Ranking of Representations } \\
\hline & Intention To Use & Intention To Use \\
\hline Representation & Mean & Standard Deviation \\
\hline Prose & 4.97 & 1.19 \\
\hline Image & 4.21 & 1.23 \\
\hline Diagram & 4.21 & 1.47 \\
\hline Video & 3.26 & 1.44 \\
\hline
\end{tabular}

Figure 6: Intention To Use Rankings

Prose ranks as the most preferred representation for intention to use, diagram and image rank equal and video is the least preferred representation. The standard deviation for diagram is higher than for image so there is a wider range of opinion on the intention to use for diagram than for image.

The spread of the mean rankings is not very large from 4.97 to 3.26 , which is 1.71 . As a percentage of the 7-point scale for all questions, apart from the gender question, this amounts to $24 \%$ of the score range. So the spread of the rankings is not extreme. Also the mean intention to use of all the representations is close to the middle score, 4, of the 7-point scale. People do not have an extreme preference of one representation over another, although video is the least preferred by a small margin.

\section{Multiple Linear Regression Model}

The secondary objective was to determine if the data was a good fit with the UTAUT model. How well did the 11 independent variables of the model predict the dependent variable, intention to use a requirements representation?

For each representation the research project used a multiple linear regression model to analyse the data and produce an equation to determine how each of the independent variables contributed to a prediction of the value of the dependent variable, intention to use a requirements representation. The independent variables for the multiple linear regression model, for each representation, were as follows:

1. Performance expectancy

2. Effort expectancy

3. Attitude toward using the representation

4. Social Influence 
5. Facilitating Conditions

6. Self-efficacy

7. Anxiety

8. Choice

9. Experience

10.Age

For all four representations the coefficients of the multiple linear regression model had some quite different rankings. These are summarised in the table below:

Determinant Rankings Comparison For All Four Representations

\begin{tabular}{|c|c|c|c|c|c|c|c|}
\hline \multirow{2}{*}{\multicolumn{2}{|c|}{$\begin{array}{c}\text { Prose } \\
\text { Coefficient }\end{array}$}} & \multirow{2}{*}{\multicolumn{2}{|c|}{$\begin{array}{c}\text { Image } \\
\text { Coefficient }\end{array}$}} & \multirow{2}{*}{\multicolumn{2}{|c|}{$\begin{array}{l}\text { Diagram } \\
\text { Coefficient } \\
\end{array}$}} & \multirow{2}{*}{\multicolumn{2}{|c|}{$\begin{array}{c}\text { Video } \\
\text { Coefficient }\end{array}$}} \\
\hline & & & & & & & \\
\hline Name & Value & Name & Value & Name & Value & Name & Value \\
\hline Gender & 0.69 & Gender & 0.59 & Self-Efficacy & 0.77 & Anxiety & 0.75 \\
\hline $\begin{array}{l}\text { Facilitating } \\
\text { Conditions }\end{array}$ & 0.49 & $\begin{array}{l}\text { Effort } \\
\text { Expectancy }\end{array}$ & 0.45 & $\begin{array}{l}\text { Performance } \\
\text { Expectancy }\end{array}$ & 0.58 & $\begin{array}{l}\text { Effort } \\
\text { Expectancy }\end{array}$ & 0.69 \\
\hline Attitude & 0.42 & Attitude & 0.40 & Experience & 0.35 & $\begin{array}{l}\text { Social } \\
\text { Influence }\end{array}$ & 0.65 \\
\hline $\begin{array}{l}\text { Performance } \\
\text { Expectancy }\end{array}$ & 0.18 & $\begin{array}{l}\text { Performance } \\
\text { Expectancy }\end{array}$ & 0.30 & Attitude & 0.18 & Gender & 0.64 \\
\hline Age & 0.10 & Age & 0.27 & $\begin{array}{l}\text { Effort } \\
\text { Expectancy }\end{array}$ & 0.14 & Attitude & 0.37 \\
\hline $\begin{array}{l}\text { Social } \\
\text { Influence }\end{array}$ & 0.06 & Anxiety & 0.14 & Age & -0.09 & Choice & 0.23 \\
\hline Experience & 0.01 & Choice & 0.06 & Choice & -0.12 & Experience & 0.20 \\
\hline Anxiety & -0.02 & Experience & -0.02 & Gender & -0.15 & $\begin{array}{l}\text { Performance } \\
\text { Expectancy }\end{array}$ & 0.10 \\
\hline Self-Efficacy & -0.03 & $\begin{array}{l}\text { Social } \\
\text { Influence }\end{array}$ & -0.04 & $\begin{array}{l}\text { Facilitating } \\
\text { Conditions } \\
\end{array}$ & -0.15 & Age & 0.05 \\
\hline $\begin{array}{l}\text { Effort } \\
\text { Expectancy }\end{array}$ & -0.09 & $\begin{array}{l}\text { Facilitating } \\
\text { Conditions }\end{array}$ & -0.07 & $\begin{array}{l}\text { Social } \\
\text { Influence }\end{array}$ & -0.26 & $\begin{array}{l}\text { Facilitating } \\
\text { Conditions }\end{array}$ & -0.08 \\
\hline Choice & -0.21 & Self-Efficacy & -0.28 & Anxiety & -0.80 & Self-Efficacy & -0.29 \\
\hline
\end{tabular}

Figure 7: Determinant Rankings Comparison For All Four Representations

The details of the multiple linear regression models for each representation are analysed below. 


\section{Prose}

The multiple linear regression data analysis for the prose requirements representation was as follows:

\begin{tabular}{|lc|}
\hline & \multicolumn{1}{c|}{ Linear Regression } \\
\hline Regression Statistics & \\
\hline$R$ & 0.88 \\
$R$ Square & 0.77 \\
Adjusted $R$ Square & 0.66 \\
$S$ & 0.7 \\
Total number of observations & 34 \\
\hline Linear Regression Model Equation \\
Intention To Use $=$ & \\
& $\mathbf{- 0 . 8 9}$ \\
& $+\mathbf{0 . 1 8} *$ Performance Expectancy \\
& $\mathbf{- 0 . 0 9} *$ Effort Expectancy \\
& $+\mathbf{0 . 4 2} *$ Attitude \\
& $+\mathbf{0 . 0 6} *$ Social Influence \\
& $+\mathbf{0 . 4 9} *$ Facilitating Conditions \\
& $\mathbf{- 0 . 0 3 *}$ Self-Efficacy \\
& $\mathbf{0 . 0 2} *$ Anxiety \\
& $\mathbf{- 0 . 2 1} *$ Choice \\
& $+\mathbf{0 . 0 1} *$ Experience \\
& $+\mathbf{0 . 1 0} *$ Age \\
& $+\mathbf{0 . 6 9} *$ Gender \\
& \\
\hline
\end{tabular}

\begin{tabular}{|c|c|c|c|c|c|c|c|}
\hline & Coefficien & $\begin{array}{c}\text { Standard } \\
\text { Error }\end{array}$ & $L C L$ & $U C L$ & $t$ Stat & $p$-level & $\begin{array}{l}H 0(2 \%) \\
\text { rejected? }\end{array}$ \\
\hline Intercept & -0.89 & 2.67 & -7.59 & 5.81 & -0.33 & 0.74 & No \\
\hline Performance & 0.18 & 0.19 & -0.29 & 0.65 & 0.95 & 0.35 & No \\
\hline $\begin{array}{l}\text { Effort } \\
\text { Expectancy }\end{array}$ & -0.09 & 0.17 & -0.53 & 0.34 & -0.54 & 0.59 & No \\
\hline Attitude & 0.42 & 0.21 & -0.11 & 0.96 & 1.98 & 0.06 & $\mathrm{No}$ \\
\hline Social Influence & 0.06 & 0.18 & -0.38 & 0.5 & 0.33 & 0.74 & $\mathrm{No}$ \\
\hline Facilitating & 0.49 & 0.39 & -0.49 & 1.47 & 1.26 & 0.22 & $\mathrm{No}$ \\
\hline Self-Efficacy & -0.03 & 0.24 & -0.64 & 0.58 & -0.13 & 0.9 & $\mathrm{No}$ \\
\hline Anxiety & -0.02 & 0.17 & -0.45 & 0.41 & -0.14 & 0.89 & $\mathrm{No}$ \\
\hline Choice & -0.21 & 0.17 & -0.63 & 0.21 & -1.27 & 0.22 & $\mathrm{No}$ \\
\hline Experience & 0.01 & 0.09 & -0.22 & 0.25 & 0.16 & 0.88 & $\mathrm{No}$ \\
\hline Age & 0.1 & 0.15 & -0.27 & 0.46 & 0.65 & 0.52 & No \\
\hline Gender & 0.69 & 0.29 & -0.05 & 1.42 & 2.35 & 0.03 & $\mathrm{No}$ \\
\hline
\end{tabular}

$T(2 \%) 2.51$

$L C L$ - Lower value of a reliable interval (LCL)

$U C L$ - Upper value of a reliable interval (UCL)

Figure 8: Prose Linear Regression Model 
The value of R Square (or $\mathrm{R}^{2}$ ), the coefficient of determination, of close to 0.8 indicates that the data is a reasonable fit to a linear model. The closer the coefficient of determination is to 1 the better the fit of the data to a linear model. This implies that the independent variables and their coefficients are reasonable linear predictors of the dependent variable, intention to use, as described in the linear regression model equation.

The column "HO (2\%) rejected" indicates that the null hypothesis that equation components fit the linear equation well is not rejected for any of the equation components.

The coefficients of the linear equation can be ranked. By looking at the absolute values of the rankings we can see how influential the positive and negative influences are in the context of all the rankings.

\begin{tabular}{|l|r|l|}
\hline Coefficient Ranking & Absolute Value & Actual Sign \\
\hline Gender & 0.69 & Positive \\
\hline Facilitating Conditions & 0.49 & Positive \\
\hline Attitude & 0.42 & Positive \\
\hline Choice & 0.21 & Negative \\
\hline $\begin{array}{l}\text { Performance } \\
\text { Expectancy }\end{array}$ & 0.18 & Positive \\
\hline Age & 0.10 & Positive \\
\hline Effort Expectancy & 0.09 & Negative \\
\hline Social Influence & 0.06 & Positive \\
\hline Self-Efficacy & 0.03 & Negative \\
\hline Anxiety & 0.02 & Negative \\
\hline Experience & 0.01 & Positive \\
\hline
\end{tabular}

Figure 9: Prose Linear Regression Coefficient Rankings.

This ranking indicates a number of positive and negative influences on the intention to use a prose requirements representation.

The intercept is slightly negative so at least some of the coefficients need to be positive to predict a positive value of intention to use.

\section{Positive Determinants}

In the context of prose, gender is the highest positive coefficient by a reasonable margin. Since the coefficient is positive, the model suggests that a higher gender value (female) increases the likelihood of selecting prose as a representation more than a lower gender value (male). There may also be some effect from the data of having a much higher number female than male respondents. 
The table below shows the distribution of intention to use answers for each gender

\begin{tabular}{lrrrrrrr} 
Count of Gender & Intention To Use & & & & & & \\
Row Labels & 2 & 3 & 4 & 5 & 6 & 7 & Grand Total \\
Male & 1 & 1 & 4 & 4 & & 1 & 11 \\
Female & & & 6 & 9 & 4 & 4 & 23 \\
\hline \hline Grand Total & $\mathbf{1}$ & $\mathbf{1}$ & $\mathbf{1 0}$ & $\mathbf{1 3}$ & $\mathbf{4}$ & $\mathbf{5}$ & $\mathbf{3 4}$
\end{tabular}

Figure 10: Gender Influence On Intention To Use Prose

The female answers are weighted towards the higher end of the scale. The male answers are more widely distributed.

Is this result a consequence of more than twice as many females as males in the sample? Would the results be similar if there were equal numbers of males and females in the sample? Further research with a more balanced gender, and larger, sample would be required to evaluate this question.

Facilitating conditions is the next highest positive coefficient. The facilitating conditions for writing requirements in prose are typically a computer system with word processing, publishing and communication software. These facilities are now extremely common in most organisations. The data suggests that the availability of such preferred facilitating conditions are an important influence on the intention to use prose.

Attitude toward using the representation is the next in rank. This indicates that it is important that a person likes using prose as a means of requirements representation and that the more they like prose the more likely they are to choose this representation.

The positive rankings then drop considerably in value to the influence of performance expectancy. The next coefficient in the ranking is age. This is about half as influential as performance expectancy and about a tenth as influential as gender.

Social influence is almost half the level of age as a determinant. The opinion of others is a very small influence in the intention to use a prose representation.

Experience is the least of the positive determinants. The implication may be that the respondents have sufficient experience at writing prose, so that it is the least of their positive determinants when choosing a prose as a requirements representation.

The influence of negative coefficients is generally smaller than the positive coefficients. 
Choice is the most negative influence although less that half as influential as attitude. This may suggest that is that if people have more choice of what type of representation to use there may be a small resistance to choosing prose among the people sampled.

Effort expectancy is the next negative influence at about half of choice. So people believe that increased effort will slightly dissuade them from choosing prose as representation.

Self-efficacy is about a sixth of the influence of effort. The likelihood that selfefficacy is a negative issue in the selection of prose is even smaller than for effort.

Anxiety is slightly less than self-efficacy. So there is a smaller influence that some people are a little anxious about prose and this may influence some of them not select prose as a representation. 


\section{Image}

The multiple linear regression data analysis for the image requirements representation was as follows:

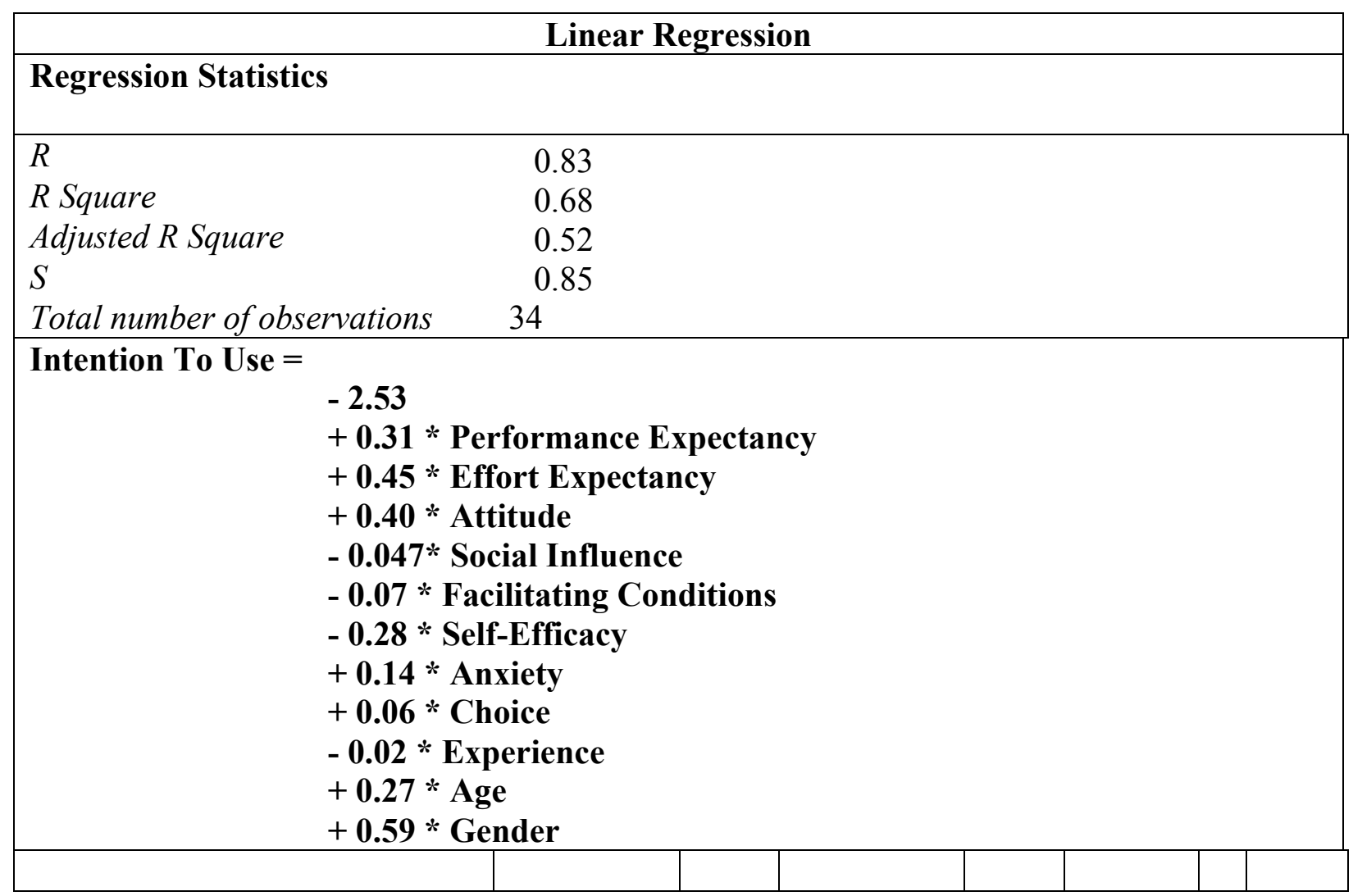

\begin{tabular}{lrrrrrrl} 
& \multicolumn{3}{c}{ Standard } & & & \multicolumn{1}{l}{ HO $(2 \%)$} \\
Coefficients & \multicolumn{1}{c}{ Error } & LCL & UCL & t Stat & p-level & rejected? \\
\hline Intercept & -2.53 & 2.08 & -7.74 & 2.67 & -1.22 & 0.23 & No \\
Performance & 0.31 & 0.20 & -0.21 & 0.82 & 1.50 & 0.15 & No \\
Effort & 0.45 & 0.23 & -0.12 & 1.01 & 1.99 & 0.06 & No \\
Attitude & 0.40 & 0.20 & -0.11 & 0.91 & 1.97 & 0.06 & No \\
Social Influence & -0.04 & 0.18 & -0.49 & 0.41 & -0.21 & 0.84 & No \\
Facilitating & -0.07 & 0.24 & -0.66 & 0.53 & -0.28 & 0.78 & No \\
Self-Efficacy & -0.28 & 0.17 & -0.70 & 0.13 & -1.70 & 0.10 & No \\
Anxiety & 0.14 & 0.16 & -0.27 & 0.55 & 0.84 & 0.41 & No \\
Choice & 0.06 & 0.16 & -0.34 & 0.47 & 0.40 & 0.69 & No \\
Experience & -0.02 & 0.11 & -0.29 & 0.25 & -0.18 & 0.86 & No \\
Age & 0.27 & 0.16 & -0.12 & 0.66 & 1.75 & 0.09 & No \\
Gender & 0.59 & 0.36 & -0.32 & 1.50 & 1.62 & 0.12 & No \\
\hline$T(2 \%)$ & 2.50832 & & & & & &
\end{tabular}

$T(2 \%)$ 2.50832

$L C L$ - Lower value of a reliable interval ( $L C L)$

$U C L$ - Upper value of a reliable interval (UCL)

Figure 11: Image Linear Regression Model 
The value of $\mathrm{R}$ Square (or $\mathrm{R}^{2}$ ), the coefficient of determination, of close to 0.7 indicates that the data is a reasonable fit to a linear model. The closer the coefficient of determination is to 1 the better the fit of the data to a linear model. This implies that the independent variables and their coefficients are reasonable predictors of the dependent variable, intention to use, as described in the linear regression model equation.

The column "HO (2\%) rejected" indicates that the null hypothesis that equation components fit the linear equation well is not rejected for any of the equation components. The intercept is negative indicating that there may be some general negative feeling toward using images as a representation.

The coefficients of the linear equation can be ranked. By looking at the absolute values of the rankings we can see how influential the positive and negative influences are in the context of all the rankings.

\begin{tabular}{|l|r|l|}
\hline Coefficient Ranking & Absolute Value & Actual Sign \\
\hline Gender & 0.59 & Positive \\
\hline Effort Expectancy & 0.45 & Positive \\
\hline Attitude & 0.40 & Positive \\
\hline Performance Expectancy & 0.30 & Positive \\
\hline Self-Efficacy & 0.28 & Negative \\
\hline Age & 0.27 & Positive \\
\hline Anxiety & 0.14 & Positive \\
\hline Facilitating Conditions & 0.07 & Negative \\
\hline Choice & 0.06 & Positive \\
\hline Social Influence & 0.04 & Negative \\
\hline Experience & 0.02 & Negative \\
\hline
\end{tabular}

Figure 12: Image Linear Regression Coefficient Rankings.

This ranking indicates a number of positive and negative influences on the intention to use an image requirements representation.

The intercept is significantly negative so at least some of the coefficients need to be significantly positive to predict a positive value of intention to use.

\section{Positive Determinants}

In the context of image gender is the highest positive coefficient by a reasonable margin. Since the coefficient is positive, the model suggests that a higher gender value (female) increases the likelihood of selecting image as a representation more than a lower gender value (male). There may also be some effect from the data of having a much higher number female than male respondents. 
The table below shows the distribution of intention to use answers for each gender

\begin{tabular}{llllllr} 
Count of Gender & Intention To Use & & & & & \\
Row Labels & 2 & 3 & 4 & 5 & 6 & Grand Total \\
Male & 2 & 2 & 2 & 4 & 1 & 11 \\
Female & 1 & 6 & 5 & 7 & 4 & 23 \\
\hline \hline Grand Total & $\mathbf{3}$ & $\mathbf{8}$ & $\mathbf{7}$ & $\mathbf{1 1}$ & $\mathbf{5}$ & $\mathbf{3 4}$
\end{tabular}

Figure 13: Gender Influence on Intention to Use Images Representation

The female answers are weighted towards the higher end of the scale. The male answers are almost uniformly distributed.

Is this result a consequence of more than twice as many females as males in the sample? Would the results be similar if there were equal numbers of males and females in the sample? Further research with a more balanced gender, and larger, sample would be required evaluate this question.

Effort expectancy is the next highest positive influence. The question, "It would be easy for me to become skilful at using Narrative Images", was worded to suggest that higher values indicate less effort would be required to use the representation. Less effort would suggest a higher positive influence to use the representation.

Attitude has a positive influence slightly lower that effort expectancy. The more a person finds images interesting as a representation the more likely their intention to use them.

Performance expectancy is positive and a little lower than attitude. The model implies that if using images enables tasks to be done more quickly this increases the likelihood of choosing images as a representation.

Age also has a similar positive influence to performance expectancy. So increasing age increases the chance of intention to use an image representation. This may be because increasing age relates to more experience with images and so more confidence to select this representation. The data sample is biased towards higher ages, which may have some influence on this coefficient.

Anxiety has a little smaller positive value. The model says that higher anxiety about loss of information using images slightly increases the likelihood of choosing an image representation. The coefficient value is small so it may be within a small margin of error and not be significant. Further research should investigate the significance of this coefficient value to see if this result remains consistent and if so to attempt to understand this result. 
Freedom to choose representation is the smallest positive influence on intention to use an image representation.

\section{Negative Determinants}

Self-efficacy is the highest negative coefficient. The survey question is "I could complete a requirements task using Narrative Images if I could call someone for help when I got stuck". So higher scores in self-efficacy suggest a need for more help using the representation than lower scores. Since the sign of the coefficient in the linear model is negative, this also implies that higher scores will reduce the intention to select an image representation, because higher scores for a negative determinant reduce the contribution of that determinant to the dependent variable, intention to use, in the linear model.

Facilitating conditions is negative but considerably less than self-efficacy. So although the influence is slightly negative respondents do not believe that it would be too difficult to acquire the facilities to use images as a representation. This is not surprising with the high availability and low cost of many digital devices such as cameras and mobile phones.

The negative coefficient value of social influence is half as small as facilitating conditions. So if respondents believe that people important to them think that they should use images this will slightly influence the respondent against choosing image representation. The small value of the coefficient may be within the margin of error. Further research should attempt to discover if this data is consistent and if so try to understand the result.

Experience is a slightly smaller negative factor than social influence. This suggests that people with more experience in using requirements representation are slightly less likely to choose images as a representation. This may relate to the situation that low cost digital image devices were less common in their early days of work experience and there is a small influence from some respondents who have not yet changed their viewpoint to using images in their later years of work experience. The small value of the coefficient may be within the margin of error. Further research should attempt to discover if this data is consistent and if so try to understand the result. 


\section{Diagram}

The multiple linear regression data analysis for the diagram requirements representation was as follows:

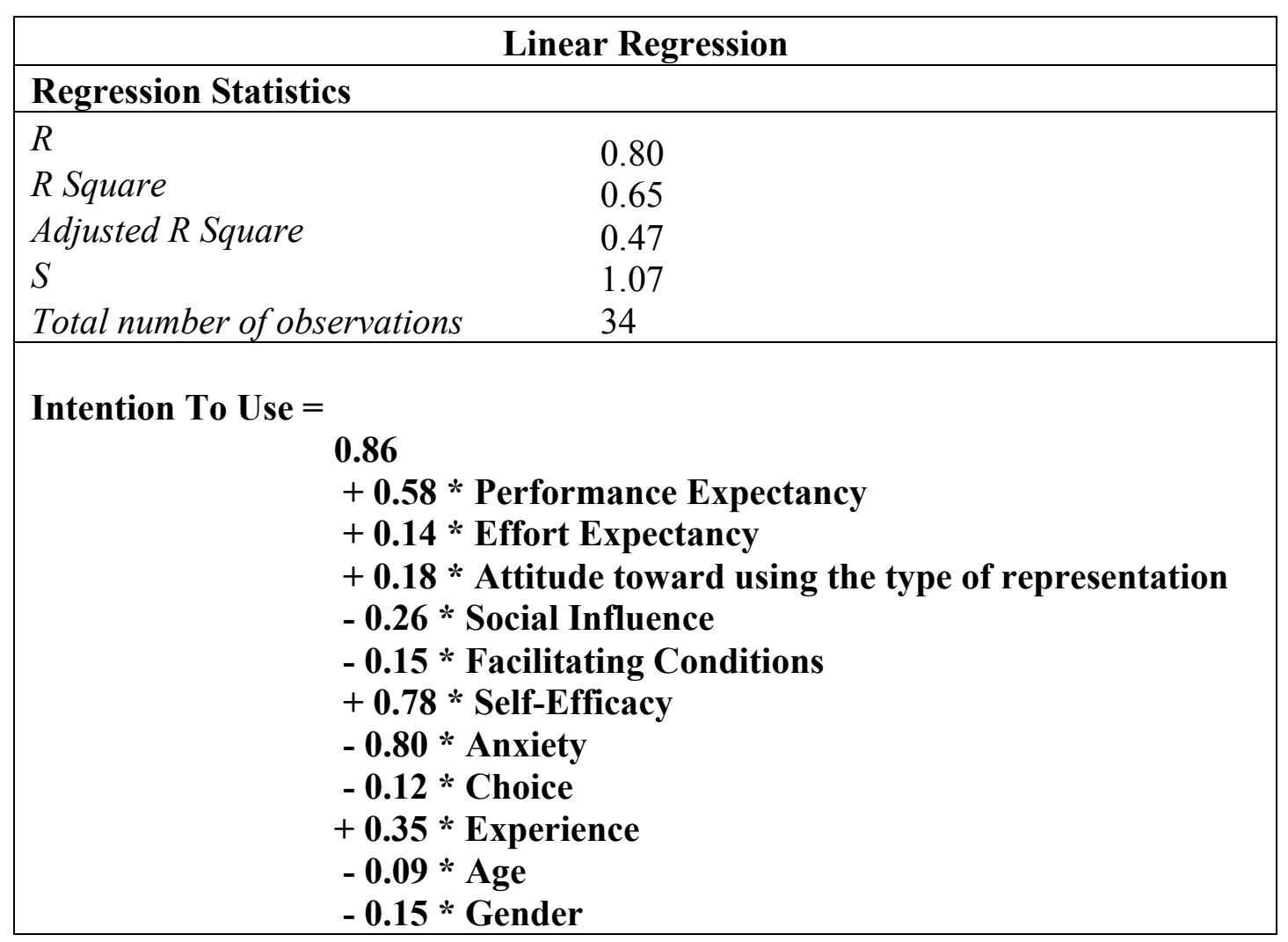

\begin{tabular}{|l|r|r|r|r|r|r|l|}
\hline & Coefficients & $\begin{array}{c}\text { Standard } \\
\text { Error }\end{array}$ & \multicolumn{1}{c|}{ LCL } & UCL & t Stat & p-level & $\begin{array}{l}\text { Ho (2\%) } \\
\text { rejected? }\end{array}$ \\
\hline Intercept & 0.86 & 3.37 & -7.59 & 9.31 & 0.26 & 0.80 & No \\
\hline Performance & 0.58 & 0.23 & 0.01 & 1.15 & 2.55 & 0.02 & Yes \\
\hline Effort & 0.14 & 0.28 & -0.57 & 0.84 & 0.48 & 0.63 & No \\
\hline Attitude & 0.18 & 0.23 & -0.40 & 0.76 & 0.79 & 0.44 & No \\
\hline $\begin{array}{l}\text { Social } \\
\text { Influence }\end{array}$ & -0.26 & 0.28 & -0.96 & 0.44 & -0.94 & 0.36 & No \\
\hline Facilitating & -0.15 & 0.25 & -0.78 & 0.47 & -0.62 & 0.54 & No \\
\hline Self-Efficacy & 0.77 & 0.03 & 0.00 & 1.53 & 2.52 & 0.02 & Yes \\
\hline Anxiety & -0.80 & 0.27 & -1.47 & -0.13 & -2.99 & 0.01 & Yes \\
\hline Choice & -0.12 & 0.22 & -0.68 & 0.44 & -0.54 & 0.60 & No \\
\hline Experience & 0.35 & 0.15 & -0.03 & 0.74 & 2.32 & 0.03 & No \\
\hline Age & -0.09 & 0.22 & -0.64 & 0.46 & -0.42 & 0.68 & No \\
\hline Gender & -0.15 & 0.45 & -1.28 & 0.99 & -0.33 & 0.75 & No \\
\hline
\end{tabular}

Figure 14: Diagram Linear Regression Model

The value of $\mathrm{R}$ Square (or $\mathrm{R}^{2}$ ), the coefficient of determination, of close to 0.7 indicates that the data is a reasonable fit to a linear model. The closer the coefficient of determination is to 1 the better the fit of the data to a linear model. 
This implies that the independent variables and their coefficients are reasonable predictors of the dependent variable, intention to use, as described in the linear regression model equation.

However, the column "HO (2\%) rejected" indicates that the null hypothesis that the equation components fit the linear equation well is rejected for some equation components. The performance expectancy, self-efficacy and anxiety coefficients are all rejected as the most suitable coefficients of the model relative to the other coefficients. So while the data is overall a reasonable fit to a linear model some components are less reliable.

The coefficients of the linear equation can be ranked. By looking at the absolute values of the rankings we can see how influential the positive and negative influences are in the context of all the rankings.

\begin{tabular}{|l|r|l|}
\hline Coefficient Ranking & $\begin{array}{l}\text { Absolute } \\
\text { Value }\end{array}$ & $\begin{array}{l}\text { Actual } \\
\text { Sign }\end{array}$ \\
\hline Anxiety & 0.80 & Negative \\
\hline Self-Efficacy & 0.77 & Positive \\
\hline Performance Expectancy & 0.58 & Positive \\
\hline Experience & 0.35 & Positive \\
\hline Social Influence & 0.26 & Negative \\
\hline Attitude & 0.18 & Positive \\
\hline Facilitating Conditions & 0.15 & Negative \\
\hline Gender & 0.15 & Negative \\
\hline Effort Expectancy & 0.14 & Positive \\
\hline Choice & 0.12 & Negative \\
\hline Age & 0.09 & Negative \\
\hline
\end{tabular}

Figure 15: Diagram Coefficient Ranking

\section{Positive Determinants}

Self-efficacy is the highest-ranking coefficient. The question, "If I had a lot of time I could complete a requirements task using Narrative Diagrams", was worded so that a high score would indicate that a person needed a lot of time to use a diagram representation. This suggests that a respondent with a high score would not intend to choose a diagram representation, which implies the coefficient should be negative. The fact that the coefficient is positive reinforces the rejection of the coefficient as a suitable component. The question may be ambiguous. If a person very strongly disagrees it may imply that they do not need a lot of time to perform the task or it may mean that even with a lot of time they still could not complete the task. It may have been better to word the question in a simpler more positive mode, without an if clause: "I would need only a small amount of time to complete a requirements task using Narrative Diagrams". The people who very strongly agreed might be more inclined to choose a diagram representation so the coefficient would 
be positive. People who very strongly disagreed would focus on "only a small amount of time" and expect a larger amount of time so they would be disinclined to choose the representation. This would fit with a linear model with a positive slope. Further research should attempt to discover if this data is consistent and if so try to understand the result.

Performance expectancy is the next highest-ranking positive coefficient. This coefficient was also rejected. In this case the wording of the question, "Using Narrative Diagrams increases my productivity", is quite simple to understand and unlikely to be ambiguous. So ambiguity of the question is not likely to be a significant cause of the rejection. The data may have a higher order relation than linear with intention to use. Further research should attempt to discover if this data is consistent and if so try to understand the result.

Experience is a little less positive influence than performance expectancy. This implies that the respondents with higher experience of requirements representations feel a little more confident to choose diagrams as a representation.

Attitude is about half as positive as experience. This suggests that if people like diagrams it has a small positive influence on their intention to use diagrams as a representation.

Effort expectancy is the least positive influence on the decision to use diagrams as a representation. So people who very strongly agree that they "would find Narrative Diagrams easy to use" feel that this would provide only a small incentive to choose diagrams as a representation.

Negative Determinants

Anxiety is the most negative coefficient and the highest absolute value of all the coefficients. This implies that a very strong agreement that respondents "hesitate to use Narrative Diagrams for fear of making mistakes" that they cannot correct is a very high influence on their decision not to use diagrams as a representation. This suggests that they do not feel comfortable that they understand the reasoning of the diagram representation enough to be able to reliably check the consistency and completeness of their diagrams. This seems reasonable however the coefficient is rejected as a good fit to the linear model. The influence of this component may be higher order than linear. Further research should attempt to discover if this data is consistent and if so try to understand the result.

Social influence is the next most negative influence at slightly more than a quarter of the anxiety coefficient.

Facilitating conditions is a negative concern slightly less than social influence. Respondents seem to believe that computers and software for diagram representations may be a small negative issue.

Gender is also a negative coefficient at the same magnitude as facilitating conditions. This implies that higher gender (female) respondents are slightly less 
inclined to have an intention to use diagrams as a representation. The higher number of female respondents may have biased this coefficient. Further research should attempt to discover if this data is consistent and if so try to understand the result.

Higher freedom to choose representations has a slightly smaller negative coefficient than gender. So if people were given more choices of representations they would be slightly less interested in choosing diagrams.

Age is the smallest negative influence. This suggests that increasing age of the respondents has a very small negative influence to avoid diagram representations. Among the older part of the data sample there may be some people who are slightly less familiar with process diagrams. The higher age of respondents may have biased this coefficient. Further research should attempt to discover if this data is consistent and if so try to understand the result. 


\section{Video}

The multiple linear regression data analysis for the video requirements representation was as follows:

\begin{tabular}{|lc|}
\hline \multicolumn{1}{|c|}{ Linear Regression } \\
\hline Regression Statistics & \\
R & 0.81 \\
R Square & 0.66 \\
Adjusted R Square & 0.49 \\
S & 1.03 \\
Total number of observations & 34 \\
\hline Intention To Use $=$ & \\
& -8.6966 \\
& $+0.1040 *$ Performance Expectancy \\
& $+0.6941 *$ Effort Expectancy \\
& $+0.3743 *$ Attitude \\
& $+0.6543 *$ Social Influence \\
& $-0.0848 *$ Facilitating Conditions \\
& $-0.2946 *$ Self-Efficacy \\
& $+0.7470 *$ Anxiety \\
& $+0.2294 *$ Choice \\
& $+0.2025 *$ Experience \\
& $+0.0515 *$ Age \\
& $+0.6450 *$ Gender \\
\end{tabular}

\begin{tabular}{|l|r|r|r|r|r|r|l|}
\hline & Coefficients & $\begin{array}{c}\text { Standard } \\
\text { Error }\end{array}$ & \multicolumn{1}{c|}{ LCL } & UCL & t Stat & p-level & $\begin{array}{l}\text { HO (2\%) } \\
\text { rejected? }\end{array}$ \\
\hline Intercept & & & - & & & & \\
\hline Performance & -8.70 & 2.50 & 14.96 & -2.43 & -3.48 & 0.00 & Yes \\
\hline Effort & 0.10 & 0.15 & -0.28 & 0.49 & 0.68 & 0.51 & No \\
\hline Attitude & 0.69 & 0.20 & 0.20 & 1.18 & 3.56 & 0.00 & Yes \\
\hline Social & 0.37 & 0.23 & -0.19 & 0.94 & 1.65 & 0.11 & No \\
\hline Facilitating & 0.65 & 0.24 & 0.04 & 1.27 & 2.69 & 0.01 & Yes \\
\hline Self-Efficacy & -0.08 & 0.25 & -0.71 & 0.54 & -0.34 & 0.74 & No \\
\hline Anxiety & -0.29 & 0.15 & -0.67 & 0.08 & -1.96 & 0.06 & No \\
\hline Choice & 0.75 & 0.20 & 0.24 & 1.25 & 3.73 & 0.00 & Yes \\
\hline Experience & 0.23 & 0.21 & -0.29 & 0.75 & 1.11 & 0.28 & No \\
\hline Age & 0.20 & 0.13 & -0.13 & 0.54 & 1.51 & 0.15 & No \\
\hline Gender & 0.05 & 0.19 & -0.43 & 0.53 & 0.27 & 0.79 & No \\
\hline
\end{tabular}

$T(2 \%) \quad 2.51$

$L C L$ - Lower value of a reliable interval (LCL)

$U C L$ - Upper value of a reliable interval (UCL)

Figure 16: Video Linear Regression Model 
The value of $\mathrm{R}$ Square (or $\mathrm{R}^{2}$ ), the coefficient of determination, of close to 0.7 indicates that the data is a reasonable fit to a linear model. The closer the coefficient of determination is to 1 the better the fit of the data to a linear model. This implies that the independent variables and their coefficients are reasonable predictors of the dependent variable, intention to use, as described in the linear regression model equation.

However, the column "HO (2\%) rejected" indicates that the null hypothesis that the equation components fit the linear equation well is rejected for some equation components. This is the only representation for which the intercept is rejected. This suggests some significant non-linearity for the intercept, which is also highly negative relative to all the other representations. It is about four times as negative as image. The high negative value suggests that there is a general high negative feeling to using video as a representation. The effort, social influence and anxiety coefficients are all rejected as the most suitable coefficients of the model relative to the other coefficients. So while the data is overall a reasonable fit to a linear model some components are less reliable.

The coefficients of the linear equation can be ranked. By looking at the absolute values of the rankings we can see how influential the positive and negative influences are in the context of all the rankings.

\begin{tabular}{|c|c|c|}
\hline Coefficient Ranking & \begin{tabular}{|l} 
Absolute \\
Value
\end{tabular} & $\begin{array}{l}\text { Actual } \\
\text { Sign }\end{array}$ \\
\hline Anxiety & 0.75 & Positive \\
\hline Effort Expectancy & 0.69 & Positive \\
\hline Social Influence & 0.65 & Positive \\
\hline Gender & 0.64 & Positive \\
\hline Attitude & 0.37 & Positive \\
\hline Age & 0.29 & Positive \\
\hline Self-Efficacy & 0.23 & Negative \\
\hline Choice & 0.20 & Positive \\
\hline Experience & 0.10 & Positive \\
\hline Facilitating Conditions & 0.08 & Negative \\
\hline Performance Expectancy & 0.05 & Positive \\
\hline
\end{tabular}

Figure 17: Video Coefficient Ranking

This ranking indicates a number of positive and negative influences on the intention to use a video requirements representation. 
intimidating" they are more likely to intend to use video as a representation. This seems counter intuitive and may be related to the reason for rejection of the coefficient from the linearity test. It is not obvious that the question is ambiguous which might have lead to inconsistent response data. The coefficient may be higher order than linear. Further research should attempt to discover if this data is consistent and if so try to understand the result.

Effort expectancy is the next highest positive coefficient. This coefficient is also rejected from linearity. It seems reasonable that people that very strongly agree "Learning to use Narrative Video is easy for me" should be more inclined to select video as a representation. So there does not seem to be ambiguity in the question or inconsistency with the response. The coefficient may be higher order than linear.

Social influence is the next level positive influence. This coefficient is also rejected from a close fit to a linear model. The positive, higher valued coefficient, the slope of the regression curve, seems consistent. If an organisation "has supported the use of Narrative Video" it seems more likely that respondents would select video as a representation. The relatively high value of the coefficient suggests that social influence is an important factor and that if organisational support were low respondents would be less likely to choose video. The coefficient may be higher order than linear.

Gender is the next highest positive influence. So being female means that a respondent is more likely to choose a video representation. The higher number of female respondents may have influenced this result.

Attitude is also positive and about half the influence of gender. People who like using video are slightly more inclined to intend to use this representation. Higher freedom of choice of representation also leads to a slight inclination to choose video as a representation. Experience is also a small positive influence on the decision to use video. Performance expectancy is positive also at about half the magnitude of experience. Age is positive also at about half the influence of performance expectancy. Age is the least of all the positive coefficients.

\section{Negative Determinants}

By looking at the absolute values of the rankings we can see how influential the negative influences are in the context of all the rankings.

There are only two negative coefficients. The most negative of the coefficients is self-efficacy. So respondents that very strongly agree that they "could complete a requirements task using Narrative Video if", they "had only a built-in help facility for assistance", are a little less inclined to select video as a representation. This seems reasonable. 
The remaining, small negative influence is facilitating conditions. So respondents who very strongly agree that at least one person is available for assistance with difficulties using video are slightly less inclined to select video as a representation. This seems slightly contradictory. The question does not seem ambiguous so the research project would have expected this coefficient to be slightly positive. Further research should attempt to discover if this data is consistent and if so try to understand the result.

\section{Discussion}

\section{Application of theory}

This research has applied the UTAUT model (Venkatesh et al, 2003) to information system requirements representations.

The UTAUT model used partial least squares to analyse the determinants of intention to use computer technology. In a similar way the research project used multiple linear regression, using the least squares method, to analyse determinants. However unlike the UTAUT model the research project was investigating four different concepts, the four requirements representation types. So the research model was partitioned into four separate exhibit types.

The research found that the sample data from the survey is a reasonable overall fit to a linear regression model using determinants adapted from the UTAUT model. The coefficients of determination, which measures the goodness of fit to a linear model, were: Prose 0.77, Images 0.68, Diagram 0.65 and Video 0.66. A value of 1 for the coefficient of determination means the data is an excellent fit to a linear model.

However there was some rejection of linearity for some of the individual determinants. Some determinants had two linearity tests rejected including Diagram Anxiety, Video Facilitating Conditions, Age and Gender. Diagram Social Influence and Video Attitude have three linearity tests rejected.

The reliability of linearity was consistent with the representation ranking. The highest ranking representations, prose and images, also had the most reliable linear models. The lowest ranking representations, diagrams and video, had the most uncertainty in the linear model determinants. Also video was very slightly more linear than diagram. However this assumes that the coefficient of determination is precise to two decimal places. If the precision is only one decimal place then image, diagram and video all have the same coefficient of determination, 7, and prose is the highest at 8 .

The concepts of the UTAUT model were applied from the original investigation type, computer technology, to a more abstract concept, information systems requirements representation. The synthesis behind this conceptual transformation 
was a little abstract but not excessively so. Prose, images, diagrams and video are also now all aspects of digital multimedia information systems and this is very familiar to large populations on a global scale. Multimedia information systems are dependent on computer technology and both are aspects of the even the broader concept of information architecture.

\section{Modelling}

The research project discovered that the each requirements representation type had a different permutation of the determinants. So business analysts should be aware that the intention of business people to use a representation depends on the model of the determinants for that representation. If the research considers only the top 3, by absolute value, determinant rankings for all four representations, and numerical precision is reduced to 1 decimal place, the determinant rankings comparison would look like this:

\begin{tabular}{|l|r|l|r|l|r|l|r|}
\hline \multicolumn{2}{|c|}{ Prose } & \multicolumn{2}{c|}{ Image } & \multicolumn{2}{c|}{ Diagram } & \multicolumn{2}{c|}{ Video } \\
\hline \multicolumn{2}{|c|}{ Coefficient } & \multicolumn{2}{c|}{ Coefficient } & \multicolumn{2}{c|}{ Coefficient } & \multicolumn{2}{c|}{ Coefficient } \\
\hline Name & Value & Name & Value & Name & \multicolumn{1}{l|}{ Value } & Name & Value \\
\hline Gender & 0.7 & Gender & 0.6 & Self-Efficacy & 0.8 & Anxiety & 0.8 \\
\hline $\begin{array}{l}\text { Facilitating } \\
\text { Conditions }\end{array}$ & 0.5 & $\begin{array}{l}\text { Effort } \\
\text { Expectancy }\end{array}$ & 0.5 & Anxiety & -0.8 & $\begin{array}{l}\text { Effort } \\
\text { Expectancy }\end{array}$ & 0.7 \\
\hline Attitude & 0.4 & Attitude & 0.4 & $\begin{array}{l}\text { Performance } \\
\text { Expectancy }\end{array}$ & 0.6 & $\begin{array}{l}\text { Social } \\
\text { Influence }\end{array}$ & 0.7 \\
\hline & & & & Experience & 0.4 & & \\
\hline
\end{tabular}

Figure 18: Table To Compare Determinant Rankings For All Representations

So the evidence of this model, based on this population of business people, sampled by convenience, suggests the top three determinants that business people consider when intending to use one of the four representations. These are, ranked in order from left to right, by absolute value, for each representation:

Prose: Gender, Facilitating Conditions, Attitude to Using the Representation Image: Gender, Effort Expectancy, Attitude to Using the Representation Diagram: Self-Efficacy, Anxiety (negative), Performance Expectancy, Experience Video: Anxiety, Effort Expectancy, Social Influence

Diagram anxiety is the only negative determinant in this top-level ranking. Diagram has four determinants because two determinants have equal absolute values so there is no basis for eliminating one of the two values.

The model suggests that a business analyst should use this model in a project to attempt to predict the reactions of business people when the business people are going to use one of these requirements representations. 
However, further research with a larger, more random, population of business people should be done to test this model. In particular, is the gender bias in the sample affecting the high ranking of the gender determinant? Although the linearity tests, for all of the representations, did not reject gender as a non-linear determinant.

What is the effect of a higher age in the data sample? Age was not rejected from linearity in the regression model of any of the representations. A larger, more random, sample may reduce any bias from higher ages in the data.

Also further research should investigate the high ranking of video anxiety as a positive determinant. Social influence for video is high so respondents feel that the organisation has supported the use of video narratives. Video anxiety and video effort expectancy were rejected in the linearity tests. Rejection of linearity may suggest that determinants are higher order than linear.

\section{Conclusion}

\section{Summary of Salient Points}

In summary, the research discovered that there is a ranking of requirements representations, although the separation of rankings is not extreme. The data sample fits quite well with the UTAUT model, even though there is some variation from linearity in some determinants for some representations.

The intention to use either prose or images is most strongly influenced by gender. The intention to use diagrams is most strongly influenced by self-efficacy. The intention to use video is most strongly influenced by anxiety.

Further research should investigate the high influence of gender and the high ranking of video anxiety as a positive determinant.

Diagrams and video are the representations with the most variation from linearity. Business people may not understand how to develop information system requirements diagrams as easily as some information systems people may expect. Video has yet to find a leading role in the information systems requirements narrative in the community of business people sampled.

The benefit of this research for the information systems research community is that it demonstrates the application of the UTAUT model in a new context, information systems requirements elicitation. This research extends the original domain of the model from choices of computer technologies in the hardware infrastructure world to choices in the considerably more abstract world of information system requirements. The UTAUT model adapts to a higher level of abstraction without any need to alter the fundamental model. The model questions can also be paraphrased and partitioned across four different types of representation and still 
provide useful research data. The survey data shows there are preferences by business people for different requirements representations. Also there are significant variations of the model determinant coefficients across different requirements representations. This adaptability of the UTAUT model in a new, more abstract, context provides additional evidence of its usefulness to the research community.

For the information systems practitioner community the benefit of this research is that it raises questions and provides some answers to what requirements representations are most preferred by business people and the reasons for these choices. In particular, the research explores concepts, research and applications of multimedia representations that may have benefits in improving the quality of requirements during elicitation. This may provide useful input into business cases that include the use of multimedia during requirements elicitation in information systems industry projects. Although this research suggests that more investigation is required to understand the influence of the determinants on intentions to use some aspects of multimedia, such as video, in requirements representation.

\section{Future Research}

Future research may focus on the consequences for information systems people and the information system solutions of helping business people to widen the range of requirements representations they may use. Will giving business people more capabilities and freedom to express their requirements in more representations lead to better information system solutions as imagined in the AMORE project (Christel et al, 1993) more than twenty years ago? Future research may also find ways to obtain more randomised data from a larger sample of organisations. There may be some value in a deeper, grounded theory, qualitative approach to discover any missed hypotheses and theories. 


\section{References}

Abdullah, N., N., B., Honiden, S., Sharp, H., Nuseibeh, B., Notkin D. (2011). Communication Patterns of Agile Requirements Engineering. Agile RE'11, July 26, 2011, Lancaster, U.K. ACM.

Alvarez, R., Urla, J. (2002). Tell me a good story: Using narrative analysis to examine information requirements interviews during an ERP implementation. Database for Advances in Information Systems 33. 1 (Winter 2002): 38-52.

Anderson, R., J. (1994). Representations and Requirements: The Value of Ethnography in System Design. Human-Computer Interaction. Vol. 9, Iss. 2, 1994

Appan, R., Browne, G., J. (2012). The Impact Of Analyst-Induced Misinformation On The Requirements Elicitation Process. MIS Quarterly Vol. 36 No. 1 pp. 85-106/March 2012.

Borland. (2013). Caliber. http://www.borland.com/products/caliber/, retrieved January 2013.

Boulila, N., Hoffmann, A., Herrmann, A. (2011). "Using Storytelling To Record Requirements: Elements For An Effective Requirements Elicitation Approach," Multimedia and Enjoyable Requirements Engineering - Beyond Mere Descriptions and with More Fun and Games (MERE), 2011 Fourth International Workshop on, vol., no., pp.9-16, 30-30 Aug. 2011

Byrd, T., A., Cossick, K., L., Zmud, R., W. (1992). A Synthesis of Research on Requirements Analysis and Knowledge Acquisition Techniques. MIS Quarterly/March 1992.

Choe, H. and Moon, S. (2011). A Methodology for Accurate and Redundancy-free Business Requirements Description Using Ontology. IEEE. 2011.

Christel, M., Wood, D., Stevens, S. (1993). AMORE: The Advanced Multimedia Organizer for Requirements Elicitation (CMU/SEI-93-TR-012). Retrieved January 09, 2013, from the Software Engineering Institute, Carnegie Mellon University website:

http://www.sei.cmu.edu/library/abstracts/reports/93tr012.cfm

Coulin, C., Zowghi, D., \& Sahraoui, A. (2010). MUSTER: A Situational Tool for Requirements Elicitation. In F. Meziane, \& S. Vadera (Eds.), Artificial Intelligence Applications for Improved Software Engineering Development: New Prospects (pp. 146-165). Hershey, PA: Information Science Reference. doi:10.4018/978-1-60566-758-4.ch008 
Cui, X. and Paige, R. (2012). An Integrated Framework for System/Software Requirements Development Aligning with Business Motivations. 2012 IEEE/ACIS 11th International Conference on Computer and Information Science. DOI: 10.1109/ICIS.2012.32. IEEE.

Facebook. (2013). https://www.facebook.com. Retrieved January, 2013.

Fiorini, S., T. Sampaio do Prodo Leite, J., C., L.v.de Macedo-Soarees, T., D. (1996). Integrating Business Processes with Requirements Elicitation. Proceedings of the 5th Int'l Workshops on Enabling Technologies: Infrastructure for Collaborative Enterprises (WET ICE'96). IEEE.

Gall, M., Berenbach, B. (2006). "Towards a Framework for Real Time Requirements Elicitation," Multimedia Requirements Engineering, 2006. MERE '06. First International Workshop on , vol., no., pp.4, 12-12 Sept. 2006

Green, G., I. (1989). Perceived Importance of Systems Analysts' Job Skills, Roles, and Non-Salary Incentives. MIS Quarterly/June 19.

Haumer, P., Pohl., K., Weidenhaupt, K. (1998). Requirements Elicitation And Validation With Real World Scenes. IEEE Transactions on Software Engineering. Volume 24, Issue 12. IEEE. 1998.

Hendrik, M., Maedche, A., Einoeder, M. (2011). Exploring Design Principles of Task Elicitation Systems for Unrestricted Natural Language Documents. EICS'12 - Proceedings of the 2012 ACM SIGCHI Symposium on Engineering Interactive Computing Systems. ACM.

IBM. (2012). Rational RequisitePro.

http://www-01.ibm.com/software/awdtools/reqpro/, retrieved February, 2013.

Huang, K., Nunes N., J., Nobrega, L., Constantine, L., and Chen M. (2011). Hammering Models: Designing Usable Modeling Tools. P. Campos et al. (Eds.): INTERACT 2011, Part III, LNCS 6948, pp. 537-554, 2011. IFIP International Federation for Information Processing 2011.

IIBA. (2012). The Business Analysis Body of Knowledge (BABOK). The International Institute of Business Analysis. http://www.iiba.org, retrieved August 2012.

Jensen, A., C, Cheng, B., H., C., Goldsby, H., J., and Nelson, E., C. (2011). A Toolchain for the Detection of Structural and Behavioral Latent System Properties. J. Whittle, T. Clark, and T. Ku hne (Eds.): MODELS 2011, LNCS 6981, pp. 683-698, Springer-Verlag Berlin Heidelberg. 2011. 
Kaiser, K., M., Bostrom, R., P. (1982). Personality Characteristics of MIS Project Teams: An Empirical Study and Action-Research Design. MIS Quarterly, December. 1982.

Kamalrudin, M., Hosking, J., Grundy, J. (2011). Improving Requirements Quality using Essential Use Case Interaction Patterns. ICSE'11, May 21-28, 2011, Waikiki, Honolulu, HI, USA. ACM.

Knauss, E., Lübke, D., Meyer, S. (2009). Feedback-driven requirements engineering: The heuristic requirements assistant. IEEE. 31st International Conference on Software Engineering, ICSE 2009; Vancouver, BC

Lee, A. S. (1989). A Scientific Methodology for MIS Case Studies. MIS Quarterly, 13, 1 (03 1989), 32-50.

Lehmann, H.,(2010). Grounded Theory and Information Systems: Are We Missing the Point? Proceedings of the 43rd Hawaii International Conference on System Sciences - 2010. IEEE.

Lyytinen, K., J. (1985). Implications of Theories of Language for Information Systems. MIS Quarterly. March, 1985.

Maass, W., Storey, V., C. and Kowatsch, T. (2011). Effects of External Conceptual Models and Verbal Explanations on Shared Understanding in Small Groups. M. Jeusfeld, L. Delcambre, and T.W. Ling (Eds.): ER 2011, LNCS 6998, pp. 92-103, 2011. Springer-Verlag Berlin Heidelberg. 2011.

Mahmud, I., Venezianot, V., (2011). Mind-mapping: An Effective Technique to Facilitate Requirements Engineering in Agile Software Development. Proceedings of 14th International Conference on Computer and Information Technology (ICCIT 2011) 22-24 December, 2011, Dhaka, Bangladesh.

Martin, J. (1989). Information Engineering. Englewood Cliffs, N.J.: Prentice Hall, 1989-c1990.

Microsoft. (2013). Microsoft Office.

http://www.microsoftstore.com/store/msnz/en_NZ/home, retrieved February, 2013

Nanduri, S., Rugaber, S. (1995). Requirements Validation via Automated Natural Language Parsing. Proceedings of the 28th Annual Hawaii International Conference on System Sciences - 1995. IEEE.

OMG. (2013). Universal Modelling Language. Object Management Group. http://www.uml.org/, Retrieved, January, 2013.

Orman, L. (1987). Information Intensive Modeling. MIS Quarterly/March 1987. 
Pitula, K., \& Radhakrishnan, T. (2011). On Eliciting Requirements From EndUsers In The ICT4D Domain. Requirements Engineering, 16(4), 323-351.

Qualtrics. (2013). Qualtrics Online Survey Software. https://www.qualtrics.com/. Retrieved January 2013

Raosoft. (2013). Sample size calculator. http://www.raosoft.com/samplesize.html, retrieved January 2013.

Schneider, K., Knauss, E., Houmb, S., Islam, S., Jürjens, J. (2011). Enhancing security requirements engineering by organizational learning. Requirements Eng (2012) 17:35-56. Springer.

Snyder J. (2012). Activities \& Artifacts: The Dual Nature of Image-making in Communicative Practice. iConference 2012, February 7-10, 2012, Toronto, Ontario, Canada, ACM.

Solms, F., Edwards, C., Paar, A., and Gruner S. (2011). A Domain-Specific Language for URDAD Based Requirements Elicitation. SAICSIT'11, October 3-5, Cape Town, South Africa. ACM. 2011.

Sparx Systems. (2013). Enterprise Architect. Model Driven UML Tools. http://www.sparxsystems.com/, Retrieved January 92013.

TM Forum. (2013). Business Process Framework (eTOM), http://www.tmforum.org/BusinessProcessFramework/1647/home.html, retrieved January 2013.

Urquhart, C., Lehmann, Hans \& Myers M., D., (2010). Putting the 'theory' back into grounded theory: guidelines for grounded theory studies in information systems. Info Systems J (2010) 20, 357-381. Blackwell Publishing Ltd.

Venkatesh, V., Morris, M., G. And Davis, G., B., (2003). User Acceptance Of Information Technology: Toward A Unified View. MIS Quarterly Vol. 27 No. 3, pp. 425-478/September 2003.

Wikipedia. (2013). http://en.wikipedia.org/wiki/Main_Page, Retrieved February 2013

Woolridge, R., W. and Bailey, J. (2011). Co-Adaptive Processes of Stakeholder Networks and Their Effects on Information Systems Specifications. SIGMISCPR'11, May 19-21, 2011, San Antonio, Texas, USA. ACM.

YouTube. 2013. http://www.youtube.com/, Retrieved February 2013

Zachos, K., Maiden, N., Tosar, A. (2005). Rich-Media Scenarios For Discovering Requirements. IEEE Software. Volume 22, Issue 5, IEEE. 2005 


\section{Appendix 1: Descriptive Statistics and Normality}

The following tables and charts provide descriptive statistics and normality tests for each of the representation variables, the work and demographic variables and the intention to use dependent variables. All decimal values are rounded to 2 decimal places.

The data analysis uses four different types of normality tests. Many of the data variables have one out of the four normality tests rejected. Some data variables have two normality tests rejected including Diagram Anxiety, Video Facilitating Conditions, Age and Gender. Diagram Social Influence and Video Attitude have three normality tests rejected.

The number of females in the data sample is more than twice the number of males. This may possibly influence the fact that Gender has the highest positive coefficient in Prose and Image representations, although Gender does not rank so high in Video and is slightly negative in Diagram. The age of the respondents is biased towards higher ages.

Prose

Prose Performance Expectancy

\begin{tabular}{|c|c|c|c|}
\hline Alpha value (for confidence interval) & \multicolumn{3}{|l|}{0.02} \\
\hline \multicolumn{4}{|c|}{ Variable \#1 (Performance Expectancy) } \\
\hline Count & 34. & Skewness & 0.30 \\
\hline Mean & 5.21 & Skewness Standard Error & 0.39 \\
\hline Mean LCL & 4.78 & Kurtosis & 2.72 \\
\hline Mean UCL & 5.63 & Kurtosis Standard Error & 0.72 \\
\hline Variance & 1.02 & Alternative Skewness (Fisher's) & 0.31 \\
\hline Standard Deviation & 1.01 & Alternative Kurtosis (Fisher's) & -0.12 \\
\hline Mean Standard Error & 0.17 & Coefficient of Variation & 0.19 \\
\hline Minimum & 3. & Mean Deviation & 0.76 \\
\hline Maximum & 7. & Second Moment & 0.99 \\
\hline Range & 4. & Third Moment & 0.29 \\
\hline Sum & 177. & Fourth Moment & 2.65 \\
\hline Sum Standard Error & 5.88 & Median & 5. \\
\hline Total Sum Squares & 955. & Median Error & 0.04 \\
\hline Adjusted Sum Squares & 33.56 & Percentile 25\% (Q1) & 5. \\
\hline Geometric Mean & 5.11 & Percentile 75\% (Q2) & 6. \\
\hline Harmonic Mean & 5.01 & $I Q R$ & 1. \\
\hline Mode & 5. & MAD (Median Absolute Deviation) & 0.5 \\
\hline & & Coefficient of Dispersion (COD) & 0.14 \\
\hline
\end{tabular}




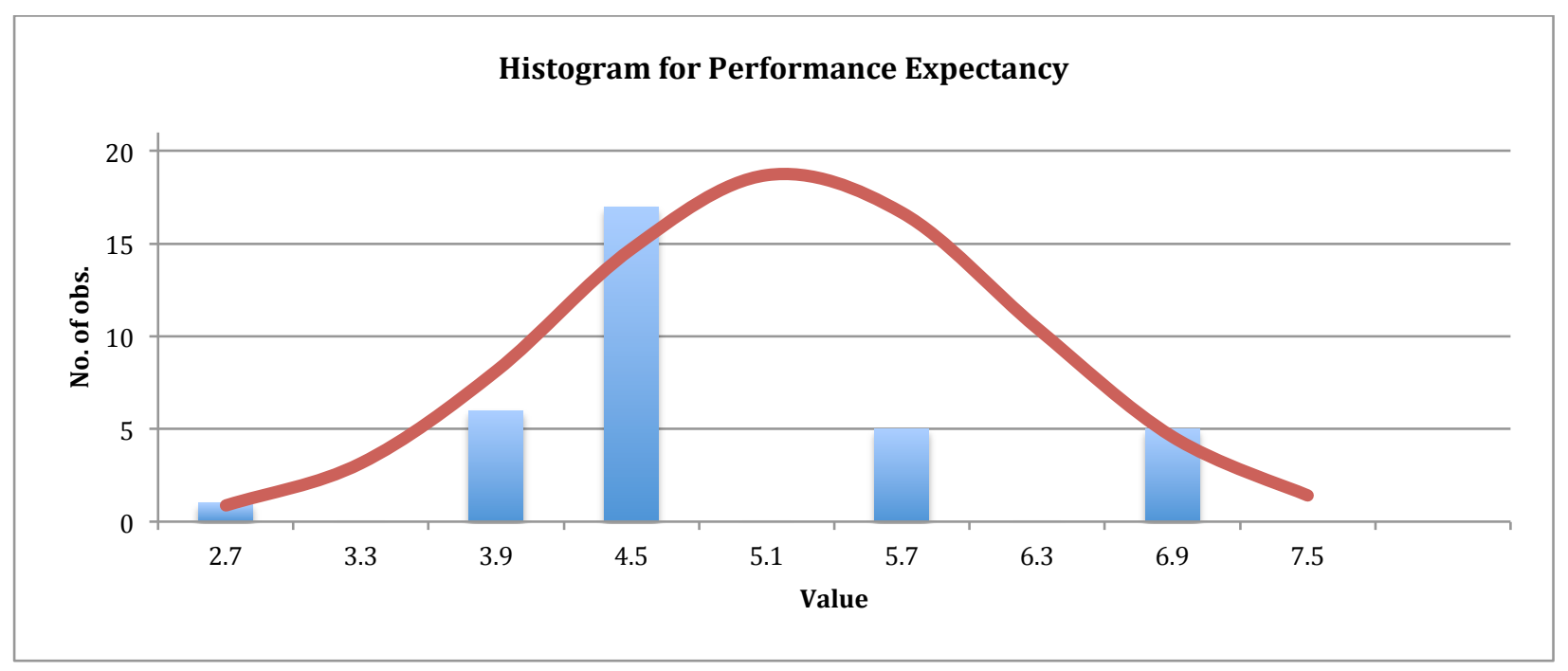

\begin{tabular}{|c|c|c|c|}
\hline \multicolumn{4}{|c|}{ Normality Tests } \\
\hline \multicolumn{4}{|l|}{ Variable \#1 (Var1) } \\
\hline Sample size & 34.00 & Mean & 5.21 \\
\hline Standard Deviation & 1.01 & Median & 5.00 \\
\hline Skewness & 0.30 & Kurtosis & 2.72 \\
\hline $\begin{array}{l}\text { Alternative Skewness } \\
\text { (Fisher's) }\end{array}$ & 0.31 & $\begin{array}{l}\text { Alternative Kurtosis } \\
\text { (Fisher's) }\end{array}$ & -0.12 \\
\hline & $\begin{array}{c}\text { Test } \\
\text { Statistics }\end{array}$ & p-level & Conclusion: (2\%) \\
\hline $\begin{array}{l}\text { Kolmogorov-Smirnov/Lilliefor } \\
\text { Test }\end{array}$ & $0 . E+0$ & 1. & $\begin{array}{l}\text { No evidence against } \\
\text { normality }\end{array}$ \\
\hline Shapiro-Wilk W & 0.88 & 0.00 & Reject Normality \\
\hline D'Agostino Skewness & 0.81 & 0.42 & Accept Normality \\
\hline D'Agostino Kurtosis & 0.05 & 0.96 & Accept Normality \\
\hline D'Agostino Omnibus & 0.66 & 0.72 & Accept Normality \\
\hline
\end{tabular}

\section{Prose Effort Expectancy}

\begin{tabular}{|l|r|l|r|}
\hline \multicolumn{2}{|c|}{ Alpha value (for confidence interval) } & 0.02 & \\
\hline \multicolumn{1}{|c|}{ Variable \#1 (Effort Expectancy) } & -0.10 \\
\hline Count & 34 & Skewness & 0.39 \\
\hline Mean & 5.44 & Skewness Standard Error & 2.58 \\
\hline Mean LCL & 5.01 & Kurtosis & 0.72 \\
\hline Mean UCL & 5.87 & Kurtosis Standard Error & -0.10 \\
\hline Variance & 1.04 & Alternative Skewness (Fisher's) & -0.29 \\
\hline Standard Deviation & 1.02 & Alternative Kurtosis (Fisher's) & 0.19 \\
\hline Mean Standard Error & 0.18 & Coefficient of Variation & 0.85 \\
\hline Minimum & 3. & Mean Deviation & 1.01 \\
\hline Maximum & 7. & Second Moment & -0.10 \\
\hline Range & 4. & Third Moment & 2.64 \\
\hline Sum & 185. & Fourth Moment & 5.00 \\
\hline Sum Standard Error & 5.95 & Median & 0.04 \\
\hline Total Sum Squares & $1,041$. & Median Error & 5. \\
\hline Adjusted Sum Squares & 34.38 & Percentile 25\% (Q1) & 6. \\
\hline Geometric Mean & 5.34 & Percentile 75\% (Q2) & 1. \\
\hline Harmonic Mean & 5.24 & IQR & 1. \\
\hline Mode & 5. & MAD (Median Absolute Deviation) & 0.16 \\
\hline
\end{tabular}




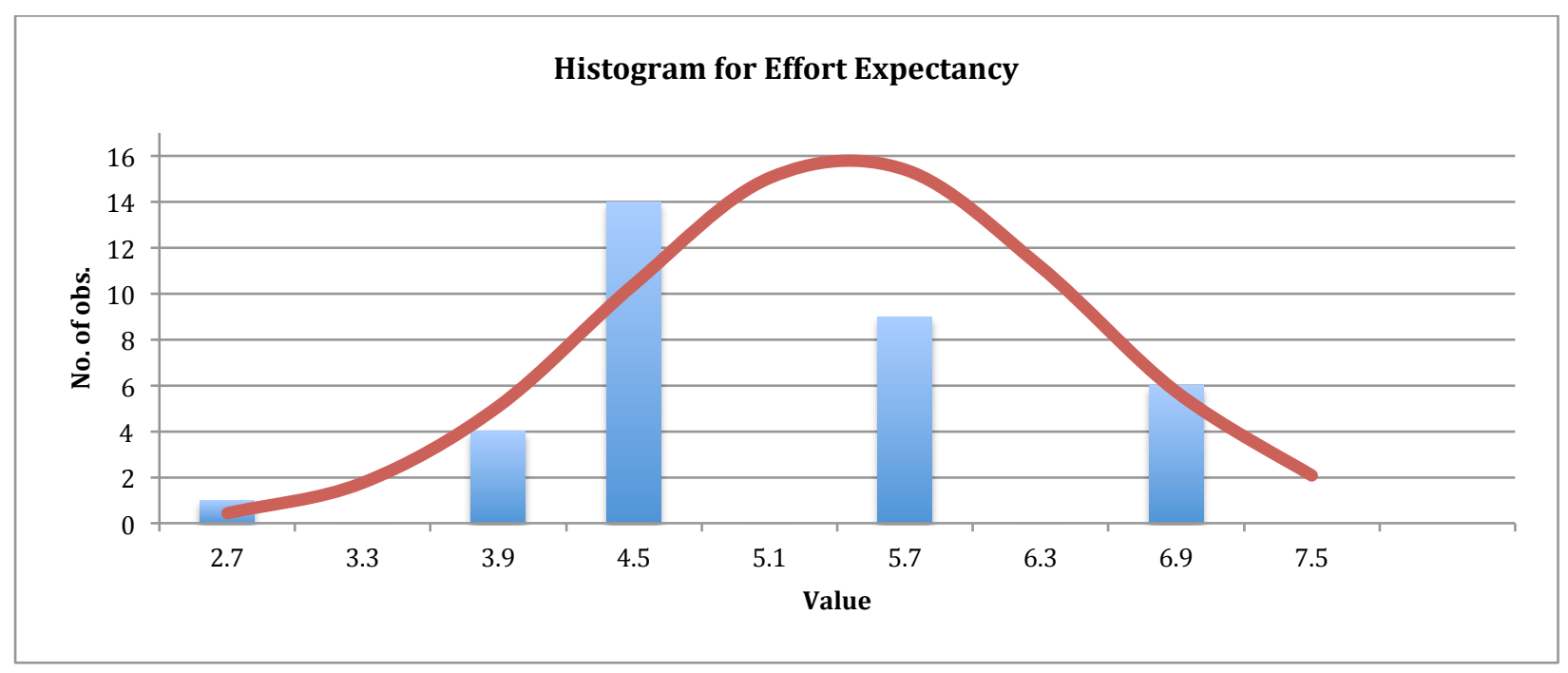

\begin{tabular}{|c|c|c|c|}
\hline \multicolumn{4}{|c|}{ Normality Tests } \\
\hline \multicolumn{4}{|l|}{ Variable \#1 (Var1) } \\
\hline Sample size & 34 & Mean & 5.44 \\
\hline Standard Deviation & 1.02 & Median & 5.00 \\
\hline Skewness & -0.10 & Kurtosis & 2.58 \\
\hline $\begin{array}{l}\text { Alternative Skewness } \\
\text { (Fisher's) }\end{array}$ & -0.10 & Alternative Kurtosis (Fisher's & -0.29 \\
\hline & $\begin{array}{c}\text { Test } \\
\text { Statistics }\end{array}$ & p-level & Conclusion: (2\%) \\
\hline $\begin{array}{l}\text { Kolmogorov-Smirnov/Lilliefor } \\
\text { Test }\end{array}$ & $0 . E+0$ & & $\begin{array}{l}\text { No evidence against } \\
\text { normality }\end{array}$ \\
\hline Shapiro-Wilk W & 0.9 & c & Reject Normality \\
\hline D'Agostino Skewness & 0.27 & 0.7 & Accept Normality \\
\hline D'Agostino Kurtosis & -0.21 & 0.8 & Accept Normality \\
\hline D'Agostino Omnibus & 0.12 & 0.9 & Accept Normality \\
\hline
\end{tabular}

Prose Attitude Toward Using The Type Of Representation

\begin{tabular}{|l|r|l|r|}
\hline \multicolumn{2}{|c|}{ Alpha value (for confidence interval) } & 0.02 & \\
\hline \multicolumn{2}{|c|}{ Variable \#1 (Attitude toward using the type of representation) } \\
\hline Count & 34 & Skewness & 0.73 \\
\hline Mean & 5.09 & Skewness Standard Error & 0.39 \\
\hline Mean LCL & 4.7 & Kurtosis & 2.83 \\
\hline Mean UCL & 5.48 & Kurtosis Standard Error & 0.72 \\
\hline Variance & 0.87 & Alternative Skewness (Fisher's) & 0.77 \\
\hline Standard Deviation & 0.93 & Alternative Kurtosis (Fisher's) & 0.01 \\
\hline Mean Standard Error & 0.16 & Coefficient of Variation & 0.18 \\
\hline Minimum & 4. & Mean Deviation & 0.66 \\
\hline Maximum & 7. & Second Moment & 0.85 \\
\hline Range & 3. & Third Moment & 0.57 \\
\hline Sum & 173. & Fourth Moment & 2.02 \\
\hline Sum Standard Error & 5.44 & Median & 5.00 \\
\hline Total Sum Squares & 909. & Median Error & 0.03 \\
\hline Adjusted Sum Squares & 28.74 & Percentile 25\% (Q1) & 4.5 \\
\hline Geometric Mean & 5.01 & Percentile 75\% (Q2) & 5.5 \\
\hline Harmonic Mean & 4.94 & IQR & 1. \\
\hline Mode & 5. & MAD (Median Absolute Deviation) & 0.50 \\
\hline & & Coefficient of Dispersion (COD) & 0.12 \\
\hline
\end{tabular}




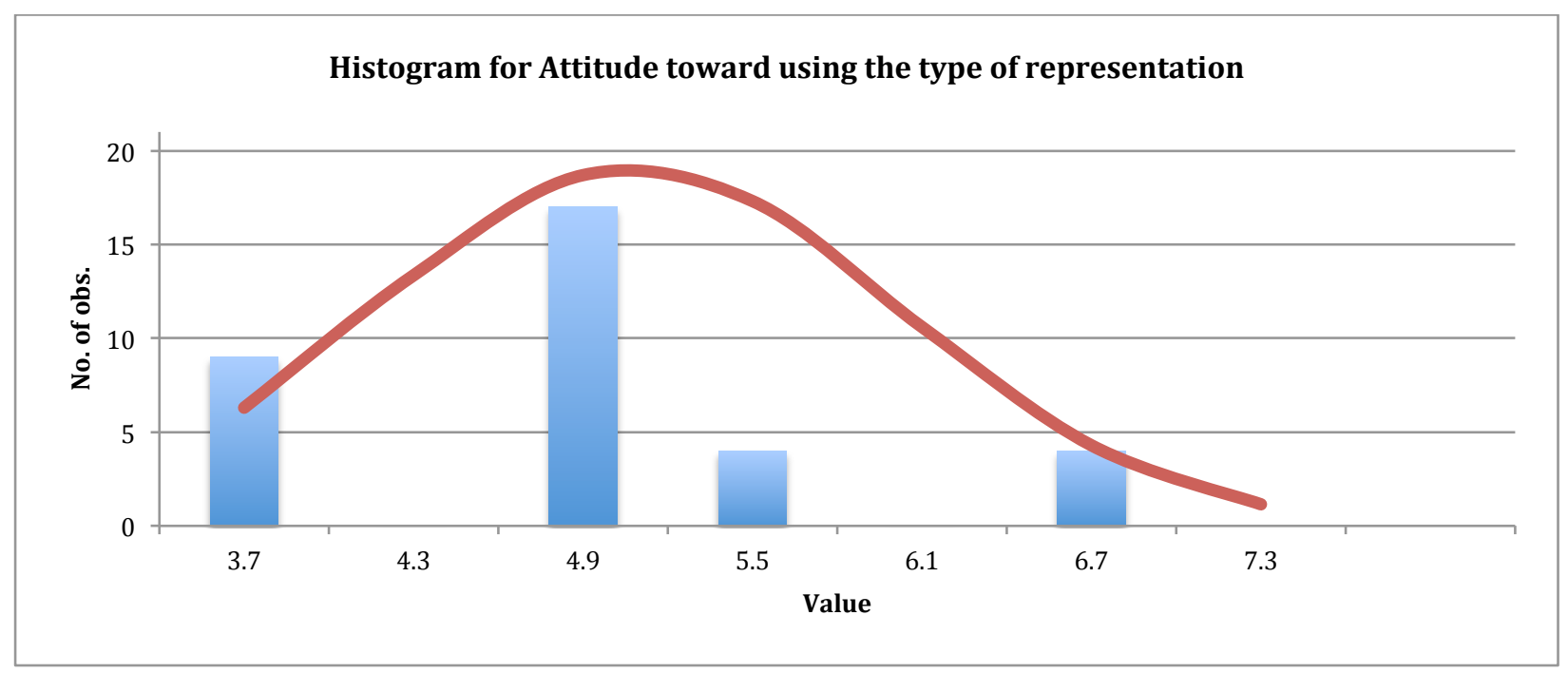

\begin{tabular}{|l|r|l|l|}
\hline \multicolumn{5}{|c|}{ Normality Tests } \\
\hline Variable \#1 (Var1) & 34 & Mean & \\
\hline Sample size & 0.93 & Median & 5.09 \\
\hline Standard Deviation & 0.73 & Kurtosis & 2.83 \\
\hline Skewness & 0.77 & $\begin{array}{l}\text { Alternative Kurtosis } \\
\text { (Fisher's) }\end{array}$ & \\
\hline $\begin{array}{l}\text { Alternative Skewness } \\
\text { (Fisher's) }\end{array}$ & & & \\
\hline & $\begin{array}{c}|c| \\
\text { Test } \\
\text { Statistics }\end{array}$ & p-level & \multicolumn{1}{|c|}{ Conclusion: (2\%) } \\
\hline Kolmogorov-Smirnov/Lilliefor & $0 . \mathrm{E}+0$ & & $\begin{array}{l}\text { No evidence against } \\
\text { normality }\end{array}$ \\
\hline Test & 0.82 & 0. & Reject Normality \\
\hline Shapiro-Wilk W & 1.89 & 0.06 & Accept Normality \\
\hline D'Agostino Skewness & 0.24 & 0.81 & Accept Normality \\
\hline D'Agostino Kurtosis & 3.62 & 0.16 & Accept Normality \\
\hline D'Agostino Omnibus & & & \\
\hline
\end{tabular}

\section{Prose Social Influence}

\begin{tabular}{|l|r|l|r|}
\hline \multicolumn{2}{|c|}{ Alpha value (for confidence interval) } & 0.02 & \\
\hline Count & 34 & Skewness & -0.63 \\
\hline Mean & 4.12 & Skewness Standard Error & 0.39 \\
\hline Mean LCL & 3.6 & Kurtosis & 3.87 \\
\hline Mean UCL & 4.63 & Kurtosis Standard Error & 0.72 \\
\hline Variance & 1.5 & Alternative Skewness (Fisher's) & -0.66 \\
\hline Standard Deviation & 1.23 & Alternative Kurtosis (Fisher's) & 1.22 \\
\hline Mean Standard Error & 0.21 & Coefficient of Variation & 0.3 \\
\hline Minimum & 1. & Mean Deviation & 0.81 \\
\hline Maximum & 6. & Second Moment & 1.46 \\
\hline Range & 5. & Third Moment & -1.1 \\
\hline Sum & 140. & Fourth Moment & 8.22 \\
\hline Sum Standard Error & 7.14 & Median & 4. \\
\hline Total Sum Squares & 626. & Median Error & 0.05 \\
\hline Adjusted Sum Squares & 49.53 & Percentile 25\% (Q1) & 4. \\
\hline Geometric Mean & 3.86 & Percentile 75\% (Q2) & 5. \\
\hline Harmonic Mean & 3.46 & IQR & 1. \\
\hline Mode & 4. & MAD (Median Absolute Deviation) & $0 . \mathrm{+}+0$ \\
\hline & & Coefficient of Dispersion (COD) & 0.19 \\
\hline
\end{tabular}




\section{Histogram for Social Influence}

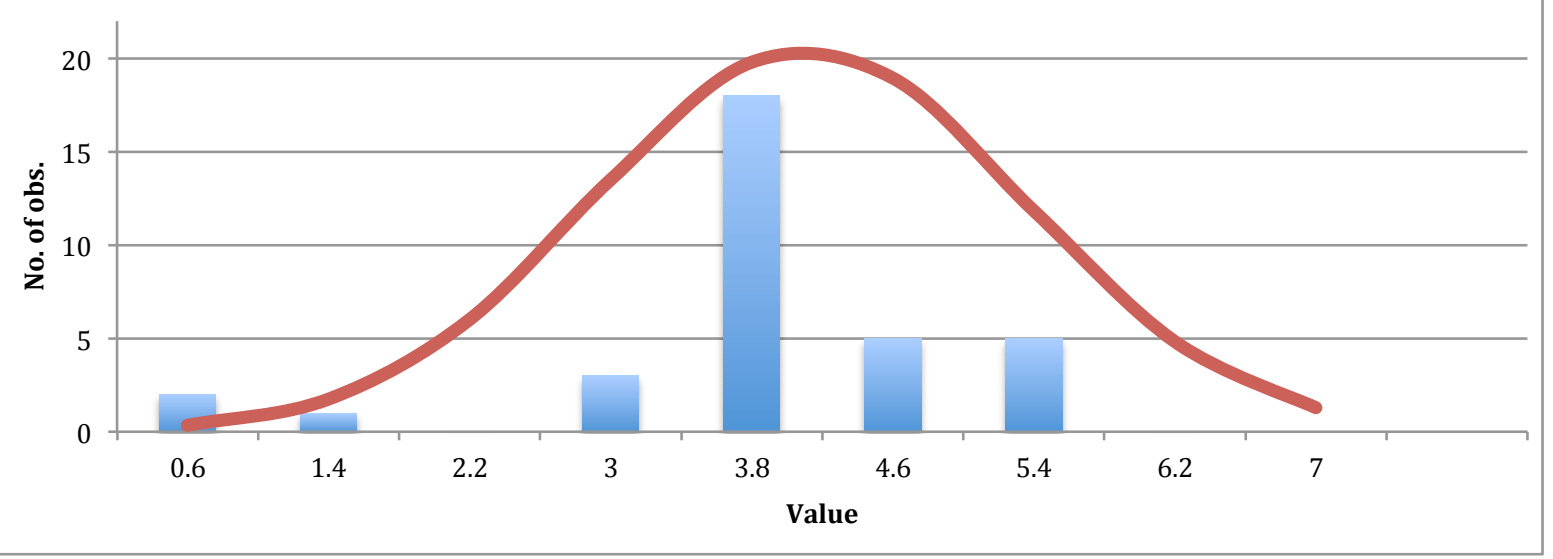

\begin{tabular}{|c|c|c|c|}
\hline \multicolumn{4}{|c|}{ Normality Tests } \\
\hline \multicolumn{4}{|l|}{ Variable \#1 (Var1) } \\
\hline Sample size & 34 & Mean & 4.12 \\
\hline Standard Deviation & 1.23 & Median & 4. \\
\hline Skewness & -0.63 & Kurtosis & 3.87 \\
\hline $\begin{array}{l}\text { Alternative Skewness } \\
\text { (Fisher's) }\end{array}$ & -0.66 & $\begin{array}{l}\text { Alternative Kurtosis } \\
\text { (Fisher's) }\end{array}$ & 1.22 \\
\hline & $\begin{array}{c}\text { Test } \\
\text { Statistics }\end{array}$ & p-level & Conclusion: (2\%) \\
\hline $\begin{array}{l}\text { Kolmogorov-Smirnov/Lilliefor } \\
\text { Test }\end{array}$ & $0 . E+0$ & & $\begin{array}{l}\text { No evidence against } \\
\text { normality }\end{array}$ \\
\hline Shapiro-Wilk W & 0.85 & & Reject Normality \\
\hline D'Agostino Skewness & 1.64 & 0 & Accept Normality \\
\hline D'Agostino Kurtosis & 1.46 & 0.1 & Accept Normality \\
\hline D'Agostino Omnibus & 4.84 & 0.0 & Accept Normality \\
\hline
\end{tabular}

\section{Prose Facilitating Conditions}

\begin{tabular}{|l|r|l|r|}
\hline \multicolumn{2}{|c|}{ Alpha value (for confidence interval) } & 0.02 & \\
\hline \multicolumn{2}{|c|}{ Variable \#1 (Facilitating Conditions) } \\
\hline Count & 34 & Skewness & 0.22 \\
\hline Mean & 5.18 & Skewness Standard Error & 0.39 \\
\hline Mean LCL & 4.72 & Kurtosis & 2.74 \\
\hline Mean UCL & 5.63 & Kurtosis Standard Error & 0.72 \\
\hline Variance & 1.18 & Alternative Skewness (Fisher's) & 0.23 \\
\hline Standard Deviation & 1.09 & Alternative Kurtosis (Fisher's) & -0.1 \\
\hline Mean Standard Error & 0.19 & Coefficient of Variation & 0.21 \\
\hline Minimum & 3. & Mean Deviation & 0.79 \\
\hline Maximum & 7. & Second Moment & 1.15 \\
\hline Range & 4. & Third Moment & 0.27 \\
\hline Sum & 176. & Fourth Moment & 3.59 \\
\hline Sum Standard Error & 6.33 & Median & 5. \\
\hline Total Sum Squares & 950. & Median Error & 0.04 \\
\hline Adjusted Sum Squares & 38.94 & Percentile 25\% (Q1) & 5. \\
\hline Geometric Mean & 5.06 & Percentile 75\% (Q2) & 6. \\
\hline Harmonic Mean & 4.95 & lQR & 1. \\
\hline Mode & 5. & MAD (Median Absolute Deviation) & $0 . E+0$ \\
\hline & & Coefficient of Dispersion (COD) & 0.14 \\
\hline
\end{tabular}




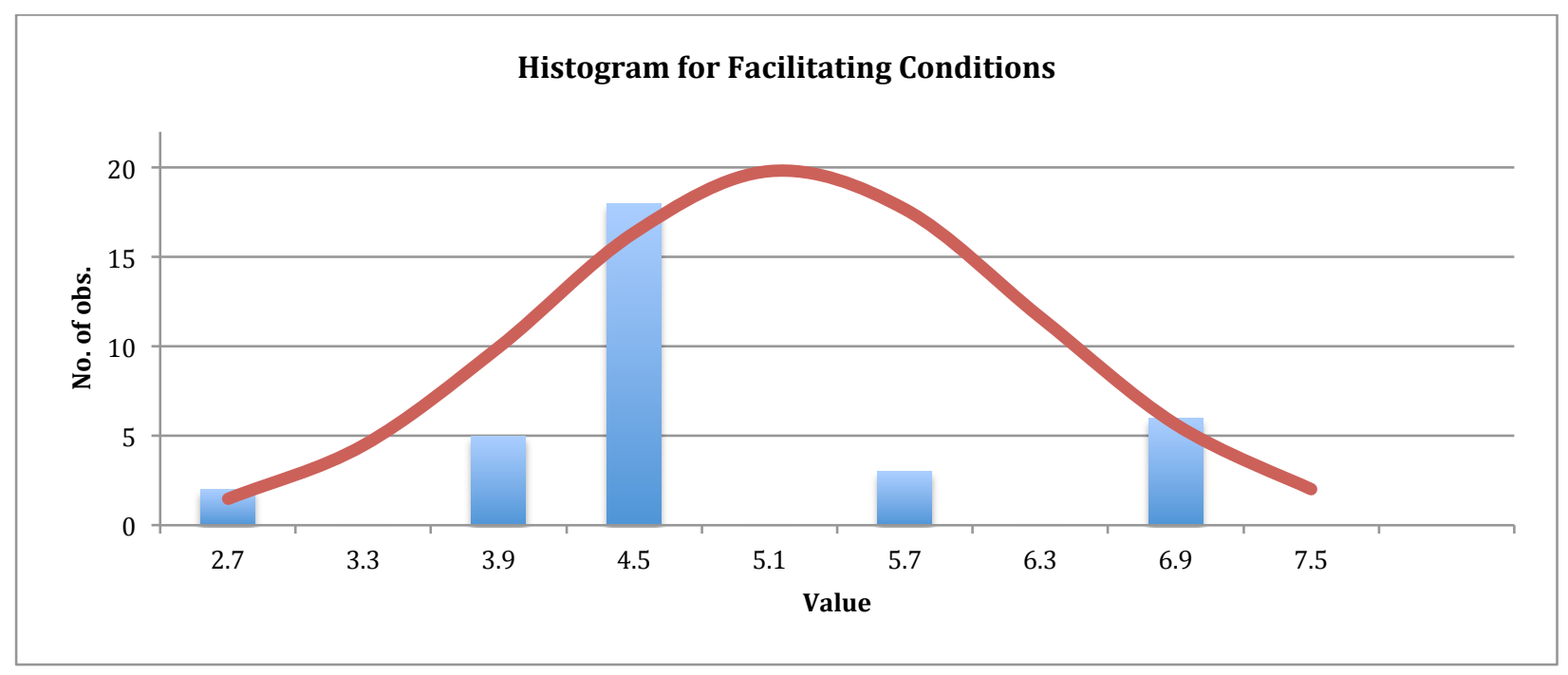

\begin{tabular}{|l|r|l|r|}
\hline \multicolumn{5}{|c|}{ Normality Tests } \\
\hline Variable \#1 (Var1) & 34 & Mean & \\
\hline Sample size & 1.09 & Median & 5.18 \\
\hline Standard Deviation & 0.22 & Kurtosis & 2.74 \\
\hline Skewness & 0.23 & $\begin{array}{l}\text { Alternative Kurtosis } \\
\text { (Fisher's) }\end{array}$ & \\
\hline $\begin{array}{l}\text { Alternative Skewness } \\
\text { (Fisher's) }\end{array}$ & & & \\
\hline & $\begin{array}{c}|c| \\
\text { Test }\end{array}$ & p-level & \multicolumn{1}{|c|}{ Conclusion: (2\%) } \\
\hline & Statistics & & $\begin{array}{l}\text { No evidence against } \\
\text { normality }\end{array}$ \\
\hline $\begin{array}{l}\text { Kolmogorov-Smirnov/Lilliefor } \\
\text { Test }\end{array}$ & $0 . \mathrm{E}+0$ & 0. & Reject Normality \\
\hline Shapiro-Wilk W & 0.86 & 0.55 & Accept Normality \\
\hline D'Agostino Skewness & 0.6 & 0.93 & Accept Normality \\
\hline D'Agostino Kurtosis & 0.08 & 0.83 & Accept Normality \\
\hline D'Agostino Omnibus & 0.37 & & \\
\hline
\end{tabular}

\section{Prose Self-Efficacy}

\begin{tabular}{|l|r|l|r|}
\hline Alpha value (for confidence interval) & 0.02 & \\
\hline & Variable \#1 (Self-Efficacy) & 0.11 \\
\hline Count & 34 & Skewness & 0.39 \\
\hline Mean & 2.94 & Skewness Standard Error & 2.54 \\
\hline Mean LCL & 2.39 & Kurtosis & 0.72 \\
\hline Mean UCL & 3.5 & Kurtosis Standard Error & 0.11 \\
\hline Variance & 1.75 & Alternative Skewness (Fisher's) & -0.33 \\
\hline Standard Deviation & 1.32 & Alternative Kurtosis (Fisher's) & 0.45 \\
\hline Mean Standard Error & 0.23 & Coefficient of Variation & 0.97 \\
\hline Minimum & 1. & Mean Deviation & 1.7 \\
\hline Maximum & 6. & Second Moment & 0.24 \\
\hline Range & 5. & Third Moment & 7.37 \\
\hline Sum & 100. & Fourth Moment & 3. \\
\hline Sum Standard Error & 7.72 & Median & 0.05 \\
\hline Total Sum Squares & 352. & Median Error & 2. \\
\hline Adjusted Sum Squares & 57.88 & Percentile 25\% (Q1) & 4. \\
\hline Geometric Mean & 2.59 & Percentile 75\% (Q2) & 2. \\
\hline Harmonic Mean & 2.2 & IQR & 1. \\
\hline Mode & 3. & MAD (Median Absolute Deviation) & 0.31 \\
\hline
\end{tabular}




\begin{tabular}{|l|r|r|r|}
\hline \multicolumn{5}{|l|}{ Histogram for Self-Efficacy } \\
\hline \\
\hline \\
\hline
\end{tabular}

Prose Anxiety

\begin{tabular}{|l|r|l|r|}
\hline Alpha value (for confidence interval) & 0.02 & \\
\hline & Variable \#1 (Anxiety) & 0.18 \\
\hline Count & 34 & Skewness & 0.39 \\
\hline Mean & 3. & Skewness Standard Error & 2.59 \\
\hline Mean LCL & 2.46 & Kurtosis & 0.72 \\
\hline Mean UCL & 3.54 & Kurtosis Standard Error & 0.18 \\
\hline Variance & 1.64 & Alternative Skewness (Fisher's) & -0.28 \\
\hline Standard Deviation & 1.28 & Alternative Kurtosis (Fisher's) & 0.43 \\
\hline Mean Standard Error & 0.22 & Coefficient of Variation & 0.94 \\
\hline Minimum & 1. & Mean Deviation & 1.59 \\
\hline Maximum & 6. & Second Moment & 0.35 \\
\hline Range & 5. & Third Moment & 6.53 \\
\hline Sum & 102. & Fourth Moment & 3. \\
\hline Sum Standard Error & 7.46 & Median & 0.05 \\
\hline Total Sum Squares & 360. & Median Error & 2. \\
\hline Adjusted Sum Squares & 54. & Percentile 25\% (Q1) & 4. \\
\hline Geometric Mean & 2.69 & Percentile 75\% (Q2) & 2. \\
\hline Harmonic Mean & 2.34 & IQR & 1. \\
\hline Mode & 3. & MAD (Median Absolute Deviation) & 0.31 \\
\hline
\end{tabular}




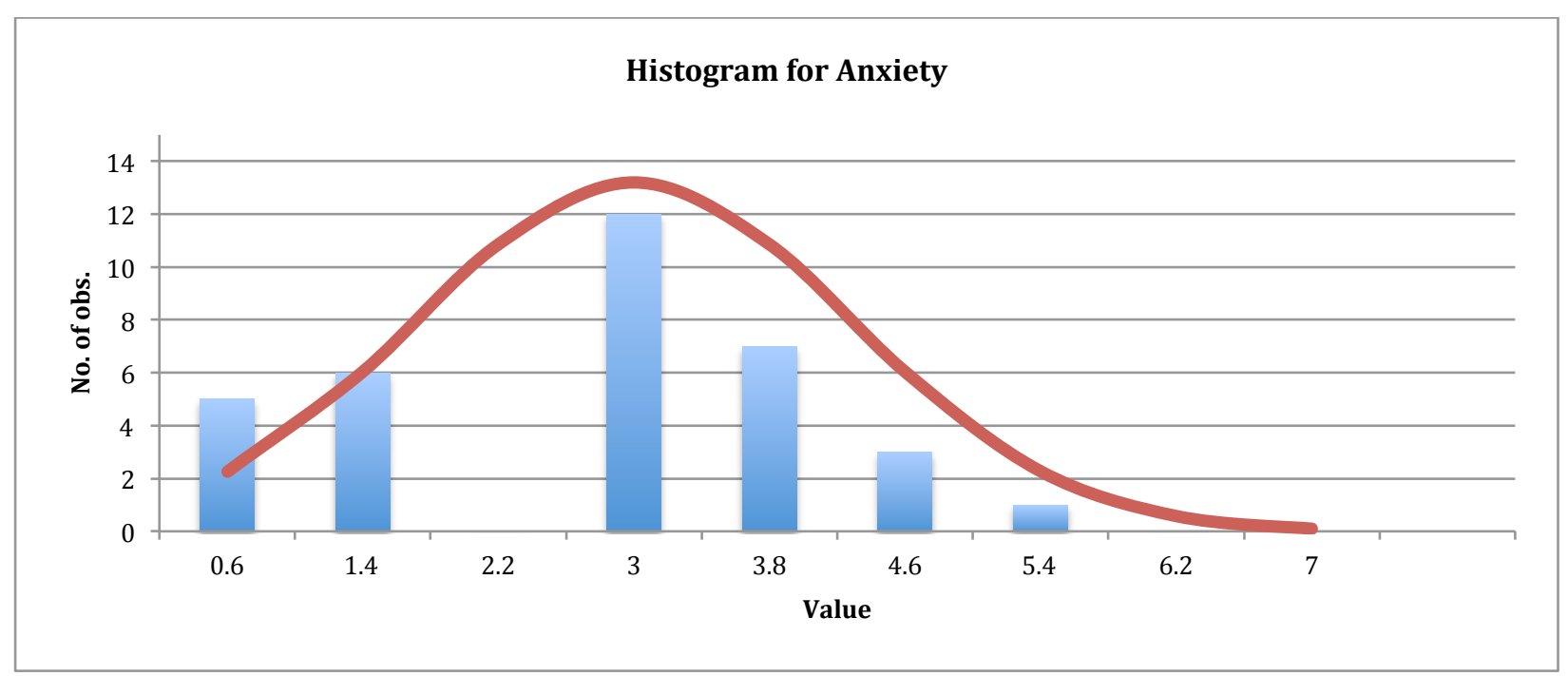

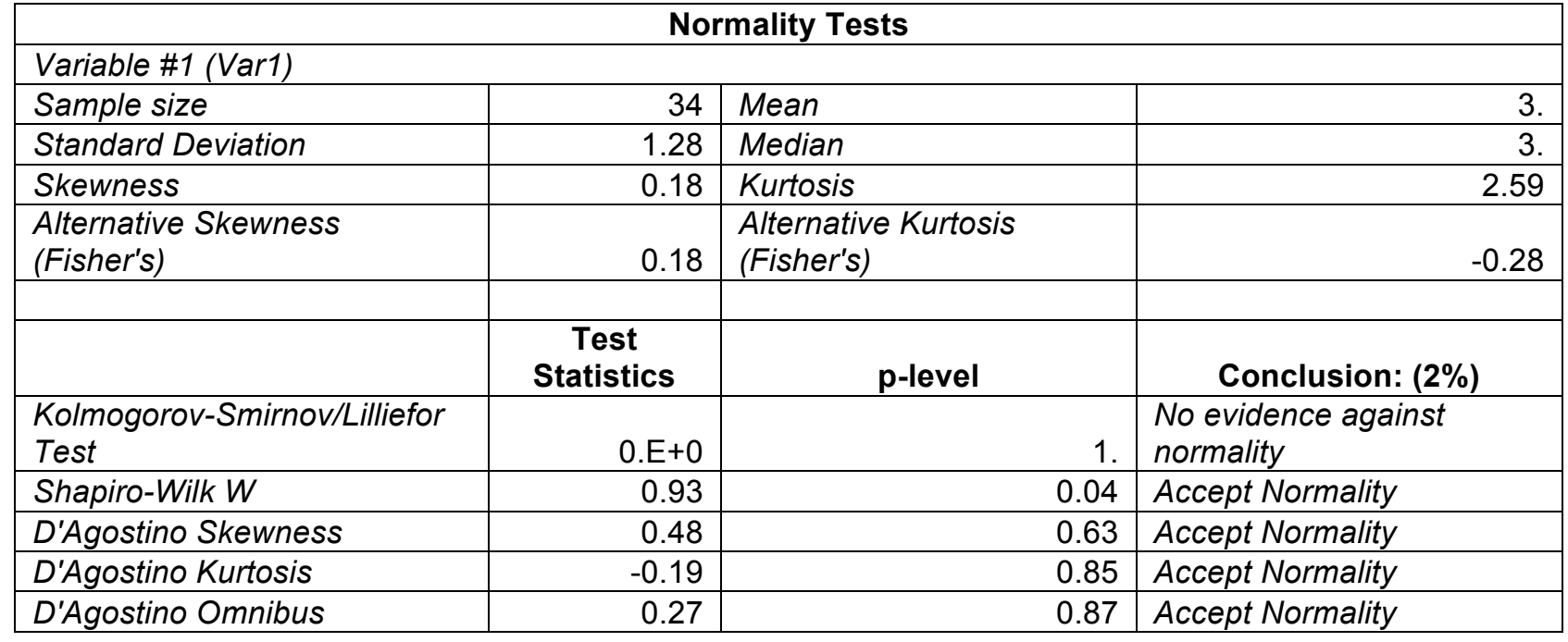

\section{Prose Intention To Use}

\begin{tabular}{|l|r|l|r|}
\hline Alpha value (for confidence interval) & 0.02 & \\
\hline \multicolumn{2}{|c|}{ Variable \#1 (Intention To Use) } & 0.06 \\
\hline Count & 34 & Skewness & 0.39 \\
\hline Mean & 4.97 & Skewness Standard Error & 2.95 \\
\hline Mean LCL & 4.47 & Kurtosis & 0.72 \\
\hline Mean UCL & 5.47 & Kurtosis Standard Error & 0.06 \\
\hline Variance & 1.42 & Alternative Skewness (Fisher's) & 0.14 \\
\hline Standard Deviation & 1.19 & Alternative Kurtosis (Fisher's) & 0.24 \\
\hline Mean Standard Error & 0.2 & Coefficient of Variation & 0.86 \\
\hline Minimum & 2. & Mean Deviation & 1.38 \\
\hline Maximum & 7. & Second Moment & 0.09 \\
\hline Range & 5. & Third Moment & 5.62 \\
\hline Sum & 169. & Fourth Moment & 5. \\
\hline Sum Standard Error & 6.96 & Median & 0.04 \\
\hline Total Sum Squares & 887. & Median Error & 4. \\
\hline Adjusted Sum Squares & 46.97 & Percentile 25\% (Q1) & 6. \\
\hline Geometric Mean & 4.82 & Percentile 75\% (Q2) & 2. \\
\hline Harmonic Mean & 4.65 & IQR & 1. \\
\hline Mode & 5. & MAD (Median Absolute Deviation) & 0.17 \\
\hline \multicolumn{2}{|l|}{} \\
\hline
\end{tabular}




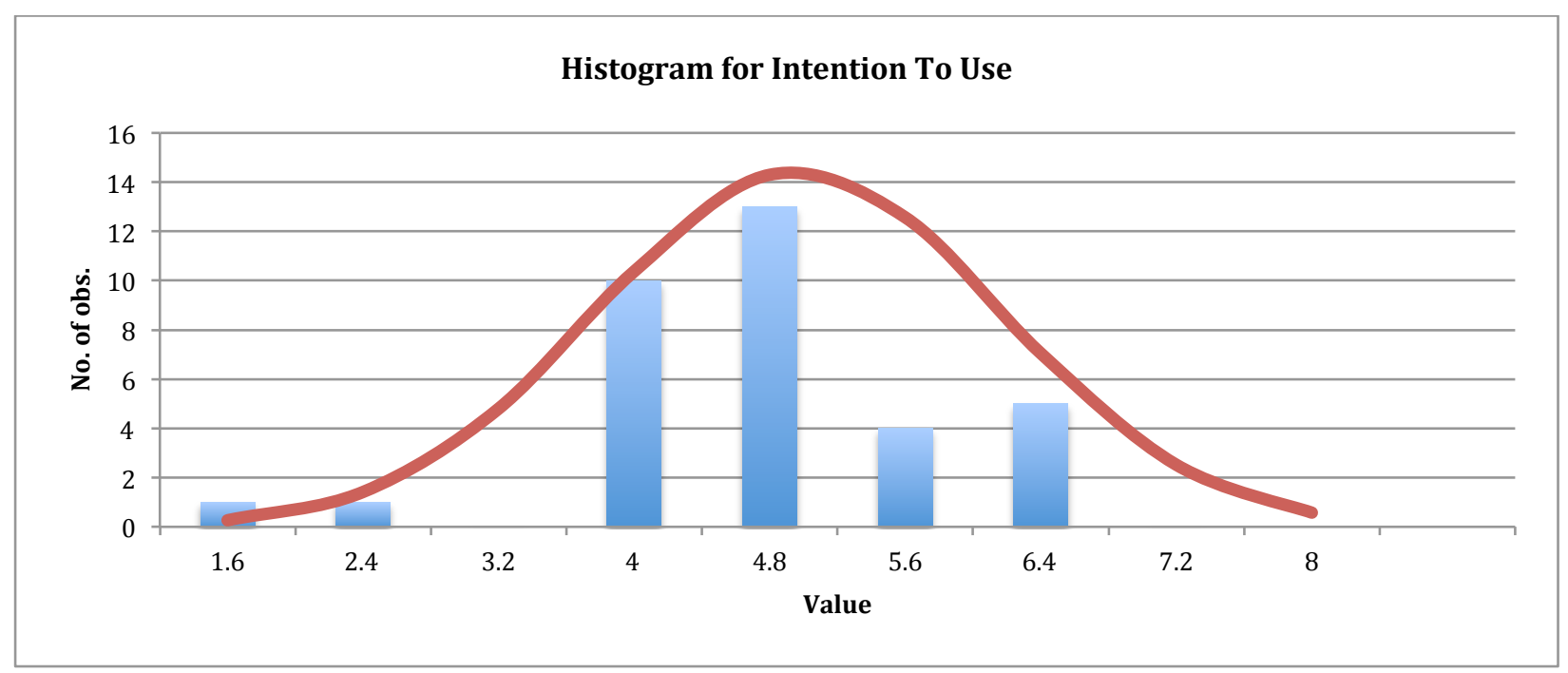

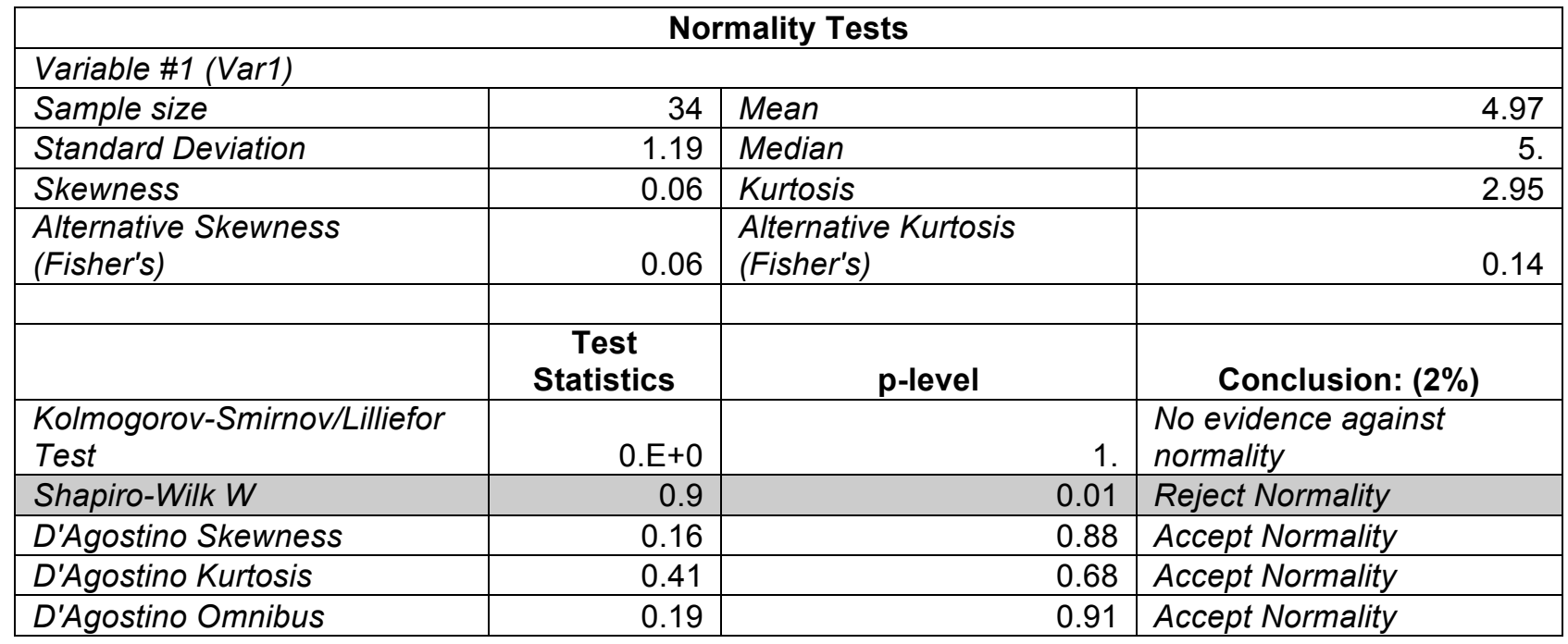

\section{Image}

Image Performance Expectancy

\begin{tabular}{|l|r|l|r|}
\hline \multicolumn{2}{|c|}{ Alpha value (for confidence interval) } & 0.02 & \\
\hline \multicolumn{2}{|c|}{ Variable \#1 (Performance Expectancy) } \\
\hline Count & 34 & Skewness & 0.37 \\
\hline Mean & 4.35 & Skewness Standard Error & 0.39 \\
\hline Mean LCL & 3.87 & Kurtosis & 3. \\
\hline Mean UCL & 4.84 & Kurtosis Standard Error & 0.72 \\
\hline Variance & 1.33 & Alternative Skewness (Fisher's) & 0.38 \\
\hline Standard Deviation & 1.15 & Alternative Kurtosis (Fisher's) & 0.2 \\
\hline Mean Standard Error & 0.2 & Coefficient of Variation & 0.26 \\
\hline Minimum & 2. & Mean Deviation & 0.92 \\
\hline Maximum & 7. & Second Moment & 1.29 \\
\hline Range & 5. & Third Moment & 0.53 \\
\hline Sum & 148. & Fourth Moment & 4.97 \\
\hline Sum Standard Error & 6.71 & Median & 4. \\
\hline Total Sum Squares & 688. & Median Error & 0.04 \\
\hline Adjusted Sum Squares & 43.76 & Percentile 25\% (Q1) & 4. \\
\hline Geometric Mean & 4.2 & Percentile 75\% (Q2) & 5. \\
\hline Harmonic Mean & 4.05 & IQR & 1. \\
\hline Mode & \#N/A & MAD (Median Absolute Deviation) & 1. \\
\hline \multicolumn{2}{|c|}{} & Coefficient of Dispersion (COD) & 0.22 \\
\hline
\end{tabular}




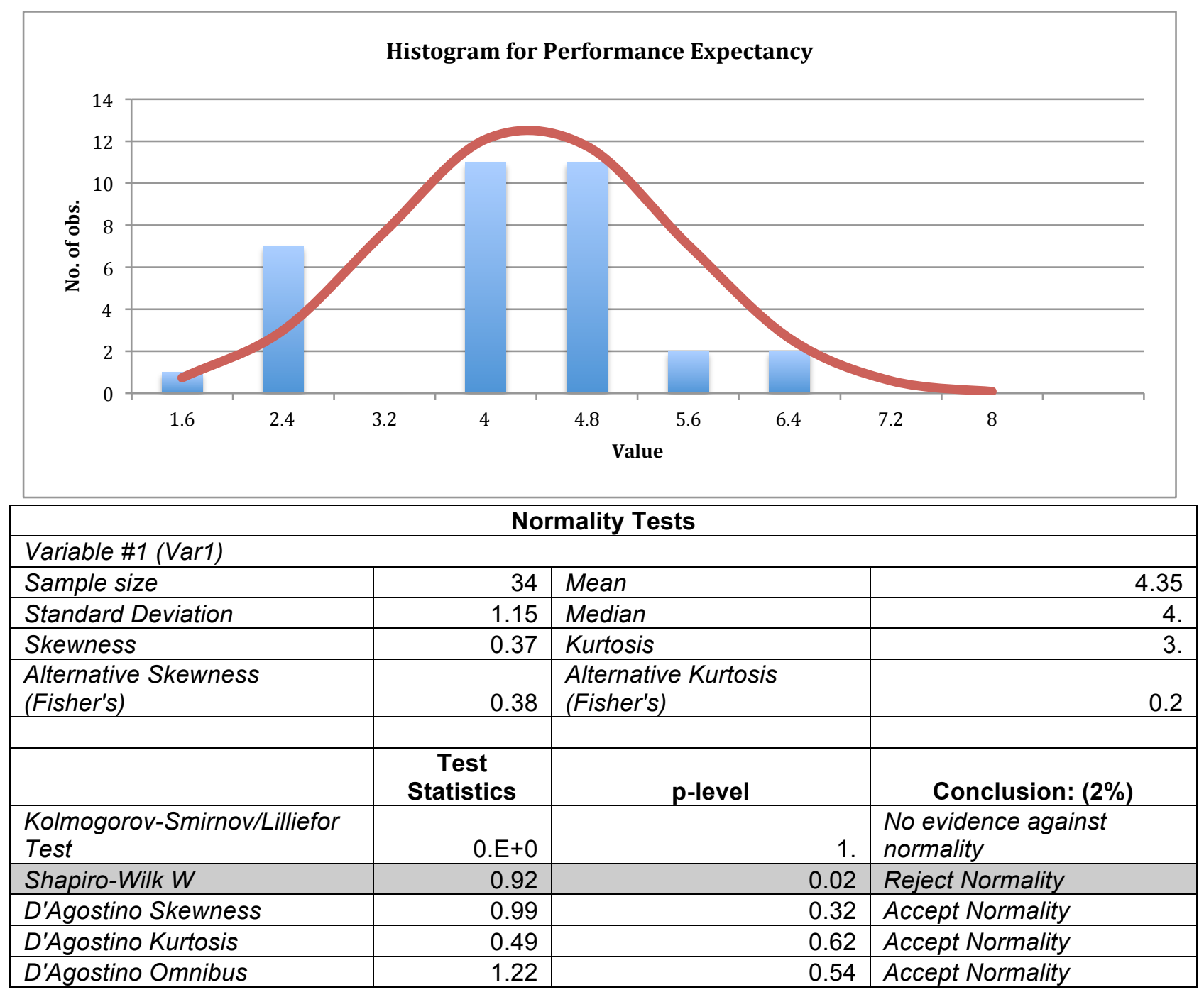

Image Effort Expectancy

\begin{tabular}{|l|r|l|r|}
\hline \multicolumn{2}{|c|}{ Alpha value (for confidence interval) } & 0.02 & \\
\hline \multicolumn{2}{|c|}{ Variable \#1 (Effort Expectancy) } & -0.02 \\
\hline Count & 34 & Skewness & 0.39 \\
\hline Mean & 4.79 & Skewness Standard Error & 2.34 \\
\hline Mean LCL & 4.29 & Kurtosis & 0.72 \\
\hline Mean UCL & 5.3 & Kurtosis Standard Error & -0.02 \\
\hline Variance & 1.44 & Alternative Skewness (Fisher's) & -0.57 \\
\hline Standard Deviation & 1.2 & Alternative Kurtosis (Fisher's) & 0.25 \\
\hline Mean Standard Error & 0.21 & Coefficient of Variation & 0.93 \\
\hline Minimum & 3. & Mean Deviation & 1.4 \\
\hline Maximum & 7. & Second Moment & -0.04 \\
\hline Range & 4. & Third Moment & 4.58 \\
\hline Sum & 163. & Fourth Moment & 5. \\
\hline Sum Standard Error & 7. & Median & 0.04 \\
\hline Total Sum Squares & 829. & Median Error & 4. \\
\hline Adjusted Sum Squares & 47.56 & Percentile 25\% (Q1) & 5.5 \\
\hline Geometric Mean & 4.64 & Percentile 75\% (Q2) & 1.5 \\
\hline Harmonic Mean & 4.48 & IQR & 1. \\
\hline Mode & 5. & MAD (Median Absolute Deviation) & 0.17 \\
\hline
\end{tabular}




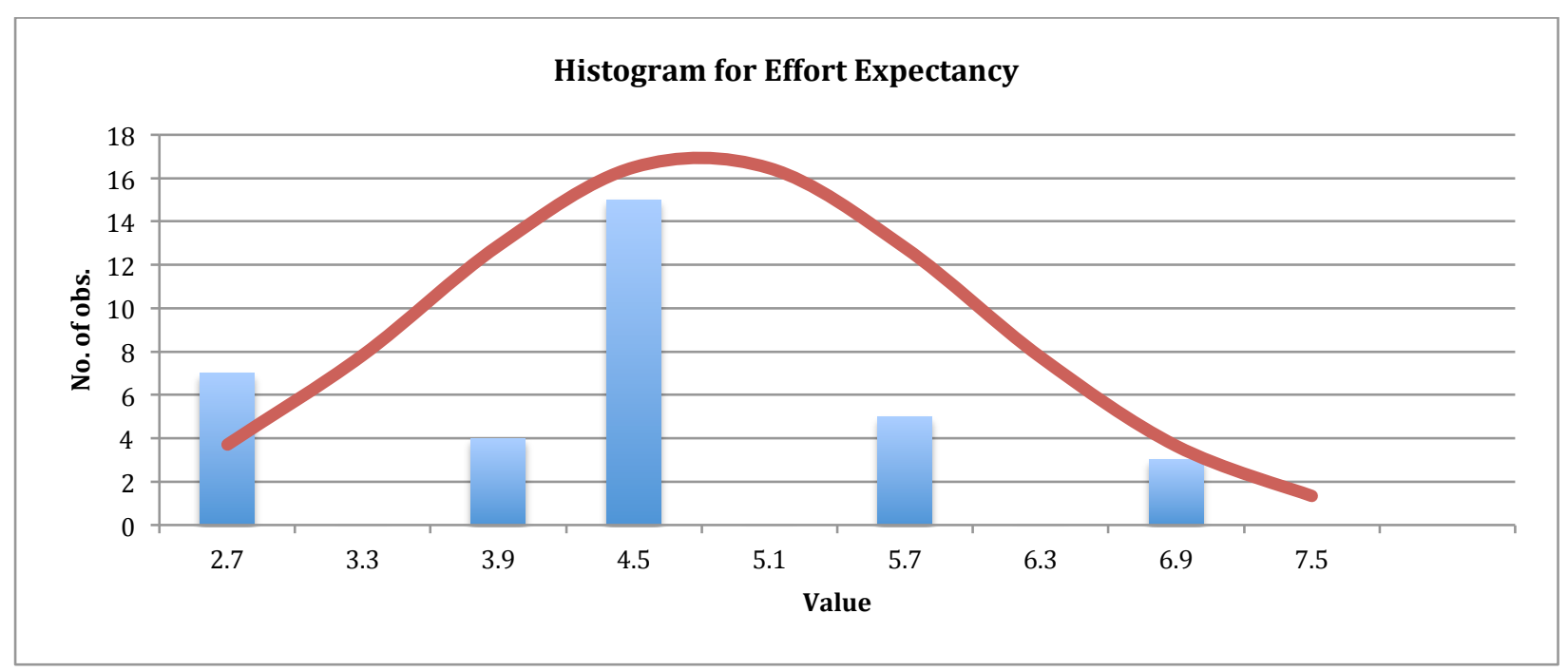

\begin{tabular}{|c|c|c|c|}
\hline \multicolumn{4}{|c|}{ Normality Tests } \\
\hline \multicolumn{4}{|l|}{ Variable \#1 (Var1) } \\
\hline Sample size & 34 & Mean & 4.79 \\
\hline Standard Deviation & 1.2 & Median & 5. \\
\hline Skewness & -0.02 & Kurtosis & 2.34 \\
\hline $\begin{array}{l}\text { Alternative Skewness } \\
\text { (Fisher's) }\end{array}$ & -0.02 & $\begin{array}{l}\text { Alternative Kurtosis } \\
\text { (Fisher's) }\end{array}$ & -0.57 \\
\hline & $\begin{array}{c}\text { Test } \\
\text { Statistics }\end{array}$ & p-level & Conclusion: (2\%) \\
\hline $\begin{array}{l}\text { Kolmogorov-Smirnov/Lilliefor } \\
\text { Test }\end{array}$ & $0 . E+0$ & 1. & $\begin{array}{l}\text { No evidence against } \\
\text { normality }\end{array}$ \\
\hline Shapiro-Wilk W & 0.89 & 0. & Reject Normality \\
\hline D'Agostino Skewness & 0.06 & 0.95 & Accept Normality \\
\hline D'Agostino Kurtosis & -0.73 & 0.47 & Accept Normality \\
\hline D'Agostino Omnibus & 0.53 & 0.77 & Accept Normality \\
\hline
\end{tabular}

Image Attitude Toward Using The Type Of Representation

\begin{tabular}{|l|r|l|r|}
\hline \multicolumn{2}{|c|}{ Vlpha value (for confidence interval) } & 0.02 & \\
\hline \multicolumn{2}{|c|}{ Variable \#1 (Attitude toward using the type of representation) } \\
\hline Meant & 34 & Skewness & -0.31 \\
\hline Mean LCL & 4.82 & Skewness Standard Error & 0.39 \\
\hline Mean UCL & 4.36 & Kurtosis & 2.2 \\
\hline Variance & 5.29 & Kurtosis Standard Error & 0.72 \\
\hline Standard Deviation & 1.24 & Alternative Skewness (Fisher's) & -0.33 \\
\hline Mean Standard Error & 1.11 & Alternative Kurtosis (Fisher's) & -0.73 \\
\hline Minimum & 0.19 & Coefficient of Variation & 0.23 \\
\hline Maximum & 3. & Mean Deviation & 0.89 \\
\hline Range & 7. & Second Moment & 1.2 \\
\hline Sum & 4. & Third Moment & -0.42 \\
\hline Sum Standard Error & 164. & Fourth Moment & 3.19 \\
\hline Total Sum Squares & 6.49 & Median & 5. \\
\hline Adjusted Sum Squares & 832. & Median Error & 0.04 \\
\hline Geometric Mean & 40.94 & Percentile 25\% (Q1) & 4. \\
\hline Harmonic Mean & 4.69 & Percentile 75\% (Q2) & 6. \\
\hline Mode & 4.54 & IQR & 2. \\
\hline & 5. & MAD (Median Absolute Deviation) & 1. \\
\hline
\end{tabular}




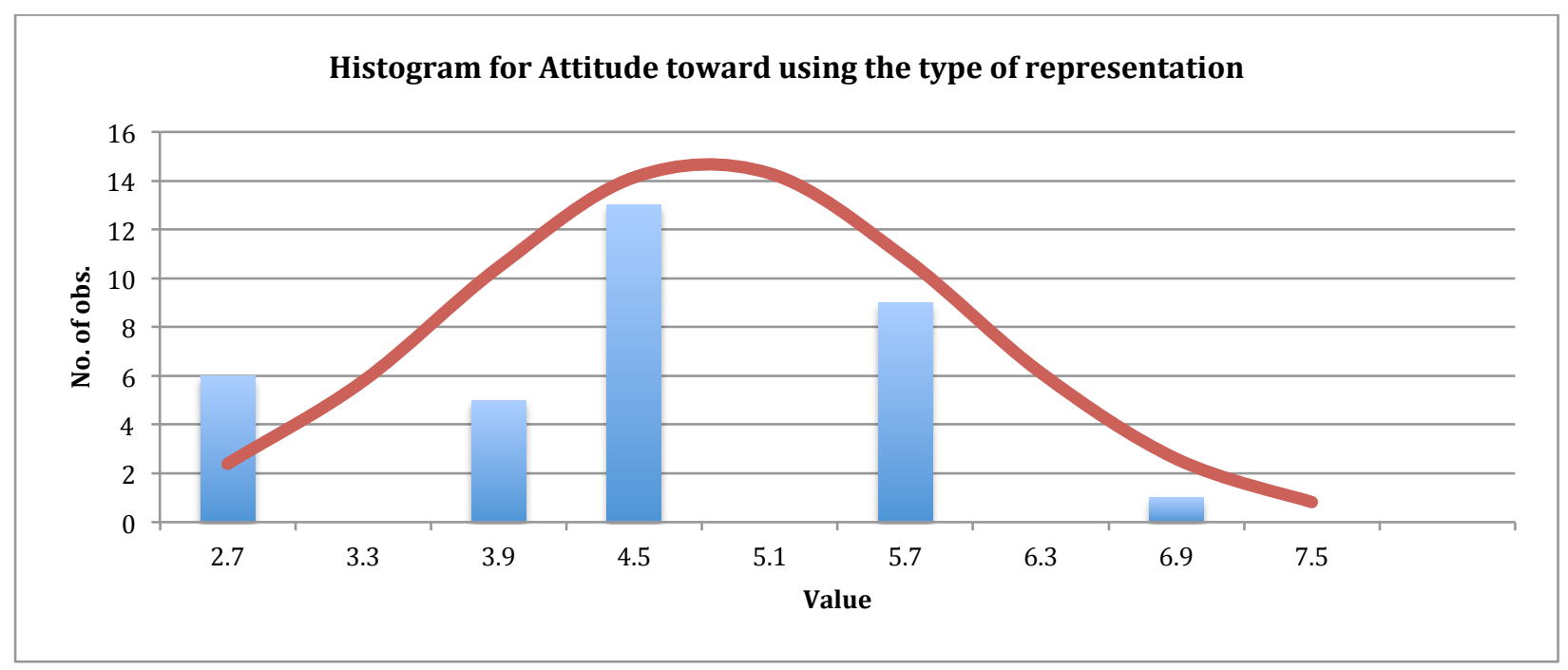

\begin{tabular}{|c|c|c|c|}
\hline \multicolumn{4}{|c|}{ Normality Tests } \\
\hline \multicolumn{4}{|l|}{ Variable \#1 (Var1) } \\
\hline Sample size & 34 & Mean & 4.82 \\
\hline Standard Deviation & 1.11 & Median & 5. \\
\hline Skewness & -0.31 & Kurtosis & 2.2 \\
\hline $\begin{array}{l}\text { Alternative Skewness } \\
\text { (Fisher's) }\end{array}$ & -0.33 & $\begin{array}{l}\text { Alternative Kurtosis } \\
\text { (Fisher's) }\end{array}$ & -0.73 \\
\hline & $\begin{array}{c}\text { Test } \\
\text { Statistics }\end{array}$ & p-level & Conclusion: (2\%) \\
\hline $\begin{array}{l}\text { Kolmogorov-Smirnov/Lilliefor } \\
\text { Test }\end{array}$ & $0 . E+0$ & & $\begin{array}{l}\text { No evidence against } \\
\text { normality }\end{array}$ \\
\hline Shapiro-Wilk W & 0.89 & & Reject Normality \\
\hline D'Agostino Skewness & 0.85 & 0. & Accept Normality \\
\hline D'Agostino Kurtosis & -1.1 & 0.2 & Accept Normality \\
\hline D'Agostino Omnibus & 1.94 & 0. & Accept Normality \\
\hline
\end{tabular}

\section{Image Social Influence}

\begin{tabular}{|l|r|l|r|}
\hline \multicolumn{2}{|c|}{ Alpha value (for confidence interval) } & 0.02 & \\
\hline Count & 34 & Skewness & \\
\hline Mean & 3.88 & Skewness Standard Error & -0.68 \\
\hline Mean LCL & 3.41 & Kurtosis & 0.39 \\
\hline Mean UCL & 4.35 & Kurtosis Standard Error & 4.02 \\
\hline Variance & 1.26 & Alternative Skewness (Fisher's) & 0.72 \\
\hline Standard Deviation & 1.12 & Alternative Kurtosis (Fisher's) & -0.71 \\
\hline Mean Standard Error & 0.19 & Coefficient of Variation & 1.38 \\
\hline Minimum & 1. & Mean Deviation & 0.29 \\
\hline Maximum & 6. & Second Moment & 0.76 \\
\hline Range & 5. & Third Moment & 1.22 \\
\hline Sum & 132. & Fourth Moment & -0.92 \\
\hline Sum Standard Error & 6.54 & Median & 5.99 \\
\hline Total Sum Squares & 554. & Median Error & 4. \\
\hline Adjusted Sum Squares & 41.53 & Percentile 25\% (Q1) & 0.04 \\
\hline Geometric Mean & 3.66 & Percentile 75\% (Q2) & 3.5 \\
\hline Harmonic Mean & 3.31 & IQR & 4.5 \\
\hline Mode & 4. & MAD (Median Absolute Deviation) & 1. \\
\hline & & Coefficient of Dispersion (COD) & 0.5 \\
\hline
\end{tabular}




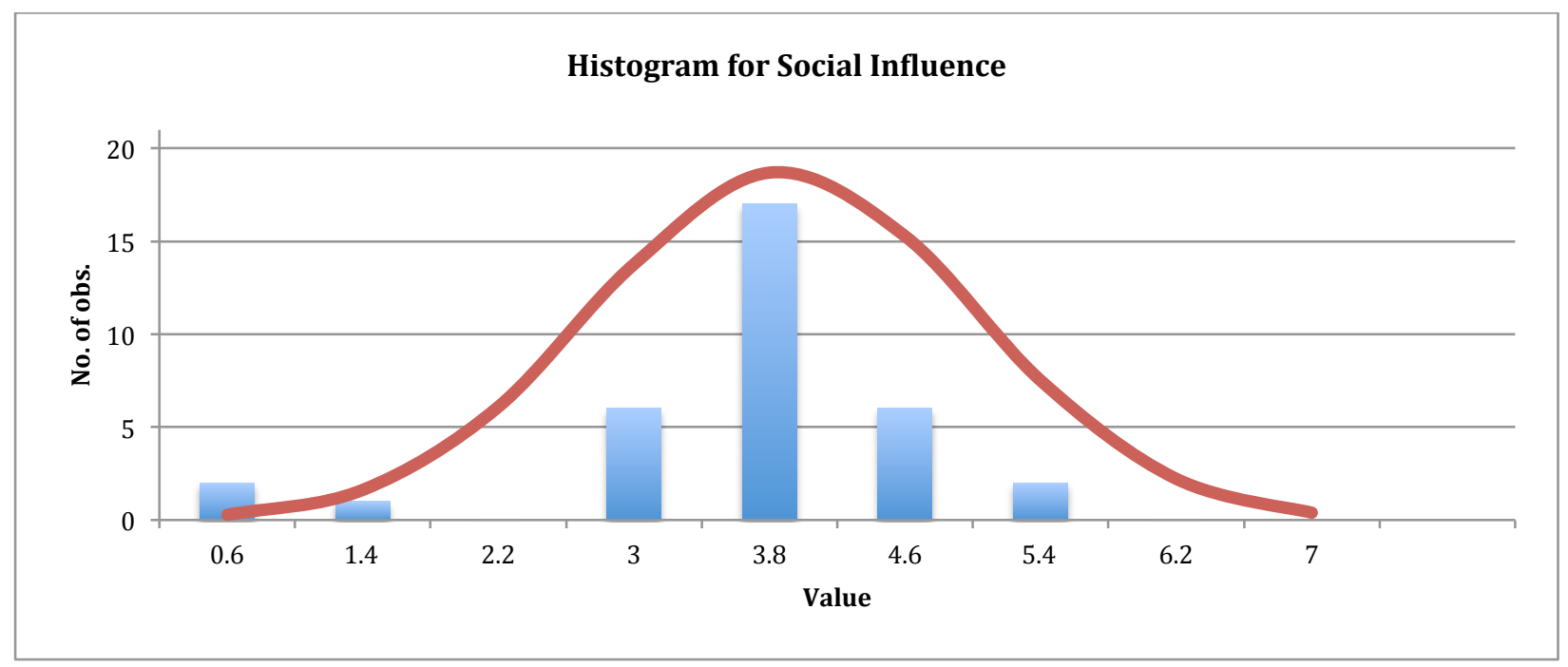

\begin{tabular}{|c|c|c|c|}
\hline \multicolumn{4}{|c|}{ Normality Tests } \\
\hline \multicolumn{4}{|l|}{ Variable \#1 (Var1) } \\
\hline Sample size & 34 & Mean & 3.88 \\
\hline Standard Deviation & 1.12 & Median & 4. \\
\hline Skewness & -0.68 & Kurtosis & 4.02 \\
\hline $\begin{array}{l}\text { Alternative Skewness } \\
\text { (Fisher's) }\end{array}$ & -0.71 & $\begin{array}{l}\text { Alternative Kurtosis } \\
\text { (Fisher's) }\end{array}$ & 1.38 \\
\hline & $\begin{array}{c}\text { Test } \\
\text { Statistics }\end{array}$ & p-level & Conclusion: (2\%) \\
\hline $\begin{array}{l}\text { Kolmogorov-Smirnov/Lilliefor } \\
\text { Test }\end{array}$ & $0 . E+0$ & 1. & $\begin{array}{l}\text { No evidence against } \\
\text { normality }\end{array}$ \\
\hline Shapiro-Wilk W & 0.88 & 0. & Reject Normality \\
\hline D'Agostino Skewness & 1.77 & 0.08 & Accept Normality \\
\hline D'Agostino Kurtosis & 1.59 & 0.11 & Accept Normality \\
\hline D'Agostino Omnibus & 5.65 & 0.06 & Accept Normality \\
\hline
\end{tabular}

Image Facilitating Conditions

\begin{tabular}{|l|r|l|r|}
\hline \multicolumn{2}{|c|}{ Alpha value (for confidence interval) } & 0.02 & \\
\hline \multicolumn{2}{|c|}{ Variable \#1 (Facilitating Conditions) } \\
\hline Count & 34 & Skewness & -0.06 \\
\hline Mean & 5.03 & Skewness Standard Error & 0.39 \\
\hline Mean LCL & 4.6 & Kurtosis & 2.98 \\
\hline Mean UCL & 5.46 & Kurtosis Standard Error & 0.72 \\
\hline Variance & 1.06 & Alternative Skewness (Fisher's) & -0.06 \\
\hline Standard Deviation & 1.03 & Alternative Kurtosis (Fisher's) & 0.17 \\
\hline Mean Standard Error & 0.18 & Coefficient of Variation & 0.2 \\
\hline Minimum & 3. & Mean Deviation & 0.69 \\
\hline Maximum & 7. & Second Moment & 1.03 \\
\hline Range & 4. & Third Moment & -0.06 \\
\hline Sum & 171. & Fourth Moment & 3.15 \\
\hline Sum Standard Error & 6. & Median & 5. \\
\hline Total Sum Squares & 895. & Median Error & 0.04 \\
\hline Adjusted Sum Squares & 34.97 & Percentile 25\% (Q1) & 5. \\
\hline Geometric Mean & 4.92 & Percentile 75\% (Q2) & 6. \\
\hline Harmonic Mean & 4.8 & IQR & 1. \\
\hline Mode & 5. & MAD (Median Absolute Deviation) & 0.5 \\
\hline & & Coefficient of Dispersion (COD) & 0.14 \\
\hline
\end{tabular}




\begin{tabular}{|l|r|l|l|}
\hline \multicolumn{5}{|l|}{ Histogram for Facilitating Conditions } \\
\hline \\
\hline
\end{tabular}

Image Self-Efficacy

\begin{tabular}{|l|r|l|r|}
\hline Alpha value (for confidence interval) & 0.02 & \\
\hline Vount & 34 & Skewness & -0.72 \\
\hline Mean & 4.41 & Skewness Standard Error & 0.39 \\
\hline Mean LCL & 3.98 & Kurtosis & 3.04 \\
\hline Mean UCL & 4.84 & Kurtosis Standard Error & 0.72 \\
\hline Variance & 1.04 & Alternative Skewness (Fisher's) & -0.75 \\
\hline Standard Deviation & 1.02 & Alternative Kurtosis (Fisher's) & 0.25 \\
\hline Mean Standard Error & 0.17 & Coefficient of Variation & 0.23 \\
\hline Minimum & 2. & Mean Deviation & 0.83 \\
\hline Maximum & 6. & Second Moment & 1.01 \\
\hline Range & 4. & Third Moment & -0.73 \\
\hline Sum & 150. & Fourth Moment & 3.08 \\
\hline Sum Standard Error & 5.94 & Median & 5. \\
\hline Total Sum Squares & 696. & Median Error & 0.04 \\
\hline Adjusted Sum Squares & 34.24 & Percentile 25\% (Q1) & 4. \\
\hline Geometric Mean & 4.27 & Percentile 75\% (Q2) & 5. \\
\hline Harmonic Mean & 4.1 & IQR & 1. \\
\hline Mode & 5. & MAD (Median Absolute Deviation) & 1. \\
\hline & & Coefficient of Dispersion (COD) & 0.15 \\
\hline
\end{tabular}




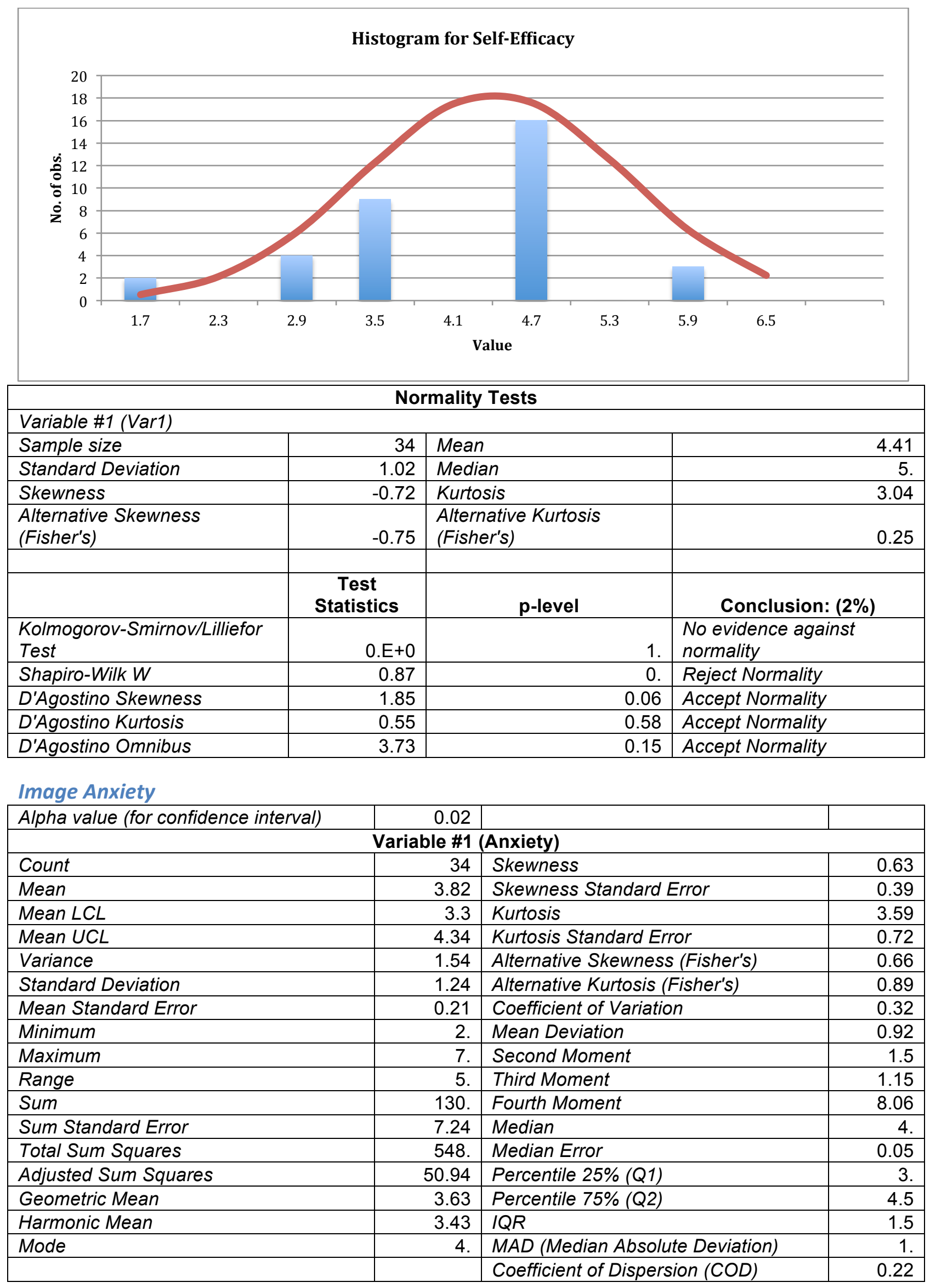




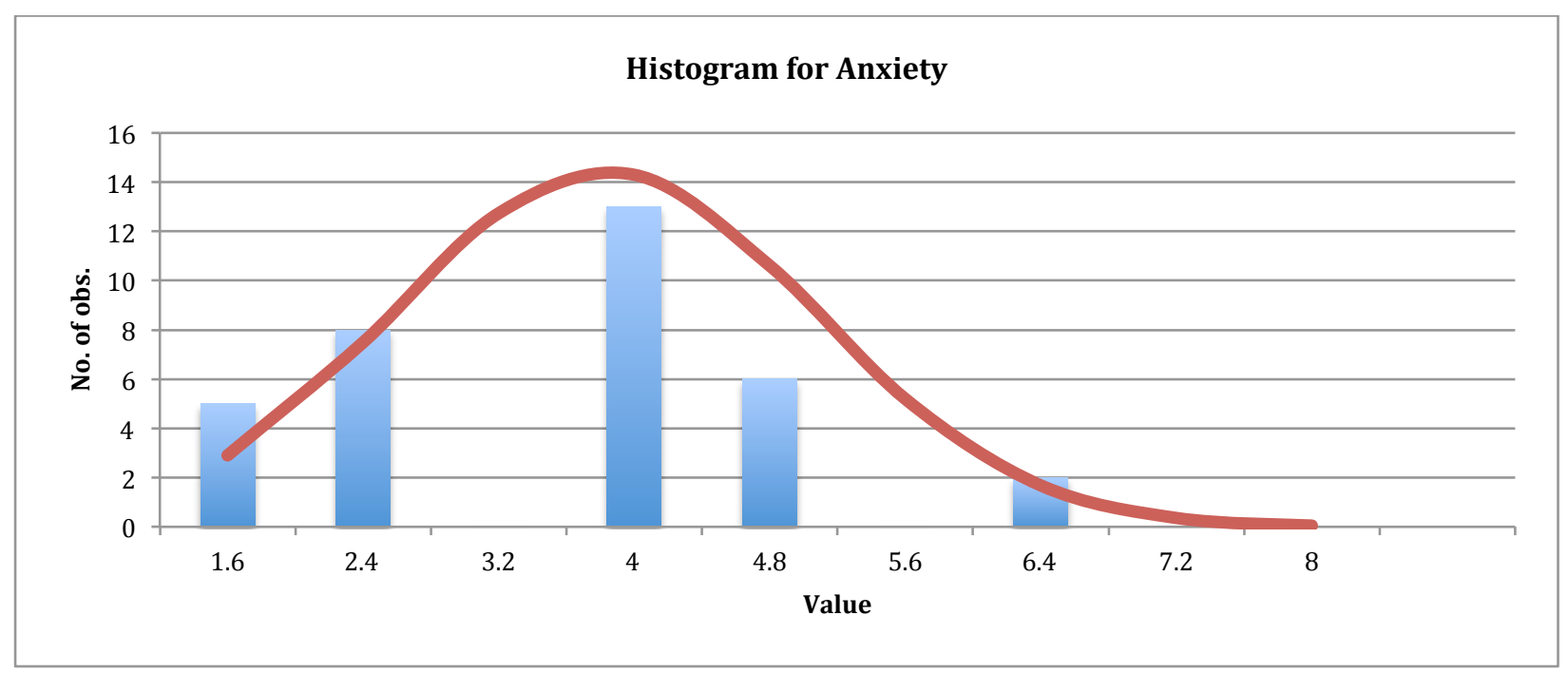

\begin{tabular}{|c|c|c|c|}
\hline \multicolumn{4}{|c|}{ Normality Tests } \\
\hline \multicolumn{4}{|l|}{ Variable \#1 (Var1) } \\
\hline Sample size & 34 & Mean & 3.82 \\
\hline Standard Deviation & 1.24 & Median & 4. \\
\hline Skewness & 0.63 & Kurtosis & 3.59 \\
\hline $\begin{array}{l}\text { Alternative Skewness } \\
\text { (Fisher's) }\end{array}$ & 0.66 & $\begin{array}{l}\text { Alternative Kurtosis } \\
\text { (Fisher's) }\end{array}$ & 0.89 \\
\hline & $\begin{array}{c}\text { Test } \\
\text { Statistics }\end{array}$ & p-level & Conclusion: (2\%) \\
\hline $\begin{array}{l}\text { Kolmogorov-Smirnov/Lilliefor } \\
\text { Test }\end{array}$ & $0 . E+0$ & 1. & $\begin{array}{l}\text { No evidence against } \\
\text { normality }\end{array}$ \\
\hline Shapiro-Wilk W & 0.89 & 0. & Reject Normality \\
\hline D'Agostino Skewness & 1.64 & 0.1 & Accept Normality \\
\hline D'Agostino Kurtosis & 1.2 & 0.23 & Accept Normality \\
\hline D'Agostino Omnibus & 4.13 & 0.13 & Accept Normality \\
\hline
\end{tabular}

Image Intention To Use

\begin{tabular}{|l|r|l|r|}
\hline \multicolumn{2}{|c|}{ Vlpha value (for confidence interval) } & 0.02 & \\
\hline Count & 34 & Skewness & -0.2 \\
\hline Mean & 4.21 & Skewness Standard Error & 0.39 \\
\hline Mean LCL & 3.69 & Kurtosis & 2. \\
\hline Mean UCL & 4.72 & Kurtosis Standard Error & 0.72 \\
\hline Variance & 1.5 & Alternative Skewness (Fisher's) & -0.21 \\
\hline Standard Deviation & 1.23 & Alternative Kurtosis (Fisher's) & -0.97 \\
\hline Mean Standard Error & 0.21 & Coefficient of Variation & 0.29 \\
\hline Minimum & 2. & Mean Deviation & 1.04 \\
\hline Maximum & 6. & Second Moment & 1.46 \\
\hline Range & 4. & Third Moment & -0.35 \\
\hline Sum & 143. & Fourth Moment & 4.24 \\
\hline Sum Standard Error & 7.15 & Median & 4. \\
\hline Total Sum Squares & 651. & Median Error & 0.05 \\
\hline Adjusted Sum Squares & 49.56 & Percentile 25\% (Q1) & 3. \\
\hline Geometric Mean & 4.01 & Percentile 75\% (Q2) & 5. \\
\hline Harmonic Mean & 3.8 & IQR & 2. \\
\hline Mode & 5. & MAD (Median Absolute Deviation) & 1. \\
\hline & & Coefficient of Dispersion (COD) & 0.26 \\
\hline
\end{tabular}




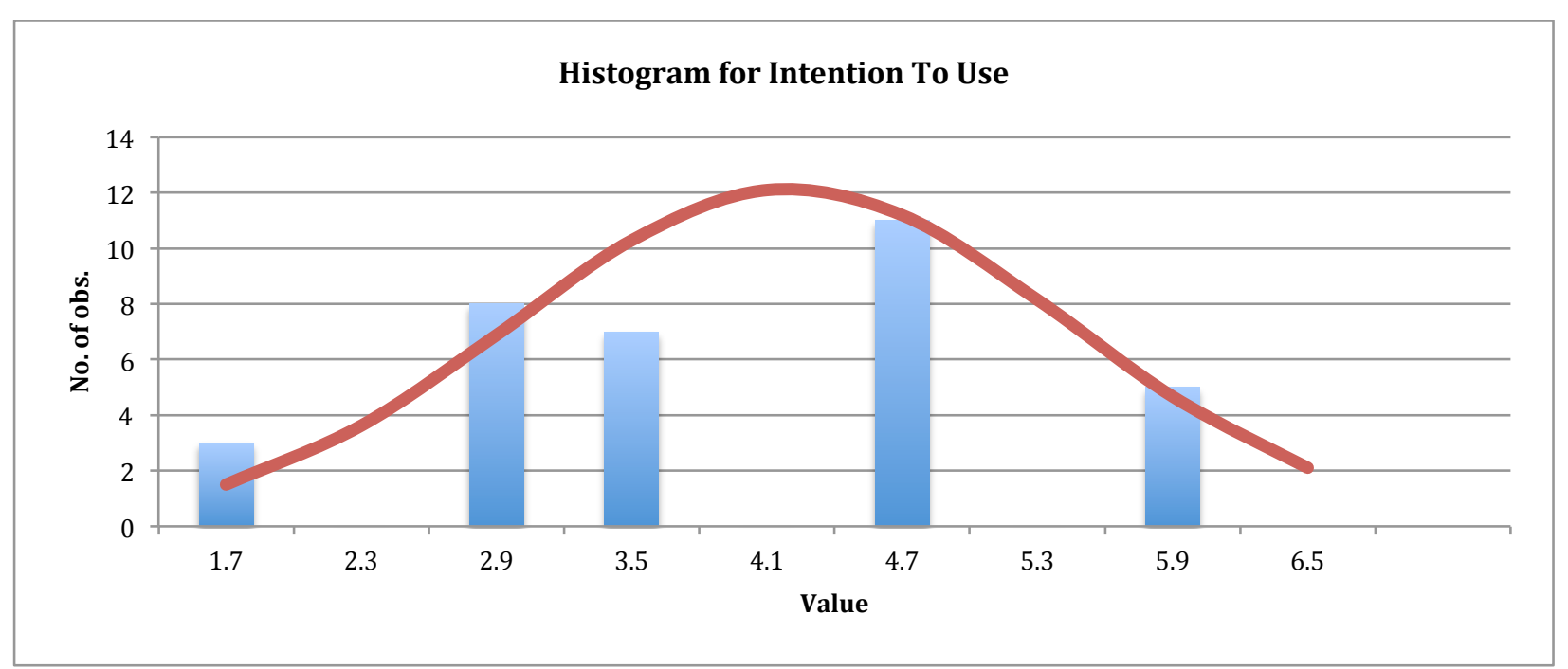

\begin{tabular}{|c|c|c|c|}
\hline \multirow{2}{*}{\multicolumn{4}{|c|}{ Normality Tests }} \\
\hline & & & \\
\hline Sample size & 34 & Mean & 4.21 \\
\hline Standard Deviation & 1.23 & Median & 4. \\
\hline Skewness & -0.2 & Kurtosis & 2. \\
\hline $\begin{array}{l}\text { Alternative Skewness } \\
\text { (Fisher's) }\end{array}$ & -0.21 & $\begin{array}{l}\text { Alternative Kurtosis } \\
\text { (Fisher's) }\end{array}$ & -0.97 \\
\hline & $\begin{array}{c}\text { Test } \\
\text { Statistics }\end{array}$ & p-level & Conclusion: (2\%) \\
\hline $\begin{array}{l}\text { Kolmogorov-Smirnov/Lilliefor } \\
\text { Test }\end{array}$ & $0 . E+0$ & 1. & $\begin{array}{l}\text { No evidence against } \\
\text { normality }\end{array}$ \\
\hline Shapiro-Wilk W & 0.91 & 0.01 & Reject Normality \\
\hline D'Agostino Skewness & 0.54 & 0.59 & Accept Normality \\
\hline D'Agostino Kurtosis & -1.74 & 0.08 & Accept Normality \\
\hline D'Agostino Omnibus & 3.33 & 0.19 & Accept Normality \\
\hline
\end{tabular}

\section{Diagram}

Diagram Performance Expectancy

\begin{tabular}{|l|r|l|r|}
\hline \multicolumn{2}{|c|}{ Vlpha value (for confidence interval) } & 0.02 & \\
\hline \multicolumn{2}{|c|}{ Variable } & (Performance Expectancy) \\
\hline Count & 34 & Skewness & 0.19 \\
\hline Mean & 4.62 & Skewness Standard Error & 0.39 \\
\hline Mean LCL & 4.22 & Kurtosis & 2.87 \\
\hline Mean UCL & 5.02 & Kurtosis Standard Error & 0.72 \\
\hline Variance & 0.91 & Alternative Skewness (Fisher's) & 0.2 \\
\hline Standard Deviation & 0.95 & Alternative Kurtosis (Fisher's) & 0.05 \\
\hline Mean Standard Error & 0.16 & Coefficient of Variation & 0.21 \\
\hline Minimum & 3. & Mean Deviation & 0.78 \\
\hline Maximum & 7. & Second Moment & 0.88 \\
\hline Range & 4. & Third Moment & 0.16 \\
\hline Sum & 157. & Fourth Moment & 2.24 \\
\hline Sum Standard Error & 5.56 & Median & 5. \\
\hline Total Sum Squares & 755. & Median Error & 0.04 \\
\hline Adjusted Sum Squares & 30.03 & Percentile 25\% (Q1) & 4. \\
\hline Geometric Mean & 4.52 & Percentile 75\% (Q2) & 5. \\
\hline Harmonic Mean & 4.42 & IQR & 1. \\
\hline Mode & 5. & MAD (Median Absolute Deviation) & 1. \\
\hline & & Coefficient of Dispersion (COD) & 0.15 \\
\hline
\end{tabular}




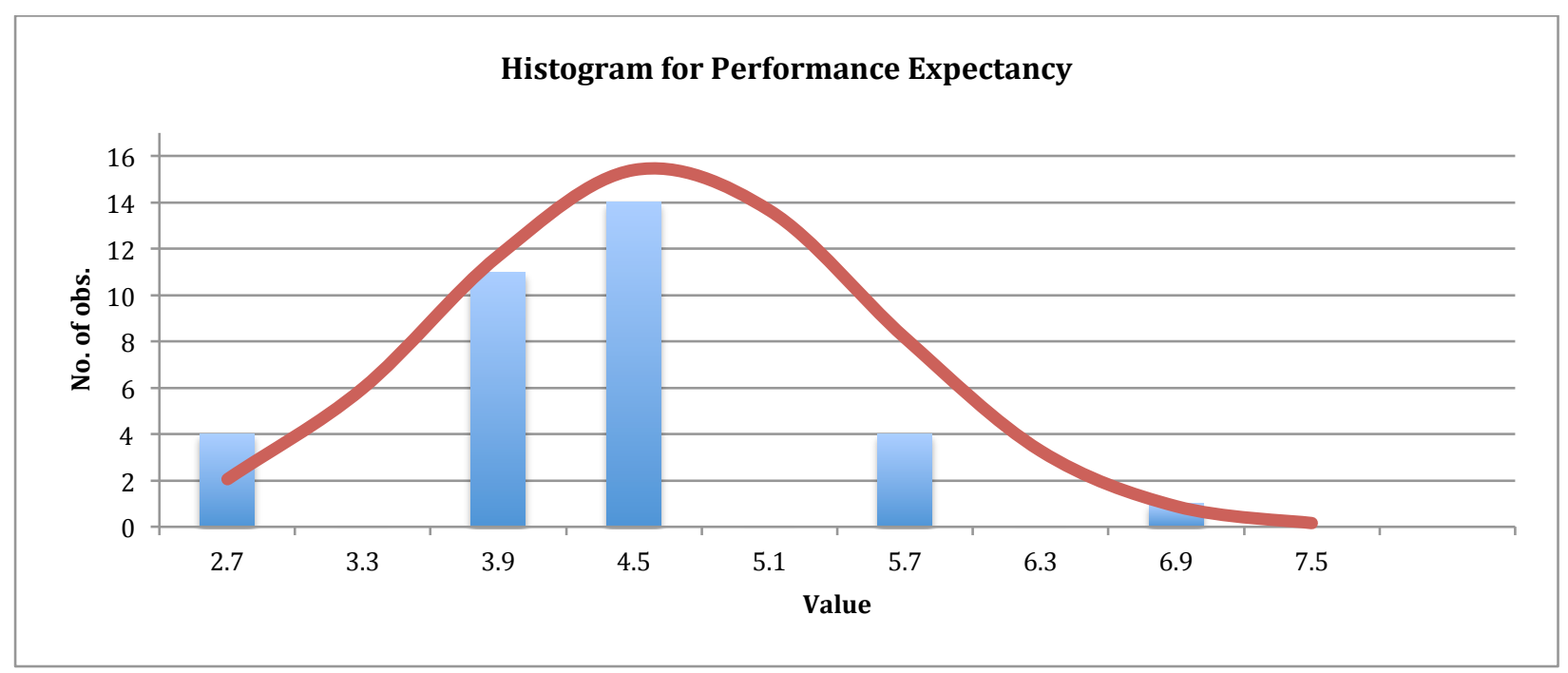

\begin{tabular}{|c|c|c|c|}
\hline \multicolumn{4}{|c|}{ Normality Tests } \\
\hline \multicolumn{4}{|l|}{ Variable \#1 (Var1) } \\
\hline Sample size & 34 & Mean & 4.62 \\
\hline Standard Deviation & 0.95 & Median & 5. \\
\hline Skewness & 0.19 & Kurtosis & 2.87 \\
\hline $\begin{array}{l}\text { Alternative Skewness } \\
\text { (Fisher's) }\end{array}$ & 0.2 & $\begin{array}{l}\text { Alternative Kurtosis } \\
\text { (Fisher's) }\end{array}$ & 0.05 \\
\hline & $\begin{array}{c}\text { Test } \\
\text { Statistics }\end{array}$ & p-level & Conclusion: (2\%) \\
\hline $\begin{array}{l}\text { Kolmogorov-Smirnov/Lilliefor } \\
\text { Test }\end{array}$ & $0 . E+0$ & & $\begin{array}{l}\text { No evidence against } \\
\text { normality }\end{array}$ \\
\hline Shapiro-Wilk W & 0.9 & & Reject Normality \\
\hline D'Agostino Skewness & 0.52 & & Accept Normality \\
\hline D'Agostino Kurtosis & 0.29 & & Accept Normality \\
\hline D'Agostino Omnibus & 0.36 & & Accept Normality \\
\hline
\end{tabular}

Diagram Effort Expectancy

\begin{tabular}{|c|c|c|c|}
\hline Alpha value (for confidence interval) & 0.02 & & \\
\hline \multicolumn{4}{|c|}{ Variable \#1 (Effort Expectancy) } \\
\hline Count & 34 & Skewness & -0.41 \\
\hline Mean & 5.06 & Skewness Standard Error & 0.39 \\
\hline Mean $L C L$ & 4.7 & Kurtosis & 3.66 \\
\hline Mean UCL & 5.42 & Kurtosis Standard Error & 0.72 \\
\hline Variance & 0.72 & Alternative Skewness (Fisher's) & -0.43 \\
\hline Standard Deviation & 0.85 & Alternative Kurtosis (Fisher's) & 0.97 \\
\hline Mean Standard Error & 0.15 & Coefficient of Variation & 0.17 \\
\hline Minimum & 3. & Mean Deviation & 0.56 \\
\hline Maximum & 7. & Second Moment & 0.7 \\
\hline Range & 4. & Third Moment & -0.24 \\
\hline Sum & 172. & Fourth Moment & 1.81 \\
\hline Sum Standard Error & 4.96 & Median & 5. \\
\hline Total Sum Squares & 894. & Median Error & 0.03 \\
\hline Adjusted Sum Squares & 23.88 & Percentile 25\% (Q1) & 5. \\
\hline Geometric Mean & 4.98 & Percentile 75\% (Q2) & 6. \\
\hline Harmonic Mean & 4.9 & $I Q R$ & 1. \\
\hline Mode & 5. & MAD (Median Absolute Deviation) & 0. \\
\hline & & Coefficient of Dispersion (COD) & 0.11 \\
\hline
\end{tabular}




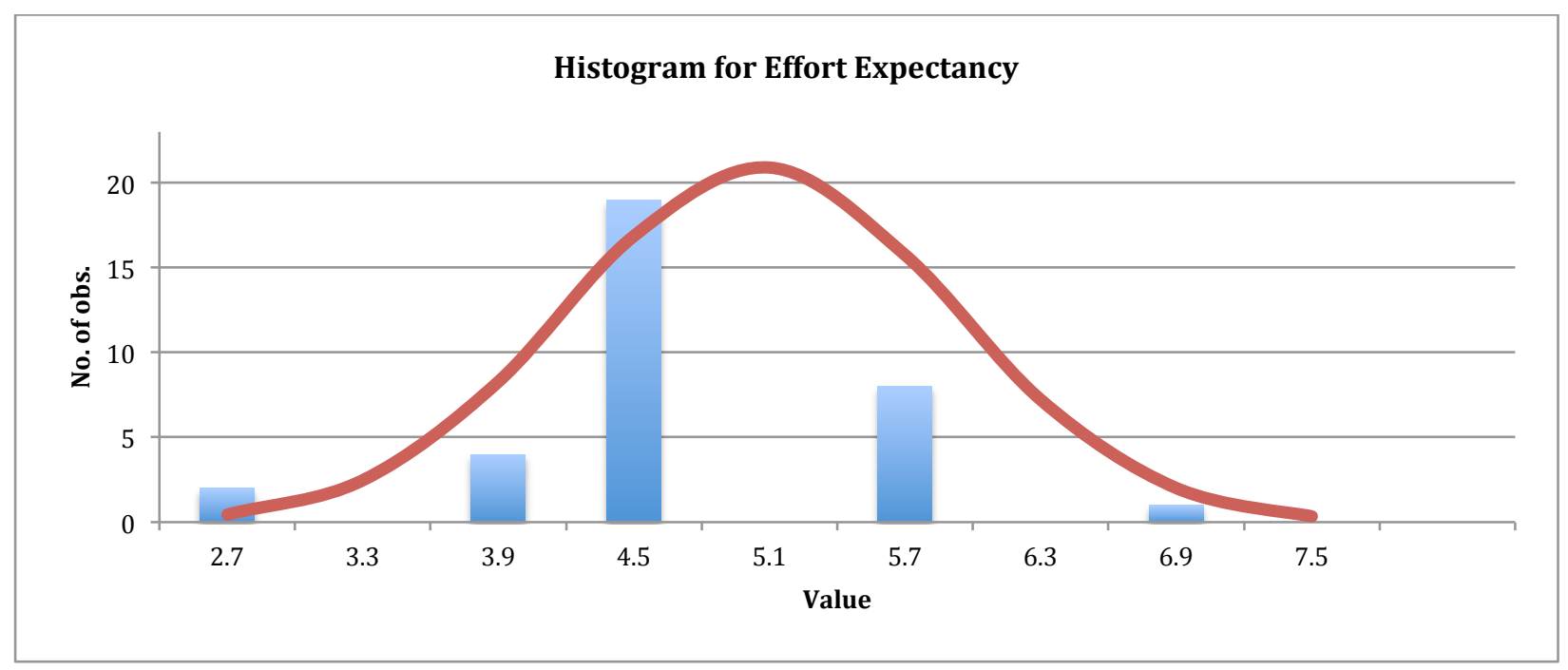

\begin{tabular}{|c|c|c|c|}
\hline \multicolumn{4}{|c|}{ Normality Tests } \\
\hline \multicolumn{4}{|l|}{ Variable \#1 (Var1) } \\
\hline Sample size & 34 & Mean & 5.06 \\
\hline Standard Deviation & 0.85 & Median & 5. \\
\hline Skewness & -0.41 & Kurtosis & 3.66 \\
\hline $\begin{array}{l}\text { Alternative Skewness } \\
\text { (Fisher's) }\end{array}$ & -0.43 & $\begin{array}{l}\text { Alternative Kurtosis } \\
\text { (Fisher's) }\end{array}$ & 0.97 \\
\hline & $\begin{array}{c}\text { Test } \\
\text { Statistics }\end{array}$ & p-level & Conclusion: (2\%) \\
\hline $\begin{array}{l}\text { Kolmogorov-Smirnov/Lilliefor } \\
\text { Test }\end{array}$ & $0 . E+0$ & & $\begin{array}{l}\text { No evidence against } \\
\text { normality }\end{array}$ \\
\hline Shapiro-Wilk W & 0.85 & & Reject Normality \\
\hline D'Agostino Skewness & 1.1 & 0.2 & Accept Normality \\
\hline D'Agostino Kurtosis & 1.27 & 0.2 & Accept Normality \\
\hline D'Agostino Omnibus & 2.83 & 0.2 & Accept Normality \\
\hline
\end{tabular}

Diagram Attitude Toward Using The Type Of Representation

\begin{tabular}{|l|r|l|r|}
\hline \multicolumn{2}{|c|}{ Vlpha value (for confidence interval) } & 0.02 & \\
\hline \multicolumn{2}{|c|}{ Variable \#1 (Attitude toward using the type of representation) } \\
\hline Count & 34 & Skewness & -0.06 \\
\hline Mean & 4.41 & Skewness Standard Error & 0.39 \\
\hline Mean LCL & 4.01 & Kurtosis & 3.83 \\
\hline Mean UCL & 4.81 & Kurtosis Standard Error & 0.72 \\
\hline Variance & 0.92 & Alternative Skewness (Fisher's) & -0.06 \\
\hline Standard Deviation & 0.96 & Alternative Kurtosis (Fisher's) & 1.17 \\
\hline Mean Standard Error & 0.16 & Coefficient of Variation & 0.22 \\
\hline Minimum & 2. & Mean Deviation & 0.76 \\
\hline Maximum & 7. & Second Moment & 0.89 \\
\hline Range & 5. & Third Moment & -0.05 \\
\hline Sum & 150. & Fourth Moment & 3.03 \\
\hline Sum Standard Error & 5.58 & Median & 4.5 \\
\hline Total Sum Squares & 692. & Median Error & 0.04 \\
\hline Adjusted Sum Squares & 30.24 & Percentile 25\% (Q1) & 4. \\
\hline Geometric Mean & 4.3 & Percentile 75\% (Q2) & 5. \\
\hline Harmonic Mean & 4.18 & IQR & 1. \\
\hline Mode & 5. & MAD (Median Absolute Deviation) & 0.5 \\
\hline & & Coefficient of Dispersion (COD) & 0.17 \\
\hline
\end{tabular}




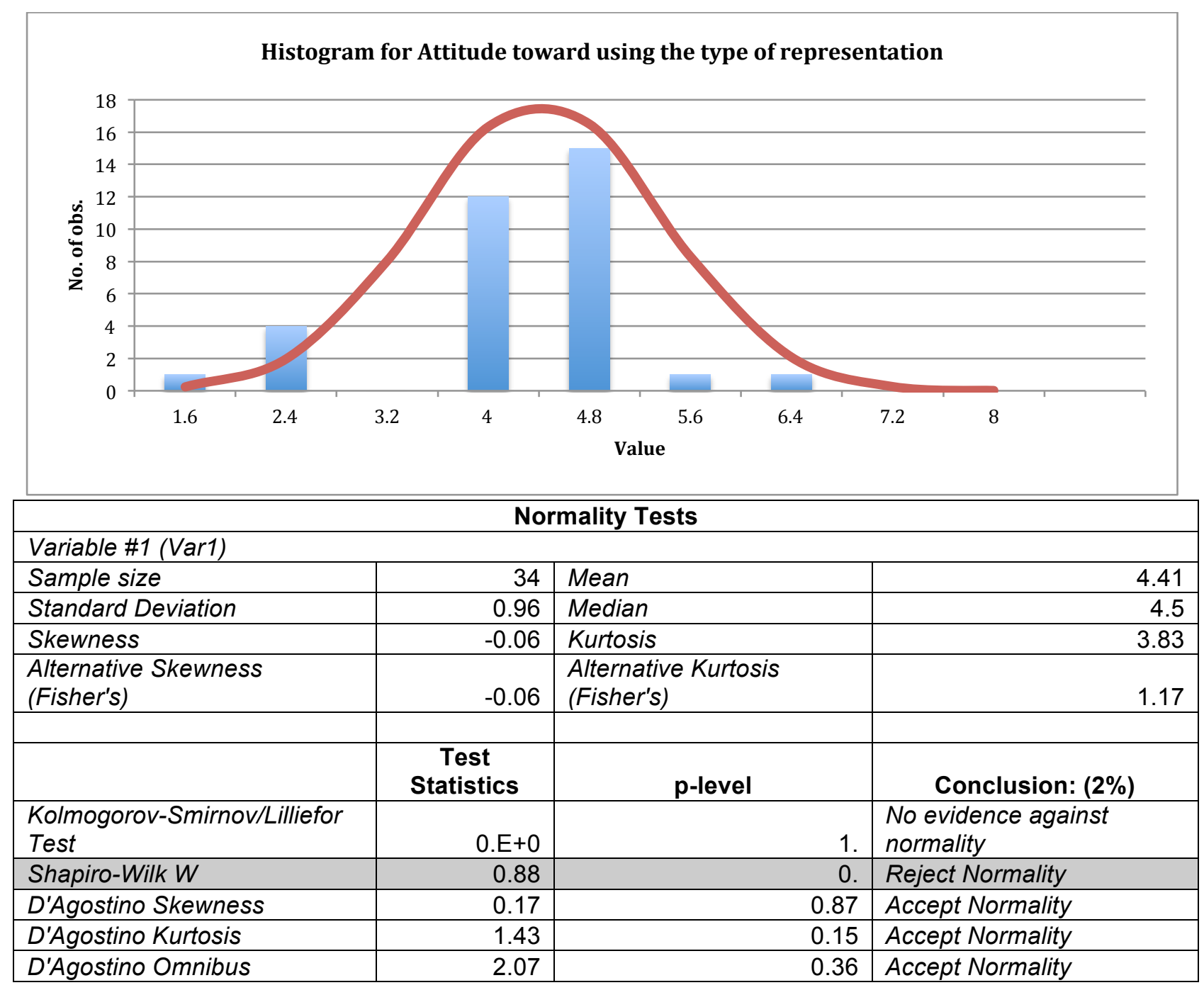

Diagram Social Influence

\begin{tabular}{|l|r|l|r|}
\hline \multicolumn{2}{|c|}{ Alpha value (for confidence interval) } & 0.02 & \\
\hline Count & 34 & Skewness & \\
\hline Mean & 4.24 & Skewness Standard Error & 0.89 \\
\hline Mean LCL & 3.89 & Kurtosis & 0.39 \\
\hline Mean UCL & 4.58 & Kurtosis Standard Error & 6.78 \\
\hline Variance & 0.67 & Alternative Skewness (Fisher's) & 0.72 \\
\hline Standard Deviation & 0.82 & Alternative Kurtosis (Fisher's) & 0.94 \\
\hline Mean Standard Error & 0.14 & Coefficient of Variation & 4.6 \\
\hline Minimum & 2. & Mean Deviation & 0.19 \\
\hline Maximum & 7. & Second Moment & 0.54 \\
\hline Range & 5. & Third Moment & 0.65 \\
\hline Sum & 144. & Fourth Moment & 0.47 \\
\hline Sum Standard Error & 4.77 & Median & 2.87 \\
\hline Total Sum Squares & 632. & Median Error & 4. \\
\hline Adjusted Sum Squares & 22.12 & Percentile 25\% (Q1) & 0.03 \\
\hline Geometric Mean & 4.16 & Percentile 75\% (Q2) & 4. \\
\hline Harmonic Mean & 4.08 & IQR & 4.5 \\
\hline Mode & 4. & MAD (Median Absolute Deviation) & 0.5 \\
\hline & & Coefficient of Dispersion (COD) & 0. \\
\hline
\end{tabular}




\begin{tabular}{|l|l|l|l|}
\hline \multicolumn{1}{|l|}{ Histogram for Social Influence } \\
\hline \\
\hline
\end{tabular}

\begin{tabular}{|c|c|c|c|c|c|}
\hline \multicolumn{6}{|c|}{ Histogram } \\
\hline No\# of valid case & & & & & 34 \\
\hline \multicolumn{6}{|c|}{ Results for layer \#1 } \\
\hline \multicolumn{4}{|c|}{ Frequency distribution of Social Influence } & & \\
\hline Social Influence & Count & Cumulative Count & Percent & Cumulative Percent & \\
\hline 1 To 2 & 1. & 1. & 0.03 & 0.03 & \\
\hline 2 To 3 & 1. & 2. & 0.03 & 0.06 & \\
\hline 3 To 4 & 24. & 26. & 0.71 & 0.76 & \\
\hline 4 To 5 & 6. & 32. & 0.18 & 0.94 & \\
\hline 5 To 6 & 1. & 33. & 0.03 & 0.97 & \\
\hline 6 To 7 & 1. & 34. & 0.03 & 1. & \\
\hline
\end{tabular}

The sample data is extremely concentrated around the 3 to 4 interval. Normality is rejected on three tests.

Diagram Facilitating Conditions

\begin{tabular}{|l|r|l|r|}
\hline \multicolumn{2}{|c|}{ Variable \#1 (Facilitating Conditions) } & \\
\hline Count & 34 & Skewness & -0.86 \\
\hline Mean & 4.71 & Skewness Standard Error & 0.39 \\
\hline Mean LCL & 4.29 & Kurtosis & 3.29 \\
\hline Mean UCL & 5.13 & Kurtosis Standard Error & 0.72 \\
\hline Variance & 1. & Alternative Skewness (Fisher's) & -0.9 \\
\hline Standard Deviation & 1. & Alternative Kurtosis (Fisher's) & 0.53 \\
\hline Mean Standard Error & 0.17 & Coefficient of Variation & 0.21 \\
\hline
\end{tabular}




\begin{tabular}{|l|r|l|r|} 
Minimum & 2. & Mean Deviation & 0.77 \\
\hline Maximum & 6. & Second Moment & 0.97 \\
\hline Range & 4. & Third Moment & -0.82 \\
\hline Sum & 160. & Fourth Moment & 3.11 \\
\hline Sum Standard Error & 5.84 & Median & 5. \\
\hline Total Sum Squares & 786. & Median Error & 0.04 \\
\hline Adjusted Sum Squares & 33.06 & Percentile 25\% (Q1) & 4. \\
\hline Geometric Mean & 4.58 & Percentile 75\% (Q2) & 5. \\
\hline Harmonic Mean & 4.43 & IQR & 1. \\
\hline Mode & 5. & MAD (Median Absolute Deviation) & 0. \\
\hline & & Coefficient of Dispersion (COD) & 0.13 \\
\hline
\end{tabular}

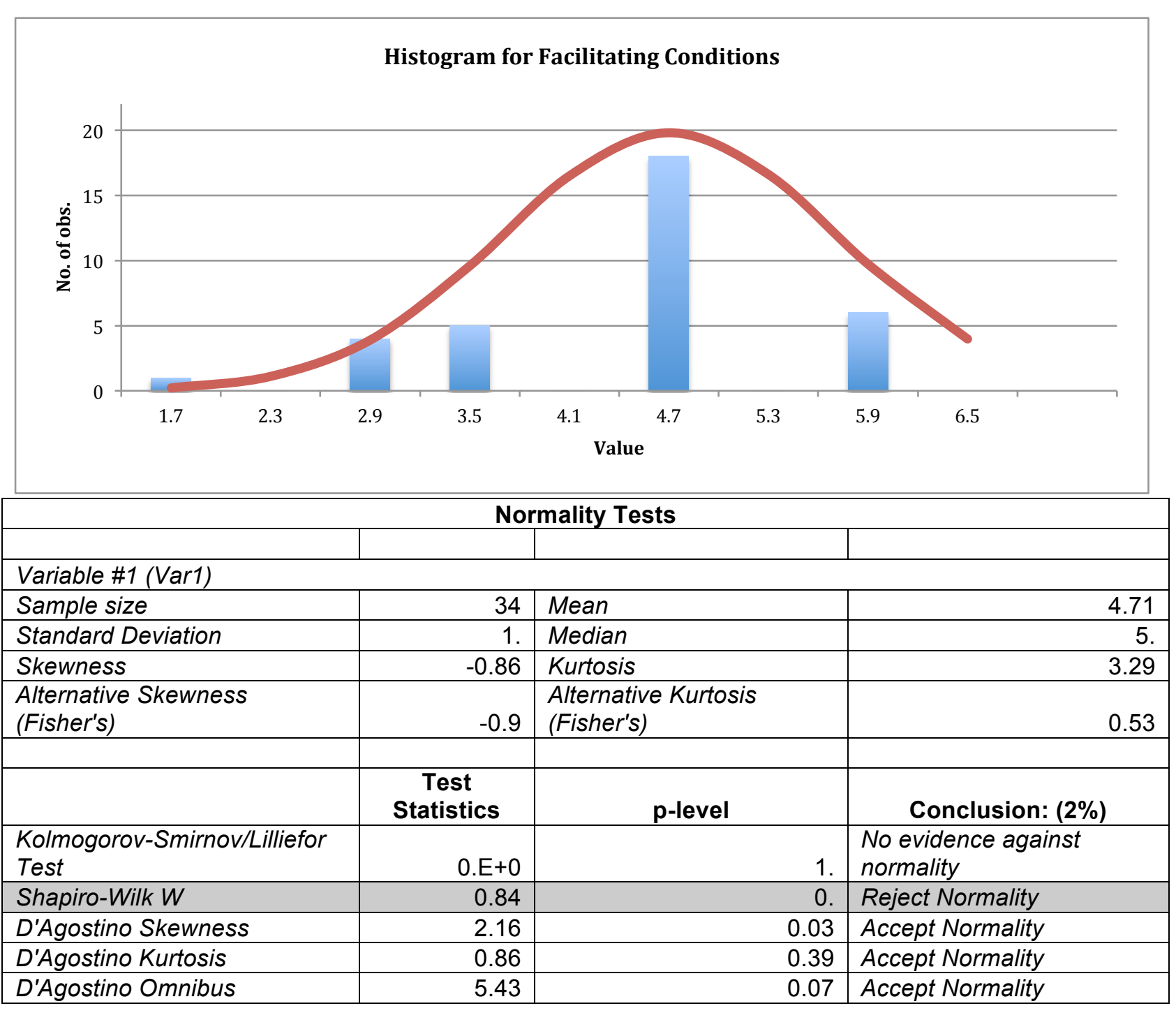

Diagram Self-Efficacy

\begin{tabular}{|l|r|l|r|}
\hline Alpha value (for confidence interval) & 0.02 & \\
\hline Count & Variable \#1 (Self-Efficacy) & 0.67 \\
\hline Mean & 34 & Skewness & 0.39 \\
\hline Mean LCL & 4.68 & Skewness Standard Error & 4.2 \\
\hline Mean UCL & 4.31 & Kurtosis & 0.72 \\
\hline Variance & 5.04 & Kurtosis Standard Error & 0.71 \\
\hline Standard Deviation & 0.77 & Alternative Skewness (Fisher's) & 1.59 \\
\hline Mean Standard Error & 0.88 & Alternative Kurtosis (Fisher's) & 0.19 \\
\hline Minimum & 0.15 & Coefficient of Variation & 0.67 \\
\hline Maximum & 3. & Mean Deviation & 0.75 \\
\hline Range & 7. & Second Moment & 0.44 \\
\hline
\end{tabular}


Page 74

\begin{tabular}{|l|r|l|r|} 
Sum & 159. & Fourth Moment & 2.35 \\
\hline Sum Standard Error & 5.12 & Median & 5. \\
\hline Total Sum Squares & 769. & Median Error & 0.03 \\
\hline Adjusted Sum Squares & 25.44 & Percentile 25\% (Q1) & 4. \\
\hline Geometric Mean & 4.6 & Percentile 75\% (Q2) & 5. \\
\hline Harmonic Mean & 4.52 & IQR & 1. \\
\hline Mode & 5. & MAD (Median Absolute Deviation) & 0.5 \\
\hline & & Coefficient of Dispersion (COD) & 0.12 \\
\hline
\end{tabular}

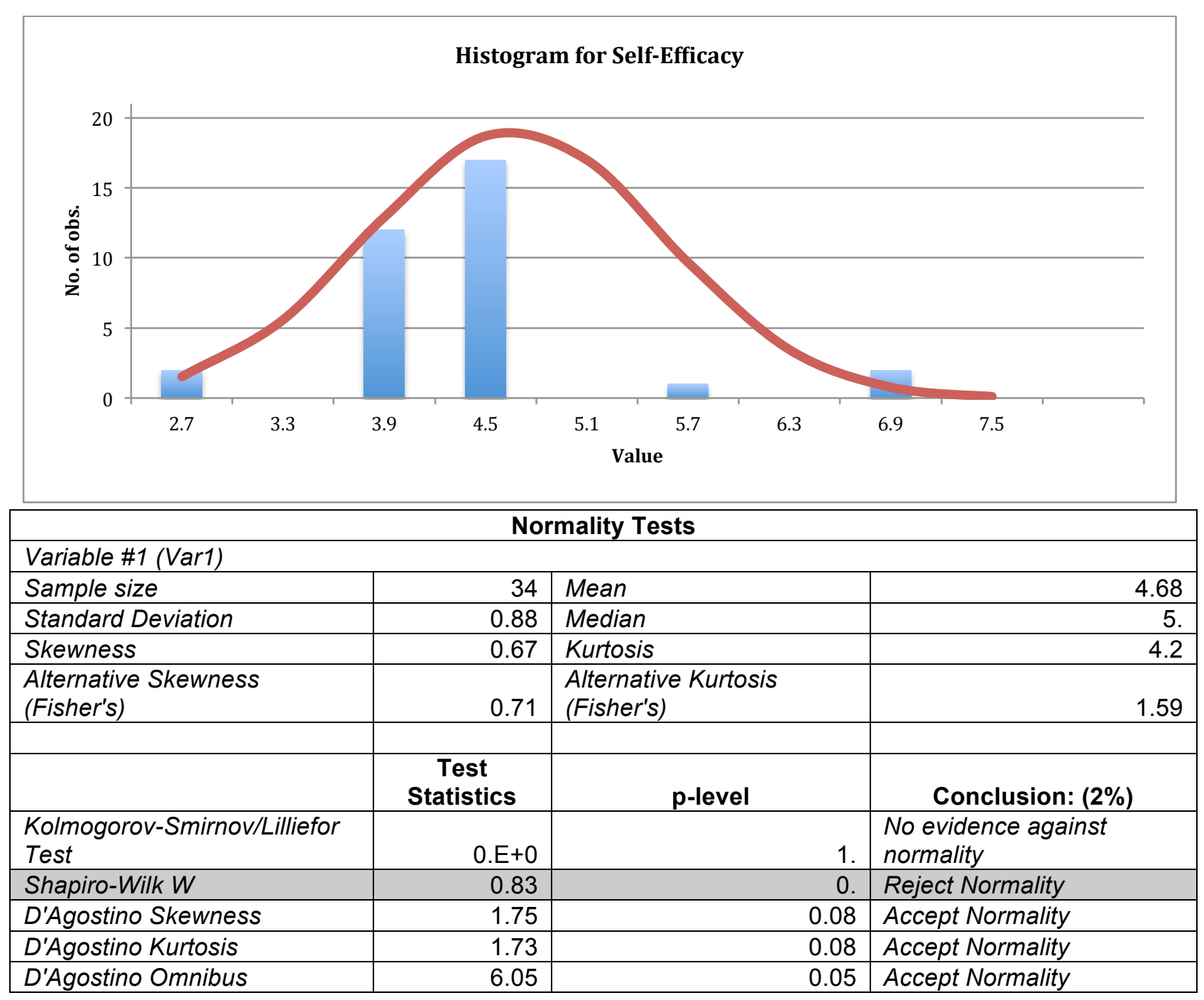

Diagram Anxiety

\begin{tabular}{|l|r|l|r|}
\hline Alpha value (for confidence interval) & 0.02 & \\
\hline & Variable \#1 (Anxiety) & 0.02 \\
\hline Count & 34 & Skewness & 0.39 \\
\hline Mean & 3.21 & Skewness Standard Error & 1.83 \\
\hline Mean LCL & 2.81 & Kurtosis & 0.72 \\
\hline Mean UCL & 3.6 & Kurtosis Standard Error & 0.02 \\
\hline Variance & 0.9 & Alternative Skewness (Fisher's) & -1.16 \\
\hline Standard Deviation & 0.95 & Alternative Kurtosis (Fisher's) & 0.3 \\
\hline Mean Standard Error & 0.16 & Coefficient of Variation & 0.82 \\
\hline Minimum & 2. & Mean Deviation & 0.87 \\
\hline Maximum & 5. & Second Moment & 0.01 \\
\hline Range & 3. & Third Moment & 1.38 \\
\hline Sum & 109. & Fourth Moment & 3. \\
\hline Sum Standard Error & 5.52 & Median & 0.03 \\
\hline Total Sum Squares & 379. & Median Error &
\end{tabular}




\begin{tabular}{|l|r|l|r|} 
Adjusted Sum Squares & 29.56 & Percentile 25\% (Q1) & 2. \\
\hline Geometric Mean & 3.06 & Percentile 75\% (Q2) & 4. \\
\hline Harmonic Mean & 2.92 & IQR & 2. \\
\hline Mode & 4. & MAD (Median Absolute Deviation) & 1. \\
\hline & & Coefficient of Dispersion (COD) & 0.26 \\
\hline
\end{tabular}

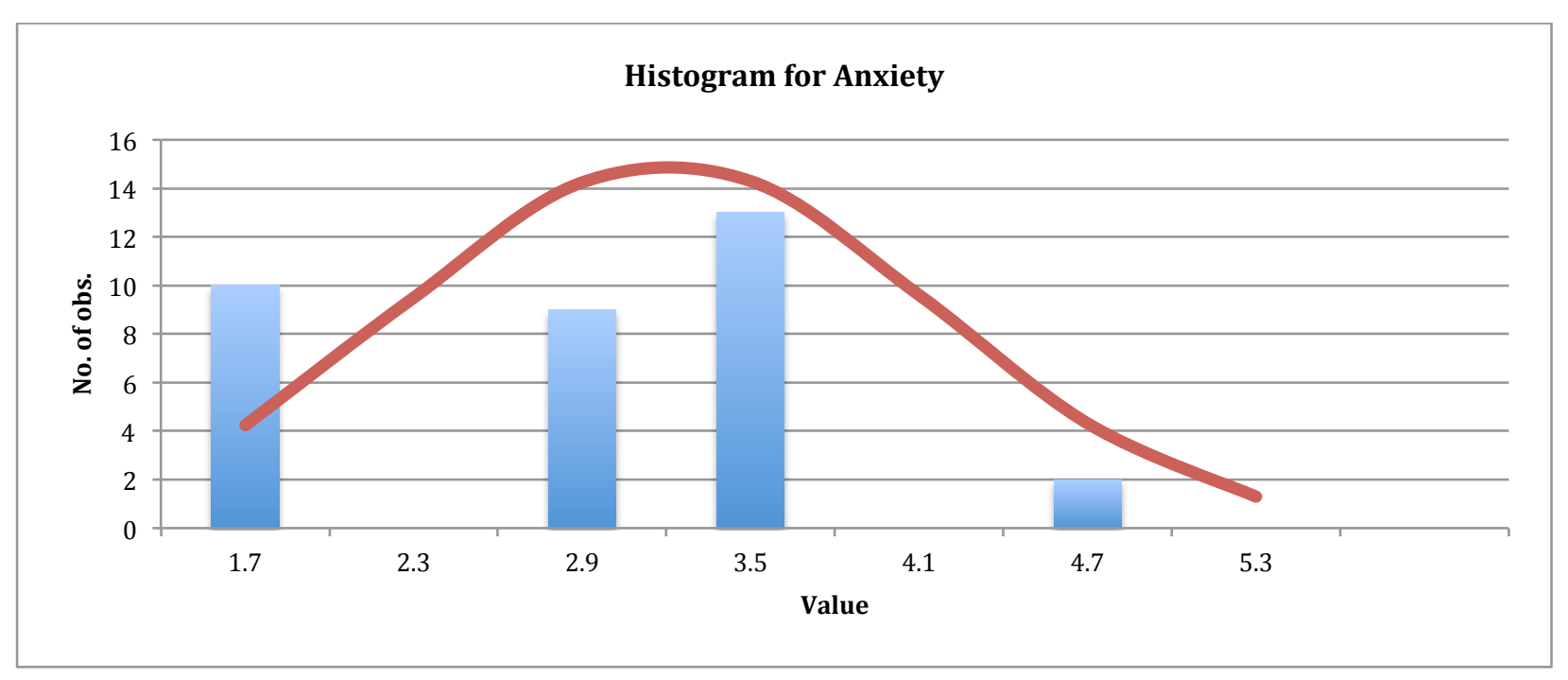

\begin{tabular}{|c|c|c|c|}
\hline \multicolumn{4}{|c|}{ Normality Tests } \\
\hline \multicolumn{4}{|l|}{ Variable \#1 (Var1) } \\
\hline Sample size & 34 & Mean & 3.21 \\
\hline Standard Deviation & 0.95 & Median & 3. \\
\hline Skewness & 0.02 & Kurtosis & 1.83 \\
\hline $\begin{array}{l}\text { Alternative Skewness } \\
\text { (Fisher's) }\end{array}$ & 0.02 & $\begin{array}{l}\text { Alternative Kurtosis } \\
\text { (Fisher's) }\end{array}$ & -1.16 \\
\hline & $\begin{array}{c}\text { Test } \\
\text { Statistics }\end{array}$ & p-level & Conclusion: (2\%) \\
\hline $\begin{array}{l}\text { Kolmogorov-Smirnov/Lilliefor } \\
\text { Test }\end{array}$ & $0 . E+0$ & 1. & $\begin{array}{l}\text { No evidence against } \\
\text { normality }\end{array}$ \\
\hline Shapiro-Wilk W & 0.85 & 0. & Reject Normality \\
\hline D'Agostino Skewness & 0.04 & 0.96 & Accept Normality \\
\hline D'Agostino Kurtosis & -2.41 & 0.02 & Reject Normality \\
\hline D'Agostino Omnibus & 5.79 & 006 & Accept Normality \\
\hline
\end{tabular}

\begin{tabular}{|c|c|c|c|c|c|}
\hline \multicolumn{6}{|c|}{ Histogram } \\
\hline No\# of valid cases & & & & & 34 \\
\hline \multicolumn{6}{|c|}{ Results for layer \#1 } \\
\hline \multicolumn{4}{|c|}{ Frequency distribution of Anxiety } & & \\
\hline Anxiety & Count & Cumulative Count & Percent & Cumulative Percent & \\
\hline 1 To 2 & 10. & 10. & 0.29 & 0.29 & \\
\hline 2 To 3 & 9. & 19. & 0.26 & 0.56 & \\
\hline 3 To 4 & 13. & 32. & 0.38 & 0.94 & \\
\hline 4 To 5 & 2. & 34. & 0.06 & 1. & \\
\hline
\end{tabular}

The data values are highly concentrated at the lower intervals. Normality is rejected on two tests.

Diagram Intention to use

\begin{tabular}{|l|r|l|r|}
\hline \multicolumn{2}{|c|}{ Alpha value (for confidence interval) } & 0.02 & \\
\hline \multicolumn{2}{|c|}{ Variable \#1 (Intention To Use) } \\
\hline Count & 34 & Skewness & -0.53 \\
\hline Mean & 4.21 & Skewness Standard Error & 0.39 \\
\hline Mean LCL & 3.59 & Kurtosis & 2.98 \\
\hline
\end{tabular}




\begin{tabular}{|l|r|l|r|} 
Mean UCL & 4.82 & Kurtosis Standard Error & 0.72 \\
\hline Variance & 2.17 & Alternative Skewness (Fisher's) & -0.56 \\
\hline Standard Deviation & 1.47 & Alternative Kurtosis (Fisher's) & 0.17 \\
\hline Mean Standard Error & 0.25 & Coefficient of Variation & 0.35 \\
\hline Minimum & 1. & Mean Deviation & 1.16 \\
\hline Maximum & 7. & Second Moment & 2.1 \\
\hline Range & 6. & Third Moment & -1.63 \\
\hline Sum & 143. & Fourth Moment & 13.19 \\
\hline Sum Standard Error & 8.59 & Median & 4. \\
\hline Total Sum Squares & 673. & Median Error & 0.05 \\
\hline Adjusted Sum Squares & 71.56 & Percentile 25\% (Q1) & 3. \\
\hline Geometric Mean & 3.84 & Percentile 75\% (Q2) & 5. \\
\hline Harmonic Mean & 3.3 & IQR & 2. \\
\hline Mode & 5. & MAD (Median Absolute Deviation) & 1. \\
\hline & & Coefficient of Dispersion (COD) & 0.29 \\
\hline
\end{tabular}

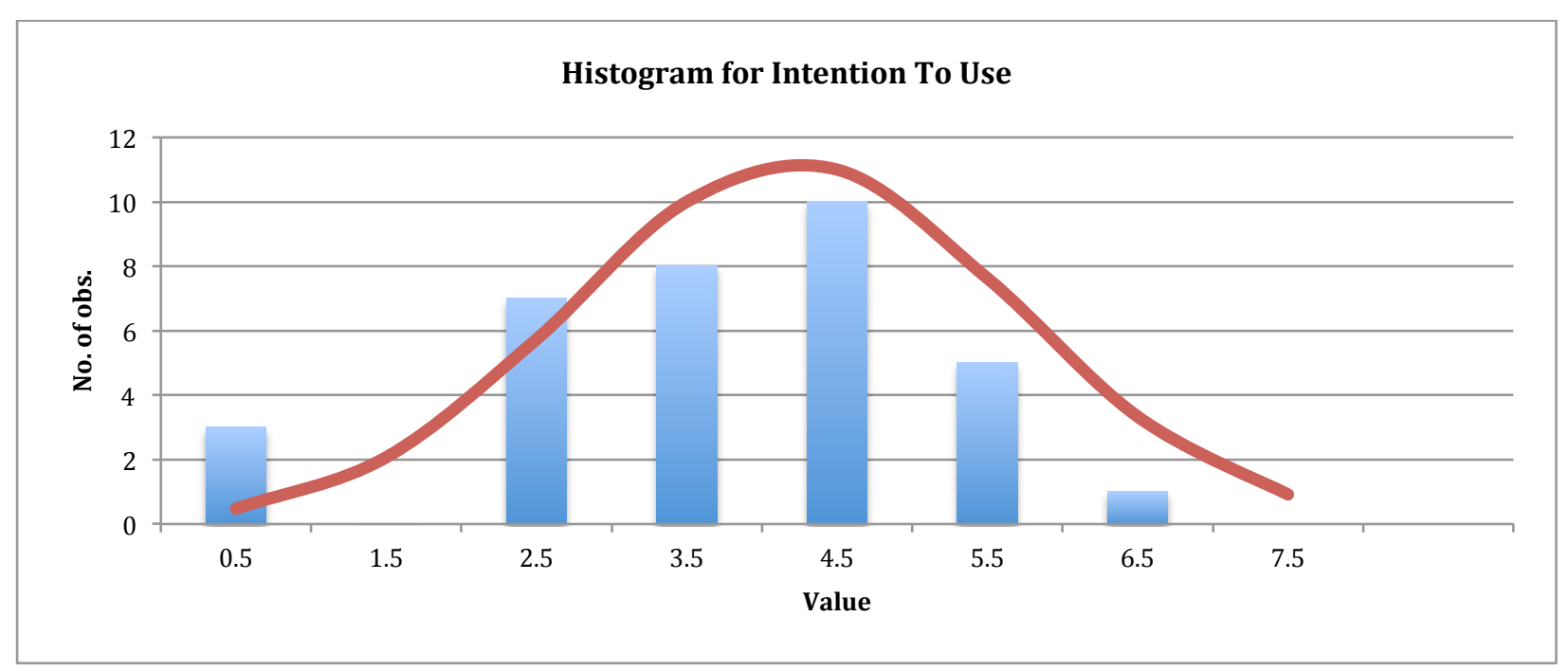

\begin{tabular}{|c|c|c|c|}
\hline \multicolumn{4}{|c|}{ Normality Tests } \\
\hline Variable \#1 (Var1) & & & \\
\hline Sample size & 34 & Mean & 4.21 \\
\hline Standard Deviation & 1.47 & Median & 4. \\
\hline Skewness & -0.53 & Kurtosis & 2.98 \\
\hline $\begin{array}{l}\text { Alternative Skewness } \\
\text { (Fisher's) }\end{array}$ & -0.56 & $\begin{array}{l}\text { Alternative Kurtosis } \\
\text { (Fisher's) }\end{array}$ & 0.17 \\
\hline & $\begin{array}{c}\text { Test } \\
\text { Statistics }\end{array}$ & p-level & Conclusion: (2\%) \\
\hline $\begin{array}{l}\text { Kolmogorov-Smirnov/Lilliefor } \\
\text { Test }\end{array}$ & $0 . E+0$ & 1. & $\begin{array}{l}\text { No evidence against } \\
\text { normality }\end{array}$ \\
\hline Shapiro-Wilk W & 0.92 & 0.02 & Reject Normality \\
\hline D'Agostino Skewness & 1.42 & 0.16 & Accept Normality \\
\hline D'Agostino Kurtosis & 0.46 & 0.65 & Accept Normality \\
\hline D'Agostino Omnibus & 2.21 & 0.33 & Accept Normality \\
\hline
\end{tabular}

Video

Video Performance Expectancy

\begin{tabular}{|l|r|l|r|}
\hline \multicolumn{2}{|c|}{ Alpha value (for confidence interval) } & 0.02 & \\
\hline \multicolumn{2}{|c|}{ Variable \#1 (Performance Expectancy) } \\
\hline Count & 34 & Skewness & -0.09 \\
\hline Mean & 3.24 & Skewness Standard Error & 0.39 \\
\hline Mean LCL & 2.65 & Kurtosis & 2.51 \\
\hline Mean UCL & 3.82 & Kurtosis Standard Error & 0.72 \\
\hline
\end{tabular}




\begin{tabular}{|l|r|l|r|} 
Variance & 1.94 & Alternative Skewness (Fisher's) & -0.09 \\
\hline Standard Deviation & 1.39 & Alternative Kurtosis (Fisher's) & -0.37 \\
\hline Mean Standard Error & 0.24 & Coefficient of Variation & 0.43 \\
\hline Minimum & 1. & Mean Deviation & 1.09 \\
\hline Maximum & 6. & Second Moment & 1.89 \\
\hline Range & 5. & Third Moment & -0.23 \\
\hline Sum & 110. & Fourth Moment & 8.94 \\
\hline Sum Standard Error & 8.13 & Median & 3. \\
\hline Total Sum Squares & 420. & Median Error & 0.05 \\
\hline Adjusted Sum Squares & 64.12 & Percentile 25\% (Q1) & 3. \\
\hline Geometric Mean & 2.86 & Percentile 75\% (Q2) & 4. \\
\hline Harmonic Mean & 2.41 & IQR & 1. \\
\hline Mode & 3. & MAD (Median Absolute Deviation) & 1. \\
\hline & & Coefficient of Dispersion (COD) & 0.35 \\
\hline
\end{tabular}

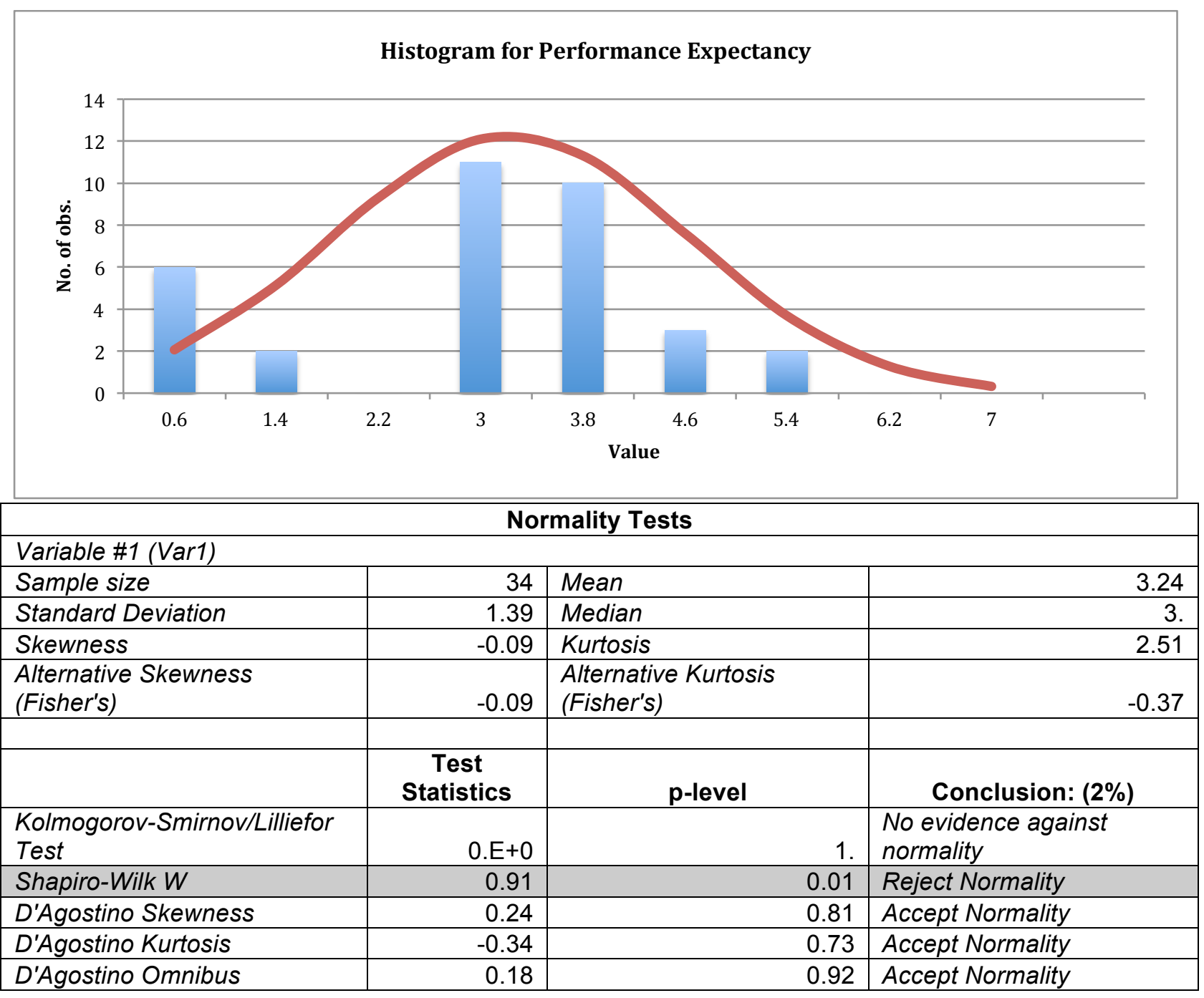

Video Effort Expectancy

\begin{tabular}{|l|r|l|r|}
\hline \multicolumn{2}{|c|}{ Alpha value (for confidence interval) } & 0.02 & \\
\hline \multicolumn{2}{|c|}{ Variable \#1 (Effort Expectancy) } \\
\hline Count & 34 & Skewness & 0.25 \\
\hline Mean & 4.56 & Skewness Standard Error & 0.39 \\
\hline Mean LCL & 3.96 & Kurtosis & 1.93 \\
\hline Mean UCL & 5.16 & Kurtosis Standard Error & 0.72 \\
\hline Variance & 2.07 & Alternative Skewness (Fisher's) & 0.26 \\
\hline Standard Deviation & 1.44 & Alternative Kurtosis (Fisher's) & -1.05 \\
\hline
\end{tabular}




\begin{tabular}{|l|r|l|r|} 
Mean Standard Error & 0.25 & Coefficient of Variation & 0.32 \\
\hline Minimum & 2. & Mean Deviation & 1.24 \\
\hline Maximum & 7. & Second Moment & 2.01 \\
\hline Range & 5. & Third Moment & 0.72 \\
\hline Sum & 155. & Fourth Moment & 7.79 \\
\hline Sum Standard Error & 8.39 & Median & 4. \\
\hline Total Sum Squares & 775. & Median Error & 0.05 \\
\hline Adjusted Sum Squares & 68.38 & Percentile 25\% (Q1) & 3. \\
\hline Geometric Mean & 4.33 & Percentile 75\% (Q2) & 6. \\
\hline Harmonic Mean & 4.11 & IQR & 3. \\
\hline Mode & 3. & MAD (Median Absolute Deviation) & 1. \\
\hline & & Coefficient of Dispersion (COD) & 0.3 \\
\hline
\end{tabular}

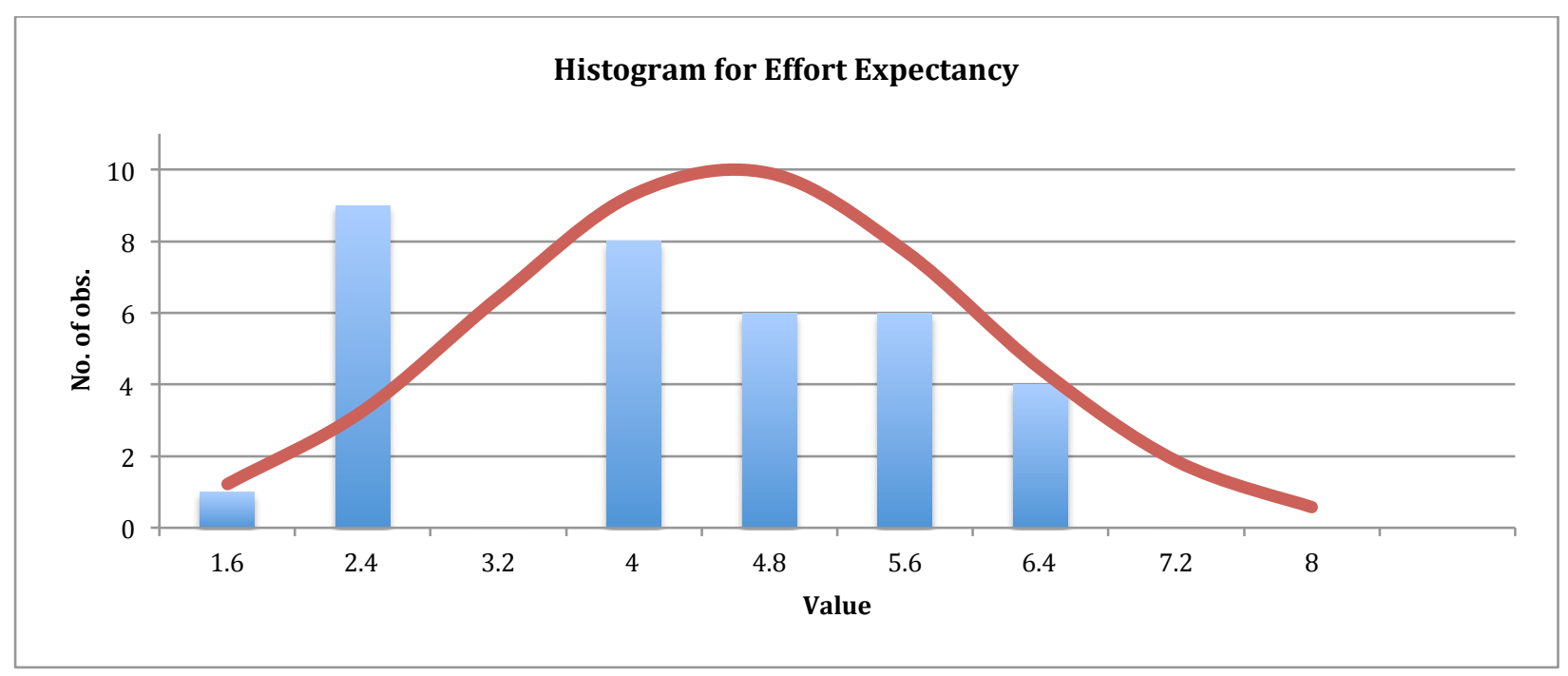

\begin{tabular}{|c|c|c|c|}
\hline \multicolumn{4}{|c|}{ Normality Tests } \\
\hline \multicolumn{4}{|l|}{ Variable \#1 (Var1) } \\
\hline Sample size & 34 & Mean & 4.56 \\
\hline Standard Deviation & 1.44 & Median & 4. \\
\hline Skewness & 0.25 & Kurtosis & 1.93 \\
\hline $\begin{array}{l}\text { Alternative Skewness } \\
\text { (Fisher's) }\end{array}$ & 0.26 & $\begin{array}{l}\text { Alternative Kurtosis } \\
\text { (Fisher's) }\end{array}$ & -1.05 \\
\hline & $\begin{array}{c}\text { Test } \\
\text { Statistics }\end{array}$ & p-level & Conclusion: (2\%) \\
\hline $\begin{array}{l}\text { Kolmogorov-Smirnov/Lilliefor } \\
\text { Test }\end{array}$ & $0 . E+0$ & & $\begin{array}{l}\text { No evidence against } \\
\text { normality }\end{array}$ \\
\hline Shapiro-Wilk W & 0.91 & 0.1 & Reject Normality \\
\hline D'Agostino Skewness & 0.69 & 0.4 & Accept Normality \\
\hline D'Agostino Kurtosis & -2 & 0. & Accept Normality \\
\hline D'Agostino Omnibus & 4.48 & 0 . & Accept Normality \\
\hline
\end{tabular}

Video Attitude Toward Using The Type Of Representation

\begin{tabular}{|l|r|l|r|}
\hline \multicolumn{2}{|c|}{ Variable \#1 (Attitude toward using the type of representation) } & \\
\hline Count & 34 & Skewness & -0.96 \\
\hline Mean & 4.06 & Skewness Standard Error & 0.39 \\
\hline Mean LCL & 3.58 & Kurtosis & 4.14 \\
\hline Mean UCL & 4.54 & Kurtosis Standard Error & 0.72 \\
\hline Variance & 1.33 & Alternative Skewness (Fisher's) & -1. \\
\hline Standard Deviation & 1.15 & Alternative Kurtosis (Fisher's) & 1.52 \\
\hline Mean Standard Error & 0.2 & Coefficient of Variation & 0.28 \\
\hline
\end{tabular}




\begin{tabular}{|l|r|l|r|} 
Minimum & 1. & Mean Deviation & 0.78 \\
\hline Maximum & 6. & Second Moment & 1.29 \\
\hline Range & 5. & Third Moment & -1.4 \\
\hline Sum & 138. & Fourth Moment & 6.89 \\
\hline Sum Standard Error & 6.72 & Median & 4. \\
\hline Total Sum Squares & 604. & Median Error & 0.04 \\
\hline Adjusted Sum Squares & 43.88 & Percentile 25\% (Q1) & 4. \\
\hline Geometric Mean & 3.82 & Percentile 75\% (Q2) & 5. \\
\hline Harmonic Mean & 3.43 & IQR & 1. \\
\hline Mode & 4. & MAD (Median Absolute Deviation) & 1. \\
\hline & & Coefficient of Dispersion (COD) & 0.19 \\
\hline
\end{tabular}

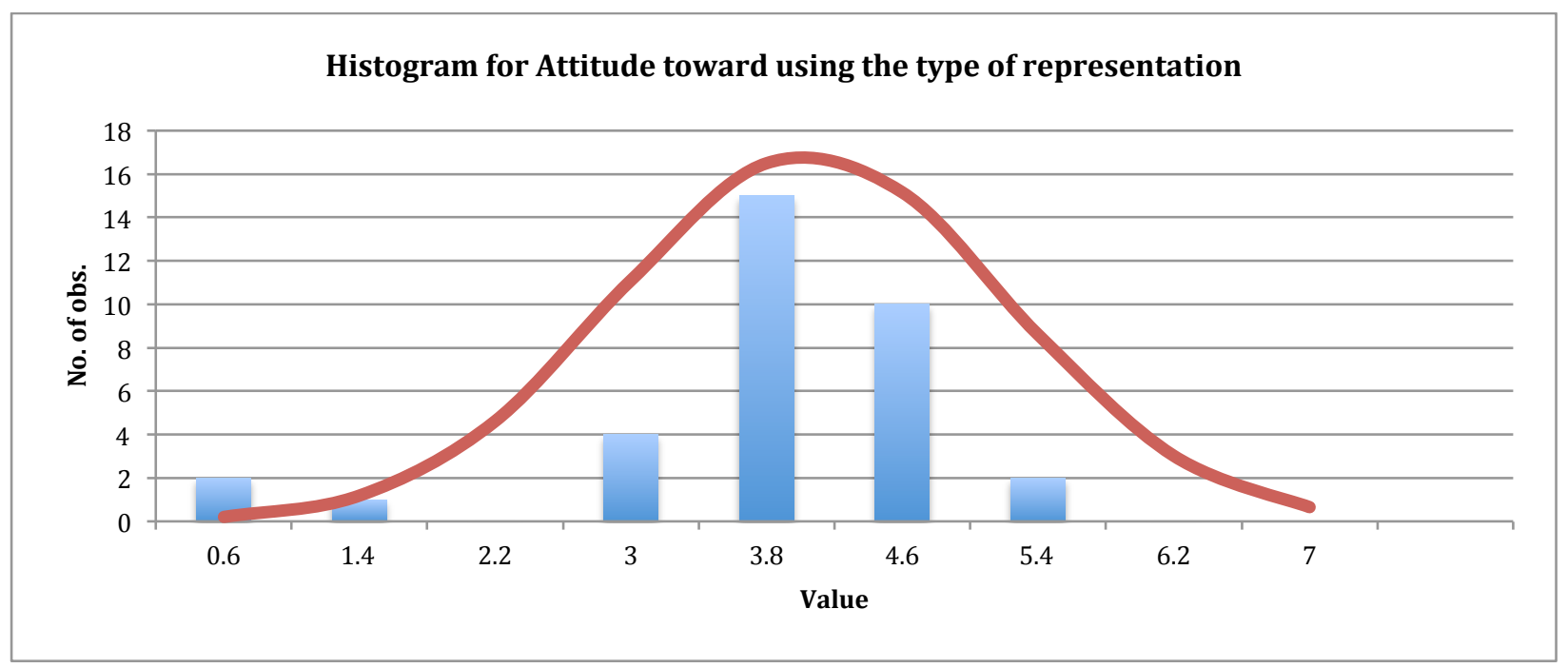

\begin{tabular}{|c|c|c|c|}
\hline \multicolumn{4}{|c|}{ Normality Tests } \\
\hline \multicolumn{4}{|l|}{ Variable \#1 (Var1) } \\
\hline Sample size & 34 & Mean & 4.06 \\
\hline Standard Deviation & 1.15 & Median & 4. \\
\hline Skewness & -0.96 & Kurtosis & 4.14 \\
\hline $\begin{array}{l}\text { Alternative Skewness } \\
\text { (Fisher's) }\end{array}$ & -1 & $\begin{array}{l}\text { Alternative Kurtosis } \\
\text { (Fisher's) }\end{array}$ & 1.52 \\
\hline & $\begin{array}{c}\text { Test } \\
\text { Statistics }\end{array}$ & p-level & Conclusion: (2\%) \\
\hline $\begin{array}{l}\text { Kolmogorov-Smirnov/Lilliefor } \\
\text { Test }\end{array}$ & $0 . E+0$ & & $\begin{array}{l}\text { No evidence against } \\
\text { normality }\end{array}$ \\
\hline Shapiro-Wilk W & 0.86 & & Reject Normality \\
\hline D'Agostino Skewness & 2.37 & & Reject Normality \\
\hline D'Agostino Kurtosis & 1.68 & & Accept Normality \\
\hline D'Agostino Omnibus & 8.47 & & Reject Normality \\
\hline
\end{tabular}

\begin{tabular}{|c|c|c|c|c|c|}
\hline \multicolumn{6}{|c|}{ Histogram } \\
\hline No\# of valid cases & & & & & 34 \\
\hline \multicolumn{6}{|c|}{ Results for layer \#1 } \\
\hline \multicolumn{6}{|c|}{ Frequency distribution of Attitude toward using the type of representation } \\
\hline $\begin{array}{l}\text { Attitude toward using } \\
\text { the type of representation }\end{array}$ & Count & Cumulative Count & Percent & Cumulative Percent & \\
\hline Up To 1 & 2. & 2. & 0.06 & 0.06 & \\
\hline 1 To 2 & 1. & 3. & 0.03 & 0.09 & \\
\hline 2 To 3 & 4. & 7. & 0.12 & 0.21 & \\
\hline 3 To 4 & 15. & 22. & 0.44 & 0.65 & \\
\hline 4 To 5 & 10. & 32. & 0.29 & 0.94 & \\
\hline 5 To 6 & 2. & 34. & 0.06 & 1. & \\
\hline
\end{tabular}


The data sample values are highly concentrated in the 3 to 4 and 4 to 5 intervals. Normality is rejected on three tests.

Video Social Influence

\begin{tabular}{|l|r|l|r|}
\hline \multicolumn{2}{|c|}{ Vlpha value (for confidence interval) } & 0.02 & \\
\hline Count & 34 & Skewness & -0.38 \\
\hline Mean & 3.97 & Skewness Standard Error & 0.39 \\
\hline Mean LCL & 3.47 & Kurtosis & 2.9 \\
\hline Mean UCL & 4.47 & Kurtosis Standard Error & 0.72 \\
\hline Variance & 1.42 & Alternative Skewness (Fisher's) & -0.4 \\
\hline Standard Deviation & 1.19 & Alternative Kurtosis (Fisher's) & 0.09 \\
\hline Mean Standard Error & 0.2 & Coefficient of Variation & 0.3 \\
\hline Minimum & 1. & Mean Deviation & 0.87 \\
\hline Maximum & 6. & Second Moment & 1.38 \\
\hline Range & 5. & Third Moment & -0.61 \\
\hline Sum & 135. & Fourth Moment & 5.54 \\
\hline Sum Standard Error & 6.96 & Median & 4. \\
\hline Total Sum Squares & 583. & Median Error & 0.04 \\
\hline Adjusted Sum Squares & 46.97 & Percentile 25\% (Q1) & 3. \\
\hline Geometric Mean & 3.75 & Percentile 75\% (Q2) & 5. \\
\hline Harmonic Mean & 3.45 & IQR & 2. \\
\hline Mode & 4. & MAD (Median Absolute Deviation) & 1. \\
\hline & & Coefficient of Dispersion (COD) & 0.21 \\
\hline
\end{tabular}

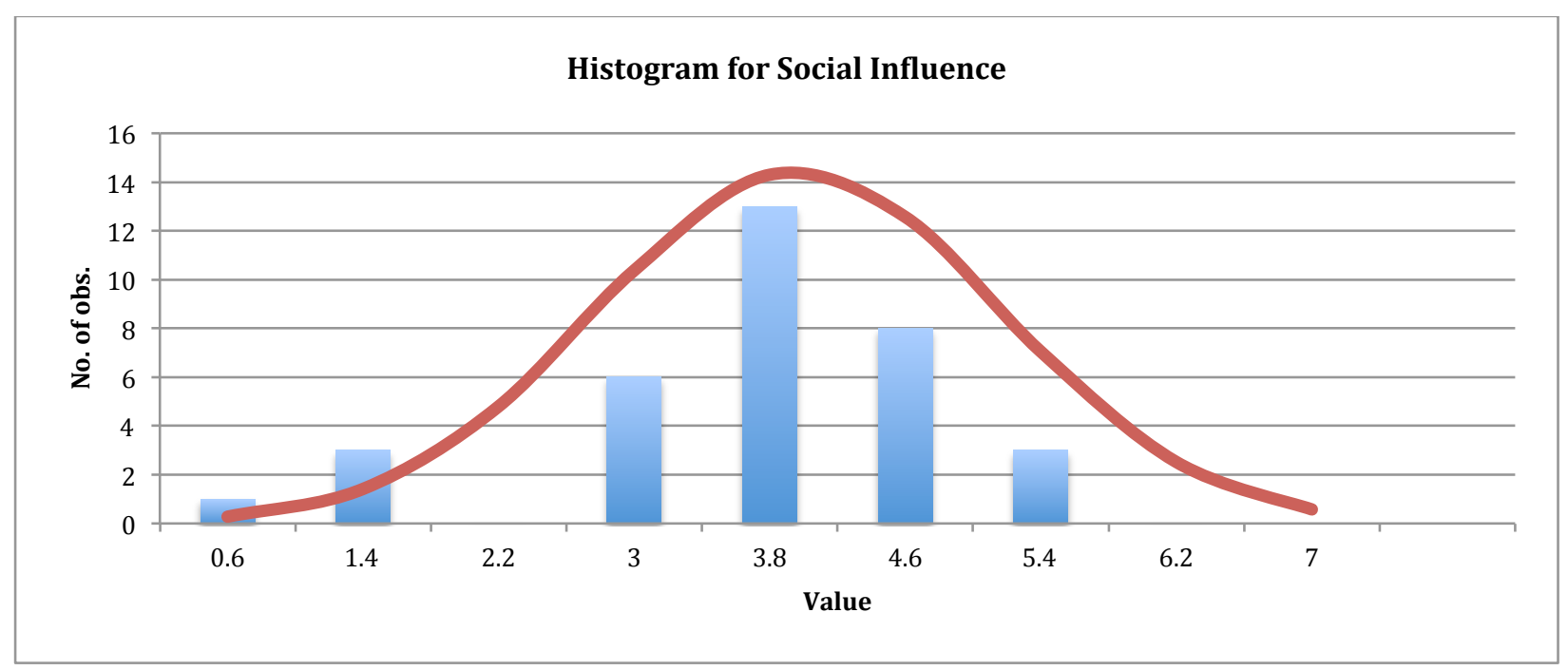

\begin{tabular}{|c|c|c|c|}
\hline \multicolumn{4}{|c|}{ Normality Tests } \\
\hline \multicolumn{4}{|l|}{ Variable \#1 (Var1) } \\
\hline Sample size & 34 & Mean & 3.97 \\
\hline Standard Deviation & 1.19 & Median & 4. \\
\hline Skewness & -0.38 & Kurtosis & 2.9 \\
\hline $\begin{array}{l}\text { Alternative Skewness } \\
\text { (Fisher's) }\end{array}$ & -0.4 & $\begin{array}{l}\text { Alternative Kurtosis } \\
\text { (Fisher's) }\end{array}$ & 0.09 \\
\hline & $\begin{array}{c}\text { Test } \\
\text { Statistics }\end{array}$ & p-level & Conclusion: (2\%) \\
\hline $\begin{array}{l}\text { Kolmogorov-Smirnov/Lilliefor } \\
\text { Test }\end{array}$ & $0 . E+0$ & 1. & $\begin{array}{l}\text { No evidence against } \\
\text { normality }\end{array}$ \\
\hline Shapiro-Wilk W & 0.93 & 0.03 & Accept Normality \\
\hline D'Agostino Skewness & 1.02 & 0.31 & Accept Normality \\
\hline D'Agostino Kurtosis & 0.34 & 0.73 & Accept Normality \\
\hline D'Agostino Omnibus & 1.16 & 0.56 & Accept Normality \\
\hline
\end{tabular}




\begin{tabular}{|l|r|l|r|}
\hline \multicolumn{2}{|c|}{ Alpha value (for confidence interval) } & 0.02 & \\
\hline \multicolumn{2}{|c|}{ Variable \#1 (Facilitating Conditions) } \\
\hline Count & 34 & Skewness & 0.75 \\
\hline Mean & 3.53 & Skewness Standard Error & 0.39 \\
\hline Mean LCL & 3.05 & Kurtosis & 4.73 \\
\hline Mean UCL & 4.01 & Kurtosis Standard Error & 0.72 \\
\hline Variance & 1.29 & Alternative Skewness (Fisher's) & 0.78 \\
\hline Standard Deviation & 1.13 & Alternative Kurtosis (Fisher's) & 2.21 \\
\hline Mean Standard Error & 0.19 & Coefficient of Variation & 0.32 \\
\hline Minimum & 1. & Mean Deviation & 0.85 \\
\hline Maximum & 7. & Second Moment & 1.25 \\
\hline Range & 6. & Third Moment & 1.04 \\
\hline Sum & 120. & Fourth Moment & 7.37 \\
\hline Sum Standard Error & 6.61 & Median & 3. \\
\hline Total Sum Squares & 466. & Median Error & 0.04 \\
\hline Adjusted Sum Squares & 42.47 & Percentile 25\% (Q1) & 3. \\
\hline Geometric Mean & 3.34 & Percentile 75\% (Q2) & 4. \\
\hline Harmonic Mean & 3.13 & IQR & 1. \\
\hline Mode & 3. & MAD (Median Absolute Deviation) & 1. \\
\hline \multicolumn{2}{|l|}{} & Coefficient of Dispersion (COD) & 0.27 \\
\hline
\end{tabular}

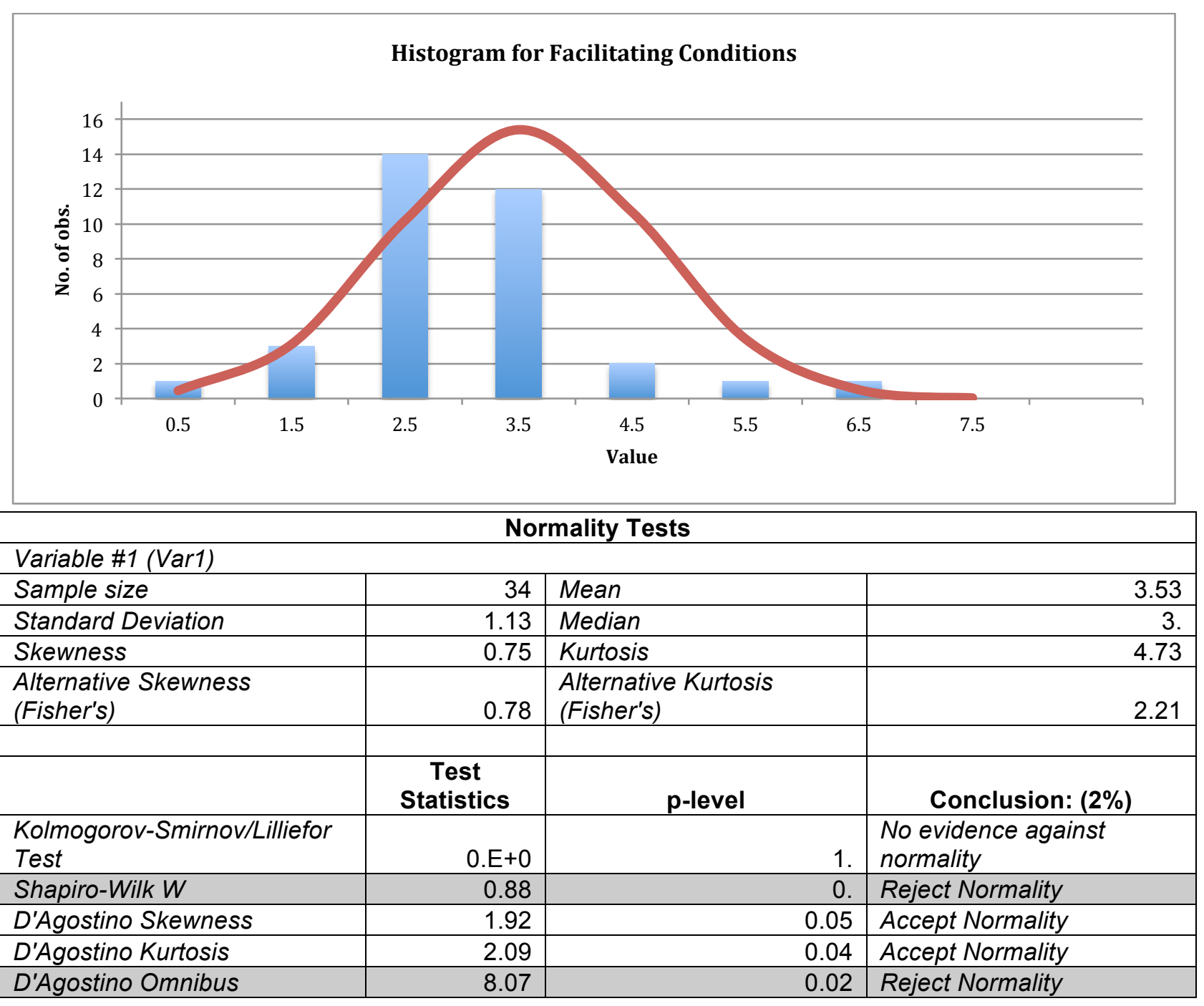




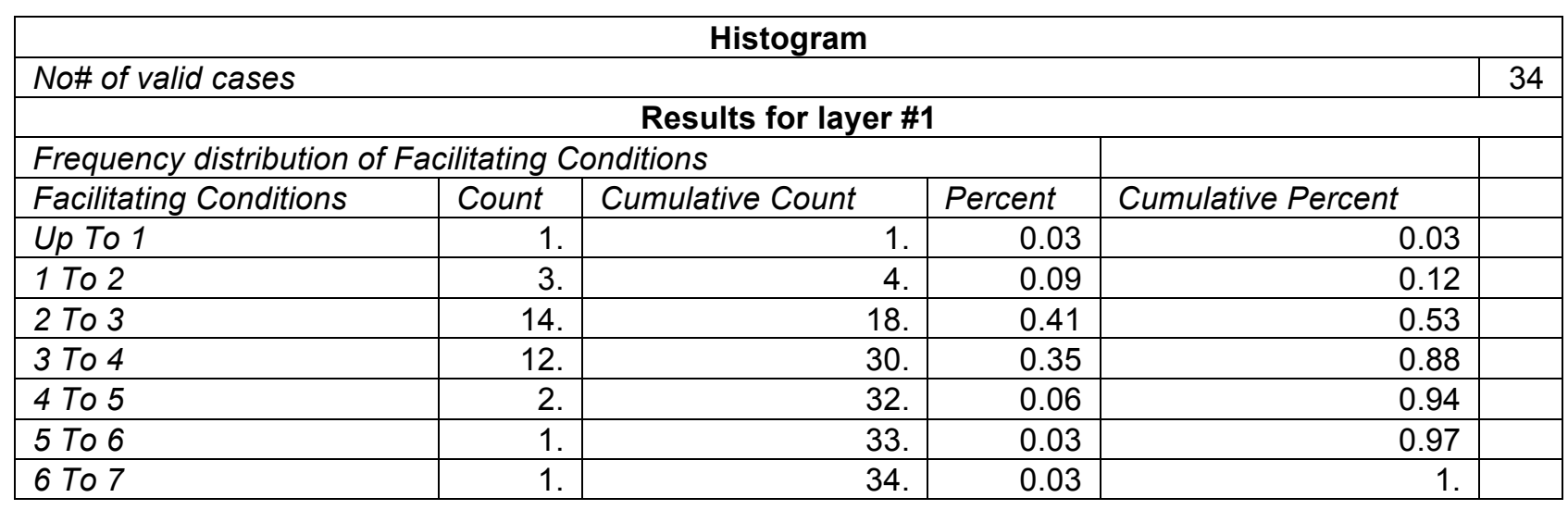

The data sample values are highly concentrated in the 2 to 3 and 3 to 4 intervals. Normality is rejected on two tests.

\section{Video Self-Efficacy}

\begin{tabular}{|l|r|l|r|}
\hline Alpha value (for confidence interval) & 0.02 & \multicolumn{1}{|c|}{} \\
\hline & Variable \#1 (Self-Efficacy) & -0.61 \\
\hline Count & 34 & Skewness & 0.39 \\
\hline Mean & 4.5 & Skewness Standard Error & 2.79 \\
\hline Mean LCL & 3.9 & Kurtosis & 0.72 \\
\hline Mean UCL & 5.1 & Kurtosis Standard Error & -0.64 \\
\hline Variance & 2.02 & Alternative Skewness (Fisher's) & -0.04 \\
\hline Standard Deviation & 1.42 & Alternative Kurtosis (Fisher's) & 0.32 \\
\hline Mean Standard Error & 0.24 & Coefficient of Variation & 1.15 \\
\hline Minimum & 1. & Mean Deviation & 1.96 \\
\hline Maximum & 7. & Second Moment & -1.68 \\
\hline Range & 6. & Third Moment & 10.68 \\
\hline Sum & 153. & Fourth Moment & 5. \\
\hline Sum Standard Error & 8.28 & Median & 0.05 \\
\hline Total Sum Squares & 755. & Median Error & 4. \\
\hline Adjusted Sum Squares & 66.5 & Percentile 25\% (Q1) & 6. \\
\hline Geometric Mean & 4.21 & Percentile 75\% (Q2) & 2. \\
\hline Harmonic Mean & 3.79 & IQR & 1. \\
\hline Mode & 5. & MAD (Median Absolute Deviation) & 0.22 \\
\hline \multicolumn{2}{|r|}{} \\
\hline
\end{tabular}

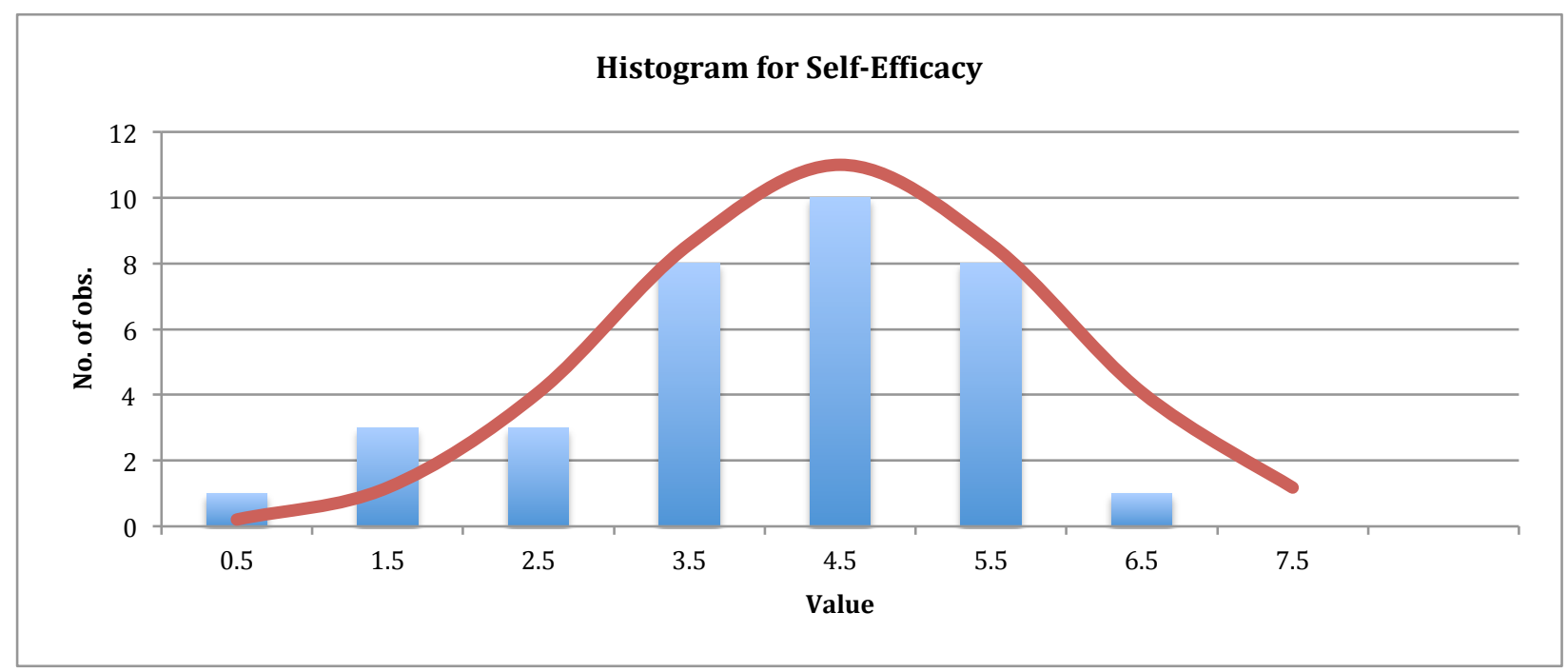




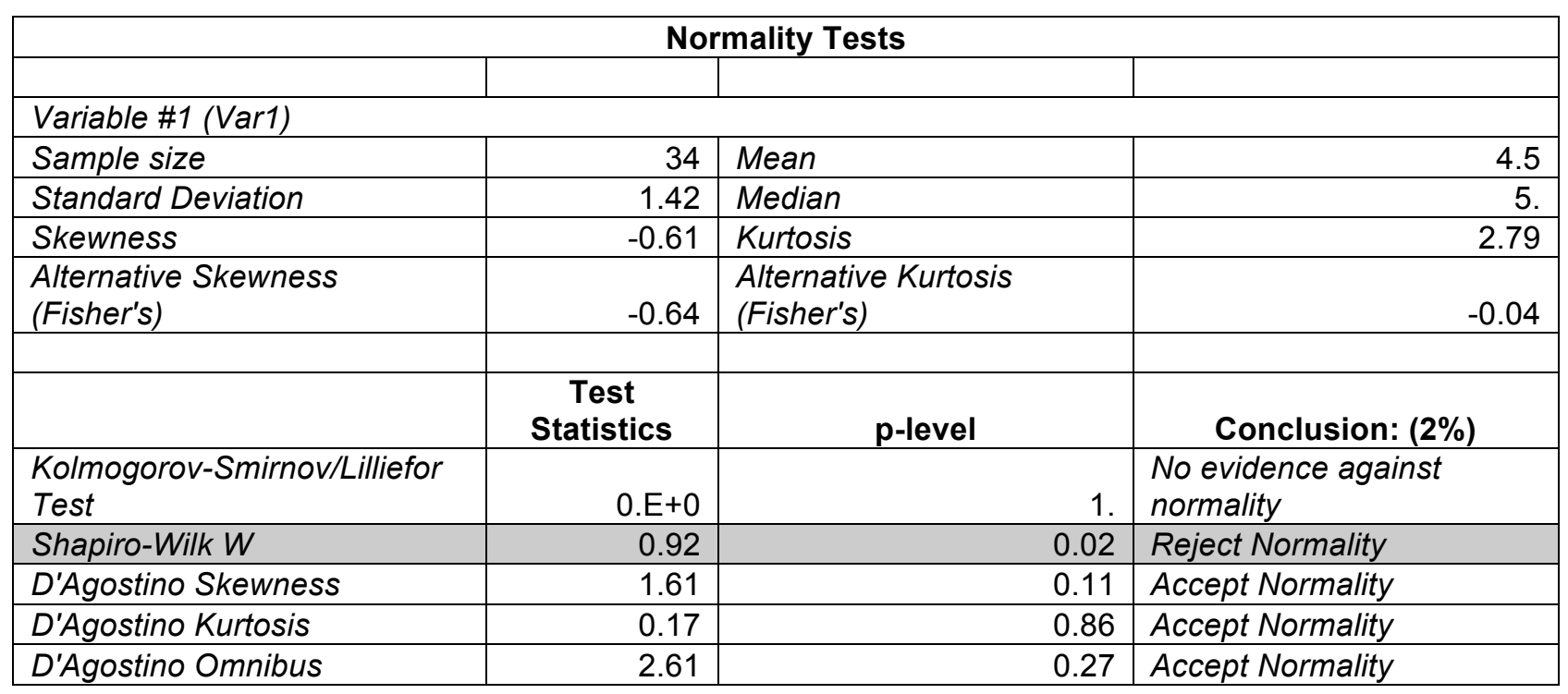

Video Anxiety

\begin{tabular}{|l|r|l|r|}
\hline Alpha value (for confidence interval) & 0.02 & \\
\hline & Variable \#1 (Anxiety) & -0.23 \\
\hline Count & 34 & Skewness & 0.39 \\
\hline Mean & 3.85 & Skewness Standard Error & 2.8 \\
\hline Mean LCL & 3.28 & Kurtosis & 0.72 \\
\hline Mean UCL & 4.43 & Kurtosis Standard Error & -0.24 \\
\hline Variance & 1.89 & Alternative Skewness (Fisher's) & -0.03 \\
\hline Standard Deviation & 1.37 & Alternative Kurtosis (Fisher's) & 0.36 \\
\hline Mean Standard Error & 0.24 & Coefficient of Variation & 1.07 \\
\hline Minimum & 1. & Mean Deviation & 1.83 \\
\hline Maximum & 7. & Second Moment & -0.57 \\
\hline Range & 6. & Third Moment & 9.4 \\
\hline Sum & 131. & Fourth Moment & 4. \\
\hline Sum Standard Error & 8.01 & Median & 0.05 \\
\hline Total Sum Squares & 567. & Median Error & 3. \\
\hline Adjusted Sum Squares & 62.26 & Percentile 25\% (Q1) & 5. \\
\hline Geometric Mean & 3.55 & Percentile 75\% (Q2) & 2. \\
\hline Harmonic Mean & 3.15 & IQR & 1. \\
\hline Mode & \#N/A & MAD (Median Absolute Deviation) & 0.26 \\
\hline
\end{tabular}

Histogram for Anxiety

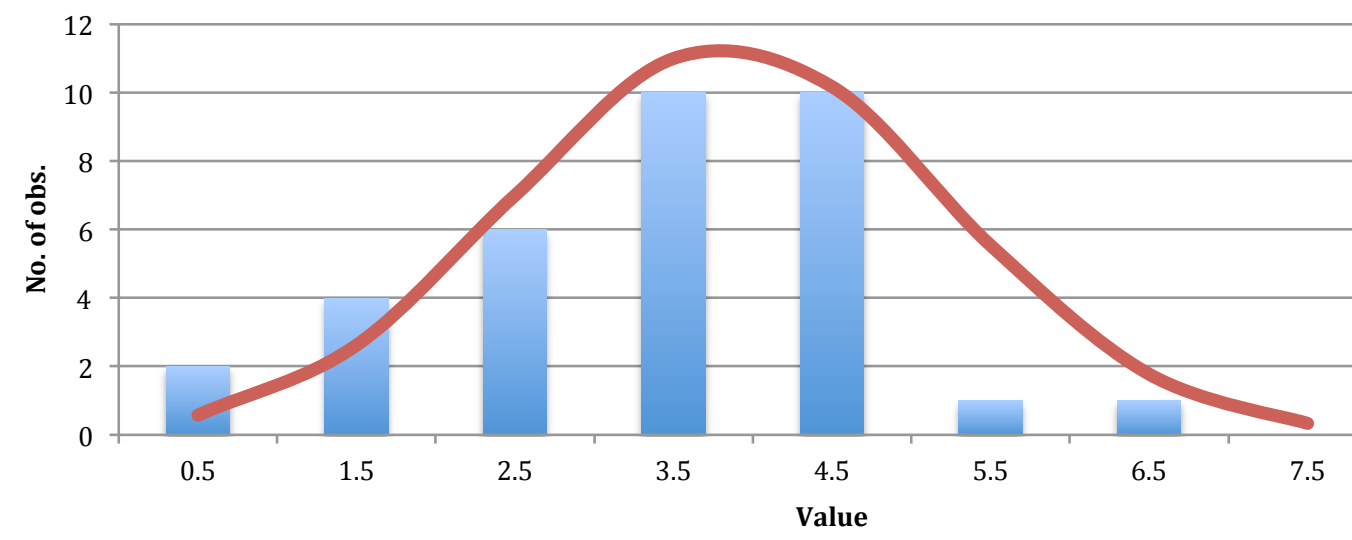




\begin{tabular}{|c|c|c|c|}
\hline \multicolumn{4}{|c|}{ Normality Tests } \\
\hline \multicolumn{4}{|l|}{ Variable \#1 (Var1) } \\
\hline Sample size & 34 & Mean & 3.85 \\
\hline Standard Deviation & 1.37 & Median & 4. \\
\hline Skewness & -0.23 & Kurtosis & 2.8 \\
\hline $\begin{array}{l}\text { Alternative Skewness } \\
\text { (Fisher's) }\end{array}$ & -0.24 & $\begin{array}{l}\text { Alternative Kurtosis } \\
\text { (Fisher's) }\end{array}$ & -0.03 \\
\hline & $\begin{array}{c}\text { Test } \\
\text { Statistics }\end{array}$ & p-level & Conclusion: (2\%) \\
\hline $\begin{array}{l}\text { Kolmogorov-Smirnov/Lilliefor } \\
\text { Test }\end{array}$ & $0 . E+0$ & 1. & $\begin{array}{l}\text { No evidence against } \\
\text { normality }\end{array}$ \\
\hline Shapiro-Wilk W & 0.94 & 0.05 & Accept Normality \\
\hline D'Agostino Skewness & 0.63 & 0.53 & Accept Normality \\
\hline D'Agostino Kurtosis & 0.19 & 0.85 & Accept Normality \\
\hline D'Agostino Omnibus & 0.43 & 0.81 & Accept Normality \\
\hline
\end{tabular}

Video Intention To Use

\begin{tabular}{|l|r|l|r|}
\hline \multicolumn{2}{|c|}{ Alpha value (for confidence interval) } & 0.02 & \\
\hline Variable \#1 (Intention To Use) & -0.1 \\
\hline Meant & 34 & Skewness & 0.39 \\
\hline Mean LCL & 3.26 & Skewness Standard Error & 1.94 \\
\hline Mean UCL & 2.66 & Kurtosis & 0.72 \\
\hline Variance & 3.87 & Kurtosis Standard Error & -0.11 \\
\hline Standard Deviation & 2.08 & Alternative Skewness (Fisher's) & -1.03 \\
\hline Mean Standard Error & 1.44 & Alternative Kurtosis (Fisher's) & 0.44 \\
\hline Minimum & 0.25 & Coefficient of Variation & 1.22 \\
\hline Maximum & 1. & Mean Deviation & 2.02 \\
\hline Range & 6. & Second Moment & -0.3 \\
\hline Sum & 5. & Third Moment & 7.9 \\
\hline Sum Standard Error & 111. & Fourth Moment & 3. \\
\hline Total Sum Squares & 8.41 & Median & 0.05 \\
\hline Adjusted Sum Squares & 431. & Median Error & 2. \\
\hline Geometric Mean & 68.62 & Percentile 25\% (Q1) & 4.5 \\
\hline Harmonic Mean & 2.88 & Percentile 75\% (Q2) & 2.5 \\
\hline Mode & 2.45 & IQR & 1. \\
\hline \multicolumn{2}{|c|}{ (2. } & MAD (Median Absolute Deviation) & 0.4 \\
\hline
\end{tabular}

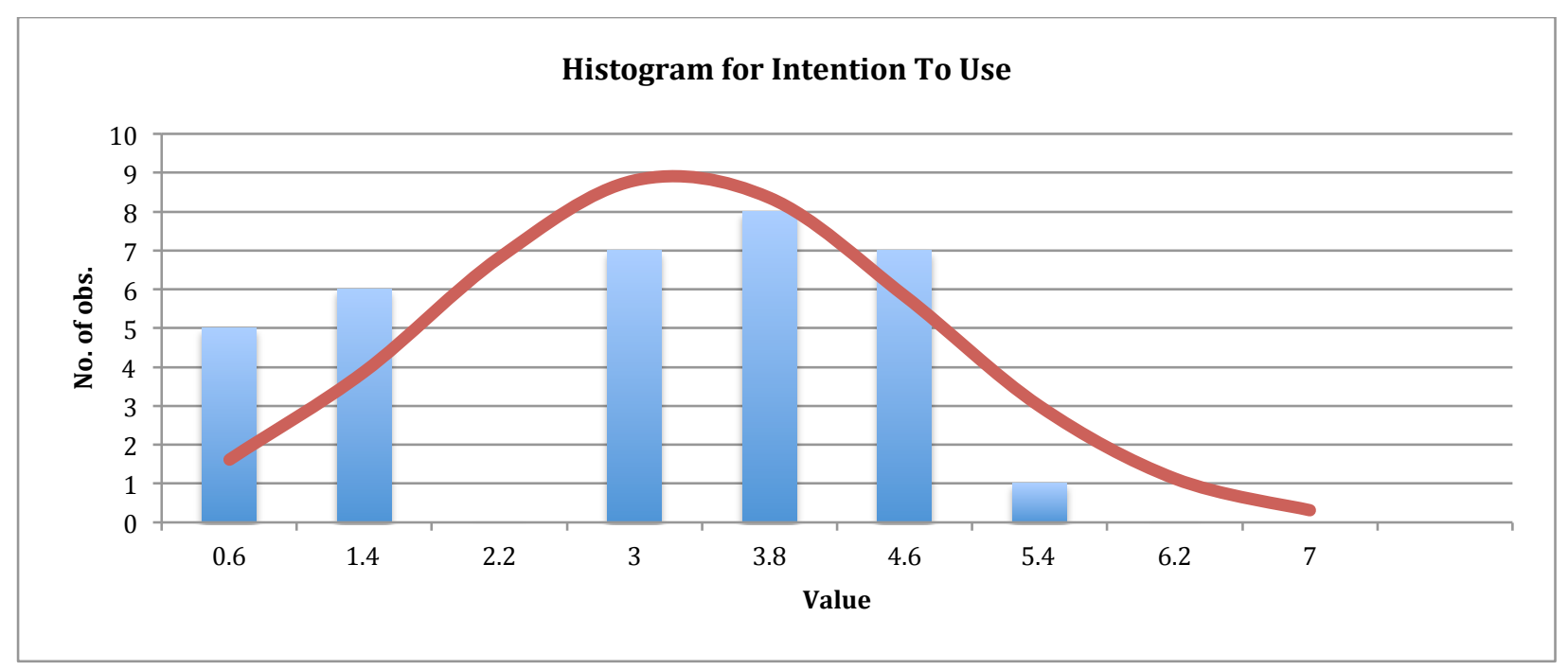


Page 85

\begin{tabular}{|c|c|c|c|}
\hline \multicolumn{4}{|c|}{ Normality Tests } \\
\hline Variable \#1 (Var1) & & & \\
\hline Sample size & 34 & Mean & 3.26 \\
\hline Standard Deviation & 1.44 & Median & 3. \\
\hline Skewness & -0.1 & Kurtosis & 1.94 \\
\hline $\begin{array}{l}\text { Alternative Skewness } \\
\text { (Fisher's) }\end{array}$ & -0.11 & $\begin{array}{l}\text { Alternative Kurtosis } \\
\text { (Fisher's) }\end{array}$ & -1.03 \\
\hline & $\begin{array}{c}\text { Test } \\
\text { Statistics }\end{array}$ & p-level & Conclusion: (2\%) \\
\hline $\begin{array}{l}\text { Kolmogorov-Smirnov/Lilliefor } \\
\text { Test }\end{array}$ & $0 . E+0$ & 1. & $\begin{array}{l}\text { No evidence against } \\
\text { normality }\end{array}$ \\
\hline Shapiro-Wilk W & 0.92 & 0.02 & Accept Normality \\
\hline D'Agostino Skewness & 0.29 & 0.78 & Accept Normality \\
\hline D'Agostino Kurtosis & -1.95 & 0.05 & Accept Normality \\
\hline D'Agostino Omnibus & 3.88 & 0.14 & Accept Normality \\
\hline
\end{tabular}

\section{Work and Demographics}

Work and Demographics Choice

\begin{tabular}{|l|r|l|r|}
\hline Alpha value (for confidence interval) & 0.02 & \\
\hline & Variable \#1 (Choice) & 0.22 \\
\hline Count & 34 & Skewness & 0.39 \\
\hline Mean & 4.65 & Skewness Standard Error & 2.46 \\
\hline Mean LCL & 4.22 & Kurtosis & 0.72 \\
\hline Mean UCL & 5.07 & Kurtosis Standard Error & 0.23 \\
\hline Variance & 1.02 & Alternative Skewness (Fisher's) & -0.43 \\
\hline Standard Deviation & 1.01 & Alternative Kurtosis (Fisher's) & 0.22 \\
\hline Mean Standard Error & 0.17 & Coefficient of Variation & 0.84 \\
\hline Minimum & 3. & Mean Deviation & 0.99 \\
\hline Maximum & 7. & Second Moment & 0.21 \\
\hline Range & 4. & Third Moment & 2.43 \\
\hline Sum & 158. & Fourth Moment & 5. \\
\hline Sum Standard Error & 5.9 & Median & 0.04 \\
\hline Total Sum Squares & 768. & Median Error & 4. \\
\hline Adjusted Sum Squares & 33.76 & Percentile 25\% (Q1) & 5. \\
\hline Geometric Mean & 4.54 & Percentile 75\% (Q2) & 1. \\
\hline Harmonic Mean & 4.43 & IQR & 1. \\
\hline Mode & 4. & MAD (Median Absolute Deviation) & 0.16 \\
\hline
\end{tabular}

Histogram for Choice

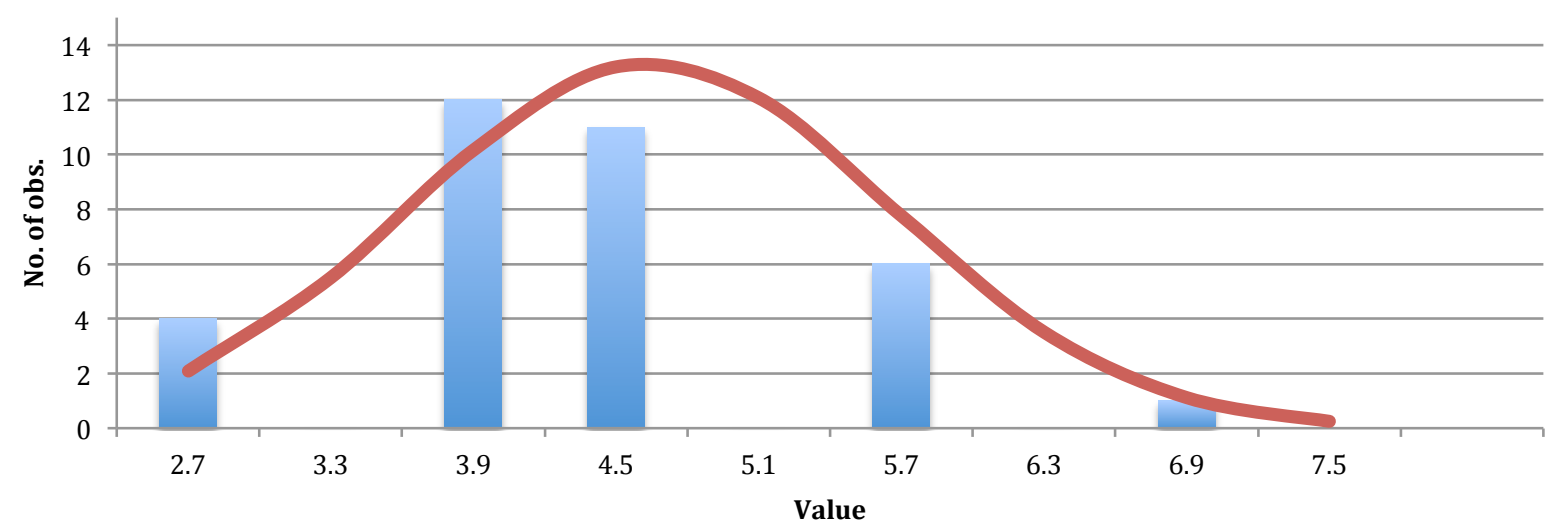


Page 86

\begin{tabular}{|c|c|c|c|}
\hline \multicolumn{4}{|c|}{ Normality Tests } \\
\hline \multicolumn{4}{|l|}{ Variable \#1 (Var1) } \\
\hline Sample size & 34 & Mean & 4.65 \\
\hline Standard Deviation & 1.01 & Median & 5. \\
\hline Skewness & 0.22 & Kurtosis & 2.46 \\
\hline $\begin{array}{l}\text { Alternative Skewness } \\
\text { (Fisher's) }\end{array}$ & 0.23 & $\begin{array}{l}\text { Alternative Kurtosis } \\
\text { (Fisher's) }\end{array}$ & -0.43 \\
\hline & $\begin{array}{c}\text { Test } \\
\text { Statistics }\end{array}$ & p-level & Conclusion: (2\%) \\
\hline $\begin{array}{l}\text { Kolmogorov-Smirnov/Lilliefor } \\
\text { Test }\end{array}$ & $0 . E+0$ & 1. & $\begin{array}{l}\text { No evidence against } \\
\text { normality }\end{array}$ \\
\hline Shapiro-Wilk W & 0.91 & 0.01 & Reject Normality \\
\hline D'Agostino Skewness & 0.59 & 0.56 & Accept Normality \\
\hline D'Agostino Kurtosis & -0.46 & 0.65 & Accept Normality \\
\hline D'Agostino Omnibus & 0.55 & 0.76 & Accept Normality \\
\hline
\end{tabular}

\section{Work and Demographics Experience}

\begin{tabular}{|l|r|l|r|}
\hline $\begin{array}{l}\text { Alpha value (for confidence } \\
\text { interval) }\end{array}$ & 0.02 & & \\
\hline \multicolumn{3}{|r|}{ Variable \#1 (Experience) } \\
\hline Count & 34 & Skewness & 0.39 \\
\hline Mean & 3.41 & Skewness Standard Error & 0.39 \\
\hline Mean LCL & 2.66 & Kurtosis & 1.96 \\
\hline Mean UCL & 4.16 & Kurtosis Standard Error & 0.72 \\
\hline Variance & 3.22 & Alternative Skewness (Fisher's) & 0.4 \\
\hline Standard Deviation & 1.79 & Alternative Kurtosis (Fisher's) & -1.01 \\
\hline Mean Standard Error & 0.31 & Coefficient of Variation & 0.53 \\
\hline Minimum & 1. & Mean Deviation & 1.51 \\
\hline Maximum & 7. & Second Moment & 3.12 \\
\hline Range & 6. & Third Moment & 2.13 \\
\hline Sum & 116. & Fourth Moment & 19.17 \\
\hline Sum Standard Error & 10.46 & Median & 3. \\
\hline Total Sum Squares & 502. & Median Error & 0.07 \\
\hline Adjusted Sum Squares & 106.24 & Percentile 25\% (Q1) & 2. \\
\hline Geometric Mean & 2.92 & Percentile 75\% (Q2) & 5. \\
\hline Harmonic Mean & 2.43 & lQR & 3. \\
\hline & & MAD (Median Absolute & 1. \\
\hline Mode & 3. & Deviation) & 0.47 \\
\hline
\end{tabular}

Histogram for Experience

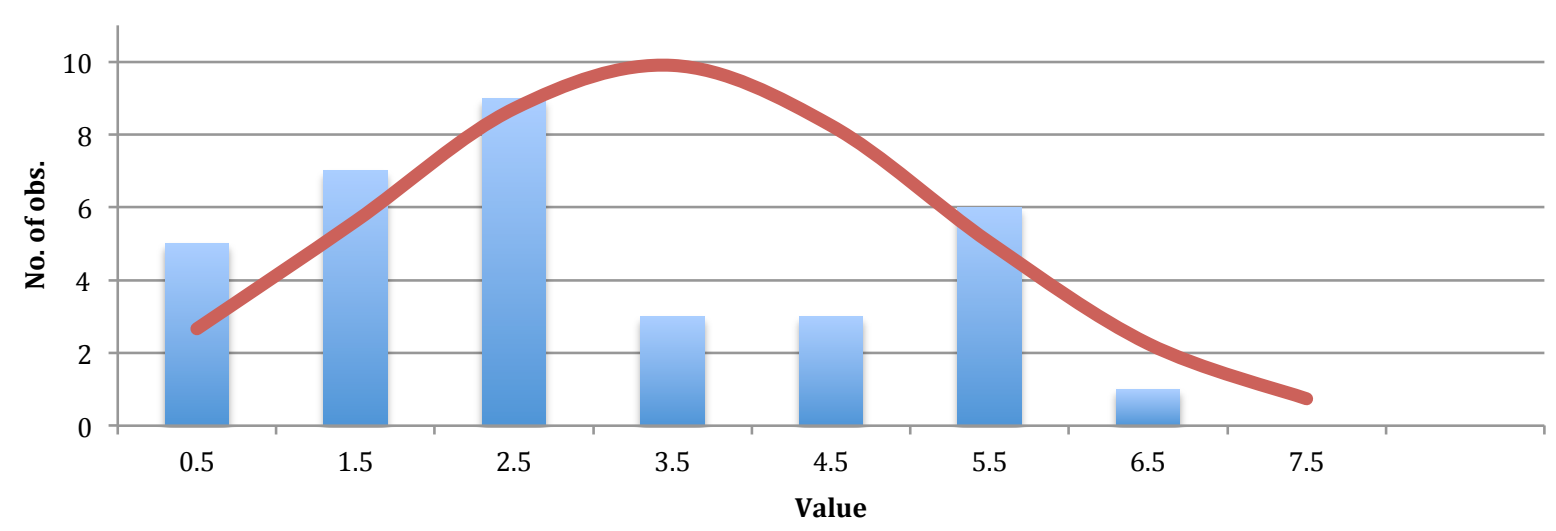




\begin{tabular}{|c|c|c|c|}
\hline \multicolumn{4}{|c|}{ Normality Tests } \\
\hline \multicolumn{4}{|l|}{ Variable \#1 (Var1) } \\
\hline Sample size & 34 & Mean & 3.41 \\
\hline Standard Deviation & 1.79 & Median & 3. \\
\hline Skewness & 0.39 & Kurtosis & 1.96 \\
\hline \multirow[t]{2}{*}{$\begin{array}{l}\text { Alternative Skewness } \\
\text { (Fisher's) }\end{array}$} & 0.4 & $\begin{array}{l}\text { Alternative Kurtosis } \\
\text { (Fisher's) }\end{array}$ & -1.01 \\
\hline & $\begin{array}{c}\text { Test } \\
\text { Statistics }\end{array}$ & p-level & Conclusion: (2\%) \\
\hline $\begin{array}{l}\text { Kolmogorov-Smirnov/Lilliefor } \\
\text { Test }\end{array}$ & $0 . E+0$ & 1. & $\begin{array}{l}\text { No evidence against } \\
\text { normality }\end{array}$ \\
\hline Shapiro-Wilk W & 0.91 & 0.01 & Reject Normality \\
\hline D'Agostino Skewness & 1.04 & 0.3 & Accept Normality \\
\hline D'Agostino Kurtosis & -1.86 & 0.06 & Accept Normality \\
\hline D'Agostino Omnibus & 4.54 & 0.1 & Accept Normality \\
\hline
\end{tabular}

\section{Work and Demographics Age}

\begin{tabular}{|l|r|l|r|}
\hline \multicolumn{2}{|c|}{ Vlpha value (for confidence interval) } & 0.02 & \\
\hline & 34 & Skewness & -1.1 \\
\hline Count & 4.76 & Skewness Standard Error & 0.39 \\
\hline Mean & 4.27 & Kurtosis & 3.47 \\
\hline Mean LCL & 5.26 & Kurtosis Standard Error & 0.72 \\
\hline Mean UCL & 1.4 & Alternative Skewness (Fisher's) & -1.15 \\
\hline Variance & 1.18 & Alternative Kurtosis (Fisher's) & 0.75 \\
\hline Standard Deviation & 0.2 & Coefficient of Variation & 0.25 \\
\hline Mean Standard Error & 2. & Mean Deviation & 0.88 \\
\hline Minimum & 6. & Second Moment & 1.36 \\
\hline Maximum & 4. & Third Moment & -1.74 \\
\hline Range & 162. & Fourth Moment & 6.38 \\
\hline Sum & 6.89 & Median & 5. \\
\hline Sum Standard Error & 818. & Median Error & 0.04 \\
\hline Total Sum Squares & 46.12 & Percentile 25\% (Q1) & 4.5 \\
\hline Adjusted Sum Squares & 4.57 & Percentile 75\% (Q2) & 6. \\
\hline Geometric Mean & 4.32 & IQR & 1.5 \\
\hline Harmonic Mean & 5. & MAD (Median Absolute Deviation) & 1. \\
\hline Mode & & Coefficient of Dispersion (COD) & 0.15 \\
\hline \multicolumn{2}{|r|}{} &
\end{tabular}

Histogram for Age

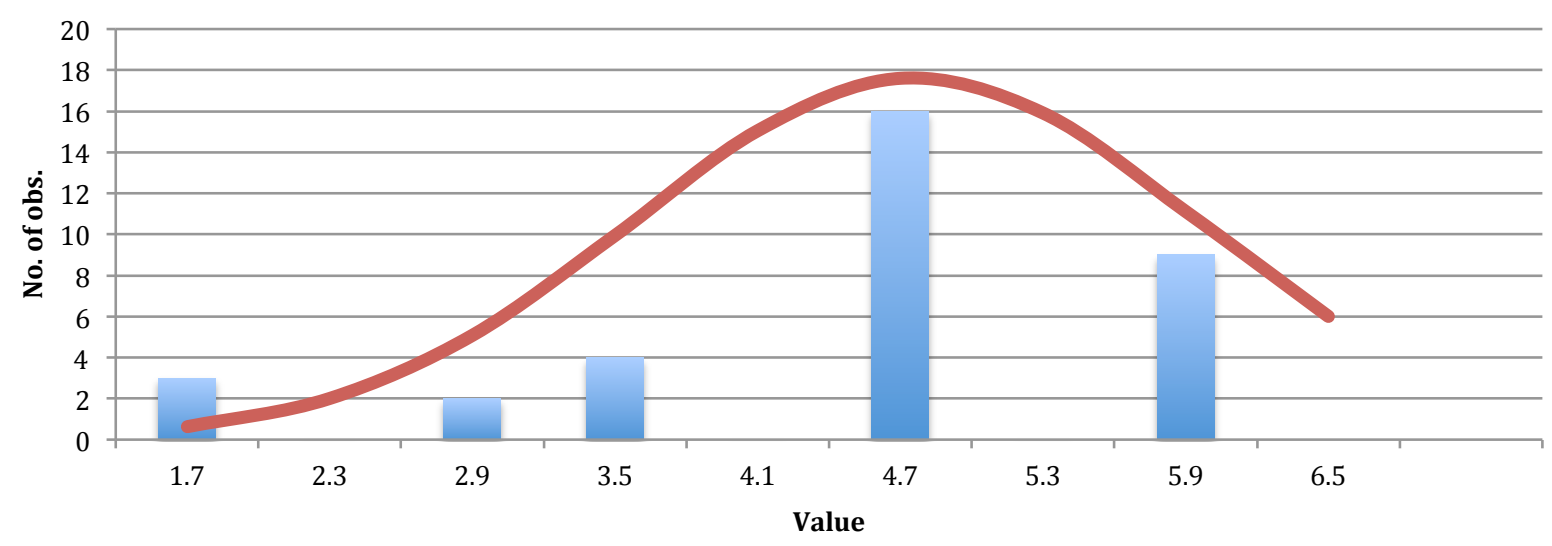


Page 88

\begin{tabular}{|c|c|c|c|}
\hline \multicolumn{4}{|c|}{ Normality Tests } \\
\hline \multicolumn{4}{|l|}{ Variable \#1 (Var1) } \\
\hline Sample size & 34 & Mean & 4.76 \\
\hline Standard Deviation & 1.18 & Median & 5. \\
\hline Skewness & -1.1 & Kurtosis & 3.47 \\
\hline \multirow[t]{2}{*}{$\begin{array}{l}\text { Alternative Skewness } \\
\text { (Fisher's) }\end{array}$} & -1.15 & $\begin{array}{l}\text { Alternative Kurtosis } \\
\text { (Fisher's) }\end{array}$ & 0.75 \\
\hline & $\begin{array}{c}\text { Test } \\
\text { Statistics }\end{array}$ & p-level & Conclusion: (2\%) \\
\hline $\begin{array}{l}\text { Kolmogorov-Smirnov/Lilliefor } \\
\text { Test }\end{array}$ & $0 . E+0$ & 1. & $\begin{array}{l}\text { No evidence against } \\
\text { normality }\end{array}$ \\
\hline Shapiro-Wilk W & 0.81 & 0. & Reject Normality \\
\hline D'Agostino Skewness & 2.66 & 0.01 & Reject Normality \\
\hline D'Agostino Kurtosis & 1.07 & 0.28 & Accept Normality \\
\hline D'Agostino Omnibus & 8.2 & 0.02 & Reject Normality \\
\hline
\end{tabular}

\begin{tabular}{|c|c|c|c|c|c|}
\hline \multicolumn{6}{|c|}{ Histogram } \\
\hline No\# of & id cases & & & & 34 \\
\hline \multicolumn{6}{|c|}{ Results for layer \#1 } \\
\hline \multicolumn{4}{|c|}{ Frequency distribution of Age } & & \\
\hline Age & Count & Cumulative Count & Percent & Cumulative Percent & \\
\hline 1 To 2 & 3. & 3. & 0.09 & 0.09 & \\
\hline 2 To 3 & 2. & 5. & 0.06 & 0.15 & \\
\hline 3 To 4 & 4. & 9. & 0.12 & 0.26 & \\
\hline 4 To 5 & 16. & 25. & 0.47 & 0.74 & \\
\hline 5 To 6 & 9. & 34. & 0.26 & 1. & \\
\hline
\end{tabular}

The data is highly concentrated in the 4 to 5 and 5 to 6 intervals. Normality is rejected on two of the normality tests. 
Work and Demographics Gender

\begin{tabular}{|l|r|l|r|}
\hline Alpha value (for confidence interval) & 0.02 & \\
\hline & Variable \#1 (Gender) & -0.75 \\
\hline Count & 34 & Skewness & 0.39 \\
\hline Mean & 1.68 & Skewness Standard Error & 1.57 \\
\hline Mean LCL & 1.48 & Kurtosis & 0.72 \\
\hline Mean UCL & 1.88 & Kurtosis Standard Error & -0.79 \\
\hline Variance & 0.23 & Alternative Skewness (Fisher's) & -1.47 \\
\hline Standard Deviation & 0.47 & Alternative Kurtosis (Fisher's) & 0.28 \\
\hline Mean Standard Error & 0.08 & Coefficient of Variation & 0.44 \\
\hline Minimum & 1. & Mean Deviation & 0.22 \\
\hline Maximum & 2. & Second Moment & -0.08 \\
\hline Range & 1. & Third Moment & 0.08 \\
\hline Sum & 57. & Fourth Moment & 2. \\
\hline Sum Standard Error & 2.77 & Median & 0.02 \\
\hline Total Sum Squares & 103. & Median Error & 1. \\
\hline Adjusted Sum Squares & 7.44 & Percentile 25\% (Q1) & 2. \\
\hline Geometric Mean & 1.6 & Percentile 75\% (Q2) & 1. \\
\hline Harmonic Mean & 1.51 & IQR & 0. \\
\hline Mode & 2. & MAD (Median Absolute Deviation) & 0.16 \\
\hline
\end{tabular}

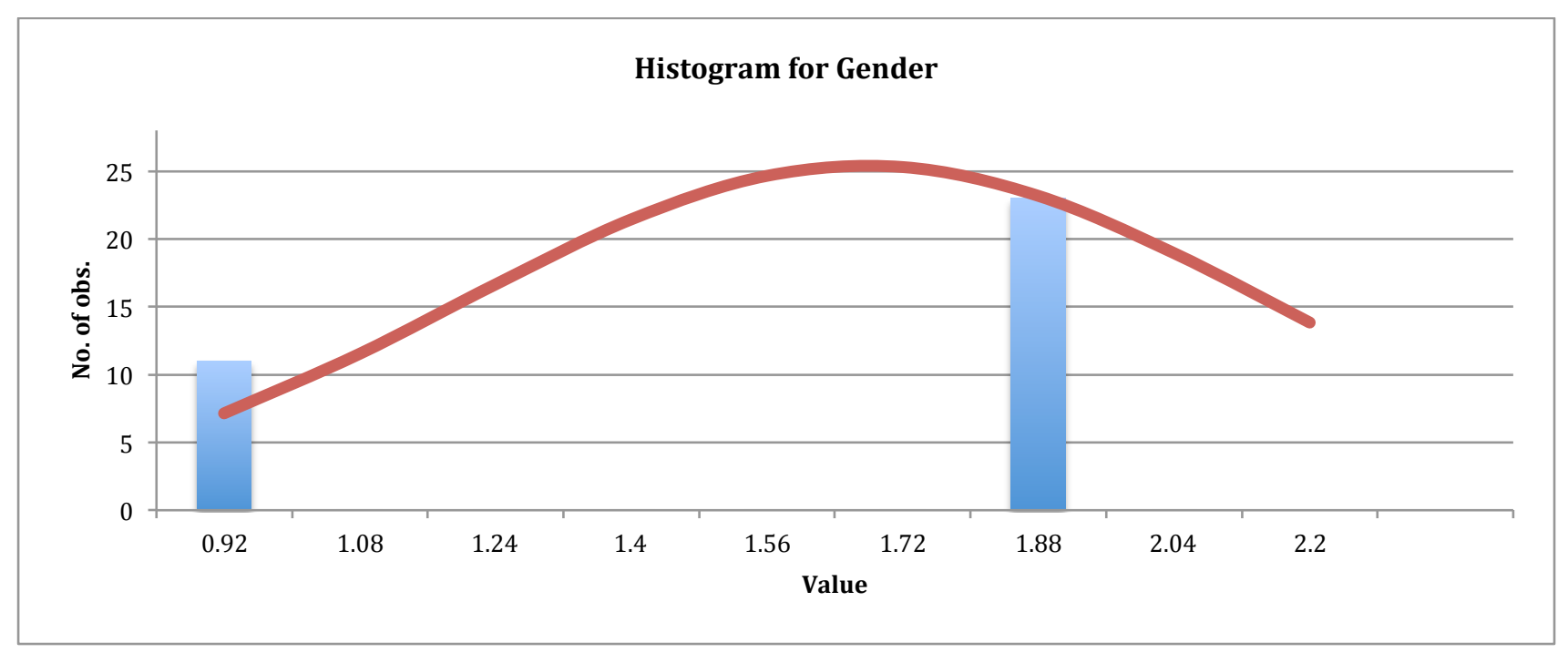

\begin{tabular}{|c|c|c|c|}
\hline \multicolumn{4}{|c|}{ Normality Tests } \\
\hline \multicolumn{4}{|l|}{ Variable \#1 (Var1) } \\
\hline Sample size & 34 & Mean & 1.68 \\
\hline Standard Deviation & 0.47 & Median & 2. \\
\hline Skewness & -0.75 & Kurtosis & 1.57 \\
\hline $\begin{array}{l}\text { Alternative Skewness } \\
\text { (Fisher's) }\end{array}$ & -0.79 & $\begin{array}{l}\text { Alternative Kurtosis } \\
\text { (Fisher's) }\end{array}$ & -1.47 \\
\hline & $\begin{array}{c}\text { Test } \\
\text { Statistics }\end{array}$ & p-level & Conclusion: (2\%) \\
\hline $\begin{array}{l}\text { Kolmogorov-Smirnov/Lilliefor } \\
\text { Test }\end{array}$ & $0 . E+0$ & 1. & $\begin{array}{l}\text { No evidence against } \\
\text { normality }\end{array}$ \\
\hline Shapiro-Wilk W & 0.59 & 0. & Reject Normality \\
\hline D'Agostino Skewness & 1.94 & 0.05 & Accept Normality \\
\hline D'Agostino Kurtosis & -3.93 & 0. & Reject Normality \\
\hline
\end{tabular}


Page 90

\begin{tabular}{|l|r|r|r|r|r|}
\hline \multicolumn{7}{|c|}{ Histogram } & 34 \\
\hline No\# of valid cases & & & \\
\hline \multicolumn{7}{|c|}{ Results for layer \#1 } \\
\hline Frequency distribution of Gender & Cumulative Count & Percent & Cumulative Percent & \\
\hline Gender & Count & 11. & 0.32 & 0.32 & \\
\hline Up To 1 & 11. & 34. & 0.68 & 1. & \\
\hline 1 To 2 & 23. & & 34 &
\end{tabular}

The data has more than twice as many female respondents as male respondents. Normality is rejected on two of the normality tests. 